UNIVERSIDAD NACIONAL DE LA PLATA

Facultad de Humanidades y CienCIAS de la EduCACIÓN

SeCRetaría de Posgrado

\title{
La agricultura familiar liderada por mujeres en Montes de María - Sucre - Colombia, fuente de ingresos con equilibrio ambiental y sostenibilidad en el último quinquenio
}

\author{
Jaime Enrique Trespalacios Martínez
}

Tesis para optar por el grado de Magíster en Políticas de Desarrollo

Director: Dr. Patricio Narodowski, UNLP

Ensenada, diciembre 26 de 2019 
Toda nación debe tener derecho a desarrollar su propia producción local de alimentos a cargo de las mujeres y hombres de la Agricultura Familiar. Este proceso hacia la Seguridad y Soberanía alimentarias debe basarse en la implementación de modelos agrícolas sostenibles y resilientes al cambio climático, por ejemplo, el modelo agroecológico, en la perspectiva de una economía solidaria.

Manifiesto de Brasilia 15 de noviembre 2014 


\section{Contenido}

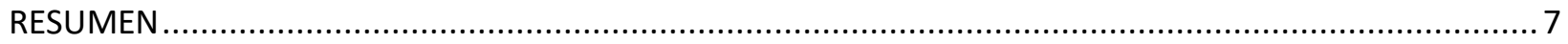

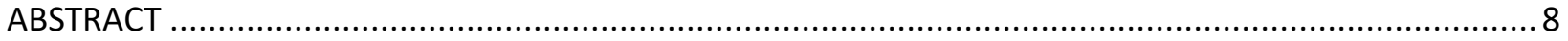

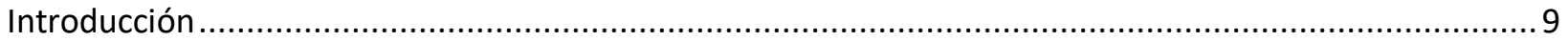

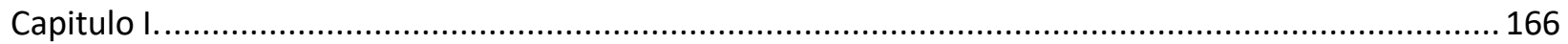

Definiciones teóricas alrededor de la agricultura familiar y la mujer campesina ................................. 166

1.1 Antecedentes en relación con la agricultura familiar ..................................................... 166

1.2 Agricultura Familiar, Necesidades, Sustentabilidad, Seguridad y Soberanía Alimentaria,

Economía Soial y Solidaria, Armonía con el Medio, y Reciprocidad ........................................ 200

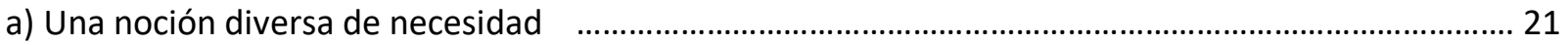

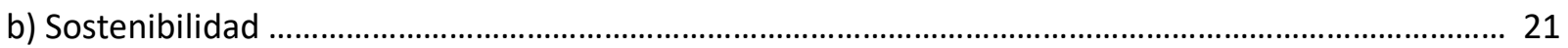

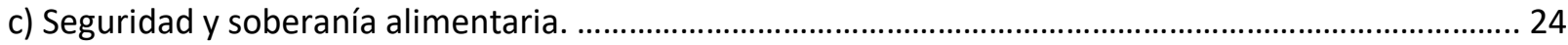

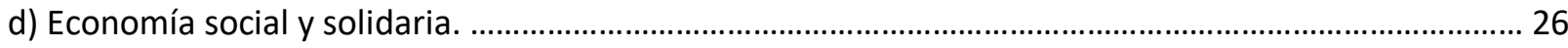

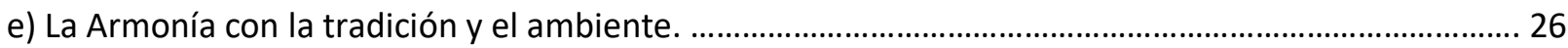

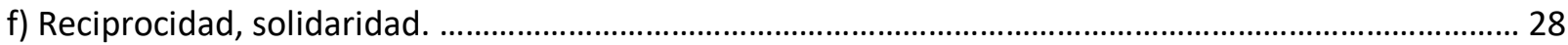

1.3. El enfoque de género en los análisis de la agricultura general .......................................... 29

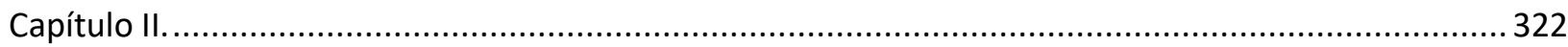

Las Características de la Agricultura Familiar en el Contexto de la Economía Colombiana y Montemariana

2.1 Desarrollo Trunco Colombiano, Estructura Agraria y Políticas del Gobierno .................... 322

2.2. La situación de la mujer campesina en Colombia............................................................. 511

2.3 La Vida en General y Agraria Particularmente, en Montes de María y Sucre.................... 544

2.4. Algunas particularidades de los municipios bajo estudio .............................................................. 62

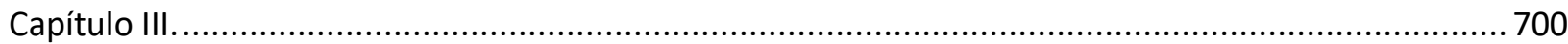

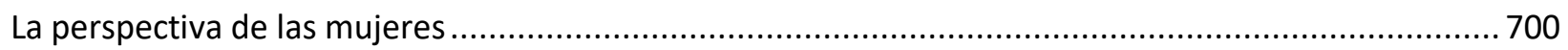

3.1. La Cuestión de la Tierra y el Capital en la Economía Social.............................................. 711

3.2. Acerca de la Actividad Familiar y Comunitaria, el Carácter Colectivo y las Tradiciones ... 766

3.3. Producciones Sustentables y Cuidado del Ambiente .......................................................... 888

3.4. Satisfacción de Necesidades y Excedentes ……................................................................ 900

3.5. Las Necesidades que Parecen Surgir de los Consumos Globalizados................................. 955

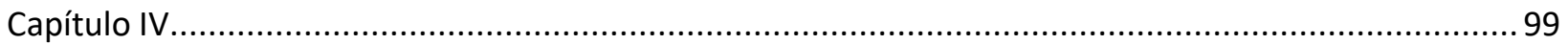

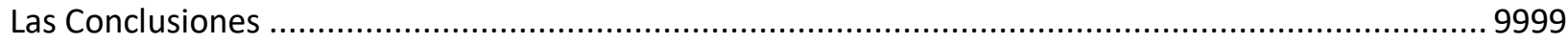

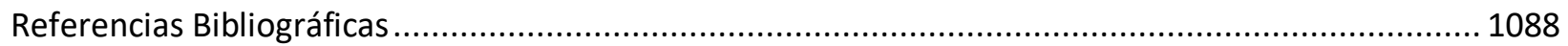




\section{Lista de figuras.}

No 1. PIB per cápita (US\$ a precios actuales) - Colombia. 34

No 2. Crecimiento del PIB y del sector agropecuario. 35

No 3. Balanza comercial de bienes y servicios (US\$ a precios actuales) - Colombia. 37

No 4. Evolución del crecimiento agropecuario frente al PIB total. Variación de 38 porcentual anual.

No 5. Destino final de la producción. Fuente: Ministerio de Agricultura.

No 6. Pobreza multidimensional y por ingresos según categorías de ruralidad de la 44

\section{Misión}

No 7. Niveles de pobreza en el Caribe colombiano.

No 8. Pobreza multinivel en mujeres rurales en Colombia

No 9. Tenencia de la tierra por parte de mujeres

No 10. Área de los patios

No 11. Porcentajes de mujeres dedicadas a la producción.

No 12. Con qué herramientas cuenta.

No 13. ¿Herramientas que le faltaría comprar? $\quad 74$

No 14. ¿Produce junto a otra familia o solo con su núcleo familiar? 75

No 15. Tipo de innovaciones realizadas por la familia en los sistemas productivos. 77

No 16. Organización a la que pertenecen las mujeres. 80

No 17 Organización a la que pertenecen las mujeres. 
Lista de tablas.

No 1. Personas en situación de pobreza monetaria y monetaria extrema.

No 2. Descripción de las organizaciones de mujeres

84

No 3. Comparativo en dólares 


\section{AGRADECIMIENTOS}

A las mujeres de Montes de María por su apoyo incondicional, por abrir las puertas a esta investigación, por su fraternidad, por su sabiduría ancestral expresada de manera sincera y sin condiciones.

Al Doctor Patricio Narodowski por ser un mentor y maestro durante el proceso académico y de investigación.

A mi familia por el impulso y amor que me brindan.

A la Corporación para la Educación y el Desarrollo de América Latina y el Caribe. CEDALC, por su invitación a participar de la Maestría. 


\section{RESUMEN}

Las mujeres Indígenas, Afro y Campesinas de Montes de María en Sucre - Colombia, trabajan la agricultura familiar de forma tradicional, mantienen un modelo productivo, que, aunque presenta bajos niveles de producción, falta de maquinarias, problemas en la comercialización, como sistemas productivos familiares son los más compatibles con el ambiente debido a que utilizan asocios, rotan cultivos, poco uso de agrotóxicos en el control de plagas. Además, producen muchos de sus alimentos, con tecnologías propias y ancestrales, tienen la garantía de que los miembros comen productos sanos, frescos y saludables, y mantienen plantas medicinales con las que sanan muchas de sus dolencias y enfermedades primarias.

Si bien los sistemas productivos son rentables, por su tamaño, no generan los ingresos suficientes para garantizar la satisfacción de sus necesidades básicas definidas por las mujeres, sobre todo porque no cubren los déficits en cuanto al hábitat. En respuesta a lo anterior, algunas mujeres han avanzado hacia sistemas productivos agropecuarios de transformación y comercialización, tales como las artesanías en caña flecha en toda su cadena de valor, la venta de productos comerciales, pollos de engorde, venta de carne en canal y carnes y bebidas frías, servicios y otros, lo que les permite aumentar el nivel de ingresos de las familias.

Vemos importante poder analizar de qué manera la agricultura familiar es fuente de ingresos para las mujeres y sus familias y cuál es el nivel de equilibrio ambiental y la sostenibilidad en las parcelas de las mujeres vinculadas a organizaciones de pequeñas productoras en los municipios de Sincelejo, San Antonio de Palmito y San Onofre en el departamento de Sucre.

Palabras clave: agricultura familiar, mujeres indígenas, afro y campesinas, ingresos, equilibrio ambiental, sostenibilidad. 


\begin{abstract}
The women from indigenous, afro and peasant origins from Montes de Maria in the Department of Sucre, Colombia, work the familiar agriculture in a traditional way. They keep a productive model that, although with low levels of production, lack of machineries and difficulties with the commercialization process as family productive systems, they are the most compatible with the environment due to the use of partners, the rotation of crops and the little use of toxic products for the control of pests. On the other hand, they produce many of their foods with their own and ancestral technologies with the warranty that their members consume healthy and fresh products keeping medicinal plants which are used to heal many of their ailments and primary diseases.
\end{abstract}

In spite of their productive systems are rentable, for their size, they do not generate the enough incomes to warranty the satisfaction of the basic women needs because they do not overcome the habitat deficit. Consequently, some women have moved towards agricultural production systems of transformation and commercialization such as crafts based on flech cane in all its value chain, the selling of commercial products, broilers, meats, cold meats, cold drinks, services and others; with all these activities, these women get to increase their family incomes.

In this project, we could analyze how the family agriculture is a source of income for these women and their families and what is the level of environmental balance and the sustainability in the women's plots linked to organizations of small producers in the municipalities of Sincelejo, San Antonio de Palmito and San Onofre in the department of Sucre, Colombia.

Key words: familiar agriculture, indigenous, afro and peasant women, incomes, environmental balance, sustainability. 


\section{Introducción}

El propósito de esta tesis de investigación es analizar los sistemas productivos agrícolas familiares de las pequeñas productoras rurales indígenas, afrodescendientes y campesinas de Montes de María en el Departamento de Sucre en Colombia, considerando la sustentabilidad económica y ambiental de dichos sistemas. Se focaliza en el periodo 2014 al 2018, tiempo en el que en el territorio disminuye la acción de grupos al margen de la ley y las familias pueden trabajar con mayor confianza y seguridad. Para ello se realiza un estudio socio productivo intentando reconocer los diferentes tipos de capacidad económica y de relacionamiento social, asociados a los sistemas productivos agrícolas familiares de las pequeñas productoras rurales de Montes de María - Sucre y en relación con el equilibrio ambiental y sostenibilidad. Esto incluye un ejercicio de detección de costos, consumos e ingresos de diversa índole, familiares y comunitarios. En ese análisis se identifican las particularidades, conocimientos y dificultades de la Agricultura Familiar, según la perspectiva de las propias actoras del territorio de Montes de María.

Y se plantea como hipótesis general que efectivamente estos sistemas productivos brindan las mejores condiciones para ejercer las funciones expuestas.

Con el estudio de los diferentes sistemas de agricultura familiar manejados por mujeres, se contribuirá a tener un diagnóstico más cercano de la situación económica de este tipo de sistemas productivos en la zona a nivel de las pequeñas productoras de la economía campesina, a partir del cual los entes encargados de la gestión del desarrollo a nivel municipal podrán identificar limitaciones y potencialidades que soportarán el planteamiento de políticas y acciones de desarrollo en el corto y mediano plazo y basados en las realidades específicas de la zona. 
La Agricultura Familiar, es una forma de organizar la producción agraria, la silvicultura, el pastoreo, la pesca y la acuicultura llevada a cabo por una unidad familiar. Depende del trabajo familiar, tanto masculino como femenino (Red Nacional de Agricultura Familiar, 2016).

Las mujeres montemarianas se dedican a la cría y producción de especies menores como gallinas, pavos, patos, cerdos, a la producción de hortalizas y cultivos de pancoger (cultivos que usan los pequeños productores para satisfacer necesidades de alimentación, cultivados en sus propias parcelas) como col, pepino, cebollín, habichuela, tomate, berenjena, ají, ahuyama, y el cultivo de plantas medicinales que utilizan para uso familiar y sanar enfermedades y algunas para vender, entre ellas tenemos: sábila, orégano, albahaca, toronjil, hierba buena, hierba santa, ultimo real, salvia amarga, singamochila, tuna o nopal, chanca piedra, entre otras.

Los varones se dedican a la producción de cultivos en mayor escala, (preparación de suelos, siembra de cultivos, asistencia y cosecha) algunos comerciales, tales como yuca, ñame, maíz, arroz, fríjol, plátano y cría de ganado (quienes tienen la posibilidad de tener sus vacas); algunos venden el jornal, ofreciendo su mano de obra en otras parcelas o fincas, otros se dedican a la comercialización de productos, servicios de transporte de pasajeros y carga.

La familia, la granja y el territorio evolucionan conjuntamente y combinan funciones económicas (en términos de supervivencia), ambientales, reproductivas, sociales y culturales (Foro Rural Mundial, 2016). En este contexto es importante el concepto de co-evolución y de seguridad y soberanía alimentaria ya que el modelo contribuye a la protección de la 
biodiversidad y provee la mayor cantidad de oportunidades de trabajo rural, desarrolla conocimientos propios del hacer agrícola y se apoya en fuertes redes familiares y comunitarias.

La hipótesis general que se señaló al comienzo se desagrega en las siguientes hipótesis más específicas.

Por un lado, los sistemas productivos familiares son los más compatibles con el ambiente y las tradiciones, incluso lo son respecto a la noción de necesidad tradicional de las familias y lo serían más si los ayudasen las regulaciones especialmente de tierras, tecnología, crédito, formación laboral y empresarial, al igual que apoyo a las asociaciones de pequeños productores y a sus alianzas con empresarios de mediana y gran escala. Sin embargo, muchas veces esta idea de necesidades se cruza con otras necesidades mínimas, más típicas de la globalización y éstas no logran alcanzarse por el escaso nivel de ingresos monetarios logrados. Por otro lado, ese nivel es insuficiente para afrontar la educación y sobre todo la salud, por lo que la dependencia del Estado es enorme y las condiciona.

La segunda hipótesis es que una relación armónica (según valores locales) entre los componentes biofísicos, agronómicos, tecnológicos y culturales permiten una satisfacción más plena de las necesidades (entendidas según el concepto local de las mismas) 
La tercera es que estas producciones pueden ser un medio para la seguridad y soberanía alimentaria de estas comunidades. Y finalmente, se encuentra una buena relación entre los componentes tecnológicos, biofísicos, agronómicos y culturales.

Para responder al tercer objetivo específico se realizaron entrevistas semiestructuradas a las mujeres de los tres grupos: indígenas, afrodescendientes y campesinas en sus espacios de trabajo y ambiente natural, donde también se hicieron las observaciones. (Kerlinger, 1979). Por un problema de tiempo y siguiendo a Marradi, Archenti y Piovani (2007), hay un momento que se suma a la observación en que se realiza una entrevista puntual para la recolección de datos específicos sobre el manejo y los resultados y para reconstruir historias pasadas, estudiar representaciones sociales, analizar qué discurso manejan las organizaciones y asociaciones y sus formas de apropiación.

Se realizaron 72 entrevistas entre los meses de enero a abril del año 2019, a las propietarias de unidades familiares siempre en los municipios de San Onofre (Afro), San Antonio de Palmito y Sincelejo (indígenas y campesinas), del departamento de Sucre, todos pertenecientes a la subregión de Montes de María. Estas unidades de observación fueron seleccionadas por el método muestral no probabilístico conocido como bola de nieve (Cea D’Ancona, 1996). Recurrimos sólo a las familias cuya vocación principal es la agrícola, las 72 mujeres entrevistadas hacen parte de organizaciones campesinas del territorio, y se hizo con un criterio muestral por conveniencia (Cea D'Ancona,1996), seleccionando aquellas organizaciones con características geográficas, políticas, productivas y culturales diferentes que dieran cuenta en lo posible de la diversidad de situaciones. 
Las entrevistas se utilizaron para conocer el punto de vista de las mujeres y cómo expresan sus propias experiencias en el tema de la agricultura familiar. De igual forma para poder reconstruir historias pasadas, en torno a los sistemas productivos, el manejo agroecológico, el aspecto criollo, estudiar representaciones sociales, analizar qué discurso manejan las organizaciones y asociaciones de la investigación, y sus formas de apropiación. Con las observaciones se logró no solo observar la vida cotidiana de las mujeres en sus sistemas productivos de agricultura familiar, sino poder participar en sus actividades, facilitando una mejor comprensión del tema en estudio.

En cuanto a la estrategia metodológica se parte de un diseño descriptivo en el que se problematiza la cuestión de la sustentabilidad de los sistemas productivos agrícolas familiares de las pequeñas productoras rurales indígenas, afrodescendientes y campesinas de Montes de María. Se utilizaron como técnicas de recolección de información el análisis documental y la observación, combinada con entrevistas semiestructuradas.

El análisis documental como herramienta de recolección de datos nos ayudó a obtener información del territorio, de los sistemas productivos, lo que también nos permitió tener una línea de tiempo de cómo se ha desarrollado este tema en el territorio y como se ha mejorado o desmejorado el nivel de vida de las mujeres, la capacidad de los sistemas productivos, las mejoras o atrasos. Para la caracterización de los sistemas productivos bajo estudio y el análisis socioeconómico utilizamos la estadística descriptiva, recurriendo a las medidas de tenencia central: media aritmética. 
La información que recolectamos de las familias en los diferentes sistemas productivos nos sirvió para la determinación de los costos e ingresos de los diferentes sistemas productivos bajo estudio. En cuanto al análisis social lo abordamos desde la demanda de jornales y la generación de ingresos; y la seguridad alimentaria generada en los diferentes sistemas productivos. Para completar realizamos un análisis cuantitativo comparativo de los sistemas productivos con el fin de evaluarlos.

La tesis se ha ordenado del siguiente modo:

En el capítulo I se abordan los debates en la Agricultura Familiar con especial interés en el concepto de necesidades, sustentabilidad, seguridad y soberanía alimentaria, armonía con el medio, y reciprocidad.

En este capítulo II se realiza un marco general en el contexto del desarrollo trunco colombiano, se analiza la economía, la estructura agraria y la situación social, las políticas del gobierno y luego se aborda el reflejo en Montes de María y Sucre, específicamente Sincelejo, San Onofre y San Antonio de Palmito, donde predominan los sistemas productivos de la agricultura familiar de pequeñas productoras indígenas, afrodescendientes y campesinas, como medio para la seguridad y soberanía alimentaria de estas comunidades.

En el Capítulo III mostramos la forma de organización, incluyendo la cuestión de la tierra y "el capital"; los saberes y las tradiciones; las producciones específicas y el mayor o menor cuidado del ambiente, costos; el nivel de satisfacción de necesidades y se hace una simulación de los excedentes, diferenciando las mujeres indígenas, las afrodescendientes y las campesinas. 
Los capítulos II y III nos permiten plantear conclusiones relativas a la lógica de la agricultura familiar y su relación con el territorio desde una lógica relacional, cultural, económica, productiva y en vínculo con el ambiente en un lugar particular, los municipios estudiados. Si bien hay bajos niveles de producción, falta de maquinarias, problemas en la comercialización, los sistemas productivos familiares son los más compatibles con el ambiente debido a que utilizan asocios, rotan cultivos, poco uso de agrotóxicos en el control de plagas. Además, producen muchos de sus alimentos, con tecnologías propias y ancestrales, tienen la garantía de que los miembros comen productos sanos, frescos y saludables, y mantienen plantas medicinales con las que sanan muchas de sus dolencias y enfermedades primarias. Resta el problema de fondo de que los ingresos generados no alcanzan muchas veces para satisfacer las necesidades definidas por los actores, sobre todo porque no cubren los déficits en cuanto al hábitat. Por eso es central el rol del Estado para generar fuentes de trabajo para algunos miembros y también garantizar ayudas económicas. Es claro que, en el contexto del subdesarrollo colombiano en general, ha habido en estos ámbitos instrumentos estatales poco efectivos e insuficientes. 


\section{Capitulo I.}

\section{Definiciones teóricas alrededor de la agricultura familiar y la mujer campesina}

En el primer capítulo referimos los aspectos teóricos que soportan esta investigación. De acuerdo con lo anterior, tuvimos en cuenta las referencias bibliográficas que hemos encontrado respecto al tema, y con base en ellas tomamos los elementos de juicio y desarrollamos un ejercicio de análisis y esbozamos los contenidos que nos permitieron organizar las categorías analíticas que fundamentan este trabajo.

\subsection{Antecedentes en relación con la agricultura familiar}

El objeto de análisis de la tesis es la agricultura familiar y su relación con el territorio. En los próximos párrafos conceptualizaremos aquella y este vínculo y luego abordaremos la lógica económica, productiva y tecnológica y en relación con el equilibrio ambiental y sostenibilidad, específicamente, las formas de producir y sobrevivir, los costos y beneficios, etc., siempre asociados a los sistemas productivos bajo análisis.

La Agricultura Familiar se ha definido de diversas maneras, para sintetizar la diversidad de opiniones diremos que las mismas se diferencian por los límites del objeto de estudio. La mayor parte, y nosotros también incluyen el primer grupo de Schneider y Escher (2015) designado como agricultura familiar "de subsistencia", "inviable”, "descapitalizada" y a veces "periférica", otros incorporan al segundo grupo "excedentaria", "comercial”, "capitalizada" o “consolidada". 
Nos quedamos con la de De la O y Garner (2012) y Salcedo, De la O, y Guzmán (2012), con la que parece coincidir la Reunión Especializada sobre Agricultura Familiar- REAF (2016), la Mesa Técnica de Agricultura Familiar y Economía Campesina, Ministerio de agricultura (2018) y la Estrategia Centroamericana de Desarrollo Rural Territorial - ECADERT (2010), en ella resalta la existencia de los siguientes elementos comunes en las diversas conceptualizaciones de la agricultura familiar: en las explotaciones predomina el trabajo familiar, la administración de la unidad económico-productiva se le adjudica a la/el jefa/e de hogar y son de escaso tamaño en cuanto a la explotación y la producción. Como se observa, estas definiciones la acercan a las más generales de economía popular, por ejemplo, de (Coraggio, el portal de la economia solidaria, 2018).

En cuanto a los sectores involucrados, si bien tomamos el nombre genérico de la agricultura, se incluye: la cría de la ganadería, la pesca, la acuicultura, la silvicultura, el aprovechamiento de los bienes y servicios de la biodiversidad, el turismo rural, las artesanías, la minería artesanal, y otras actividades de comercio y servicios no vinculadas con la actividad agropecuaria en coexistencia y articulación complementaria con otras formas de producción agraria (Ministerio de Agricultura y Desarrollo Rural, 2017, pág. 13).

Debemos aclarar algunos conceptos: la cuestión de la familia es central. Forero (2002) dice que la familia tiene un gran valor simbólico, es la referencia, en ella participan sus miembros, contribuyendo al sostenimiento del hogar según una distribución del trabajo bastante clásica en la que la mujer toma parte en algunas tareas productivas, sobre todo en la recolección, y se hace cargo fundamentalmente de las tareas del hogar en tanto que el hombre tiene bajo su 
responsabilidad los cultivos. El tema de la mujer en la agricultura familiar será retomado luego. También coinciden Ceñas (1993); Pérez (1998), pero dando valor a la vida comunitaria. Esta definición es la que permite hablar de relaciones de reciprocidad, cooperación y solidaridad. Esto se ha verificado especialmente en los tiempos del conflicto, mediante el uso del trueque o el intercambio de mano de obra en formas de trabajo compartido.

Ya Johnson (1944) destacó que la agricultura familiar se caracteriza por depender en gran medida de la mano de obra de la familia. Por otro lado, se supone una limitada ocupación de trabajadores contratados con una administración de la unidad económico-productiva que se le adjudica a la/el jefa/e de hogar, en pequeñas parcelas generalmente heredadas, donde además reside; con problemas de acceso a la tierra, al capital, a bienes y servicios de la oferta pública y los mercados (Maletta, 2011). El tema de la falta de tierra es tal vez el más grave y el más difícil de resolver (Deininger, 2004a).

Y esta precariedad a su vez los hace vulnerables al cambio climático, fluctuaciones de “mercado, vaivenes de las economías locales, escaso poder de negociación política e incipiente acceso a la información” (Esteve, 2009, p. 39); pero los enfoque usuales asumen que las familias enfrentan estas contingencias con un uso correcto de la capacidad de trabajo, utilización de saberes ancestrales, diversificación de cultivos, e innovaciones tecnológicas (Hart, 1985; Esteve, 2009; Scalerandi, 2010; Santacoloma-Varón, 2015; Varón, 2015).

En este sentido, la idea clave es que el contexto natural es fuente de sustento económico ya que por la gran variedad de cultivos y animales que allí se encuentran, no solo sirve para el sustento familiar, sino también para curar enfermedades comunes y para la venta de los 
excedentes creando dicho sustento. Se trata según estos puntos de vista, de la puesta en práctica de costumbres como la mano vuelta, el trabajo colectivo, que son expresiones de la cultura montemariana. Por ende, se asume el desarrollo de una "dimensión sociocultural” propia, caracterizada por la generación de vínculos intergeneracionales, y el traspaso de los conocimientos y de las tradiciones. La participación en vida comunitaria y en formas de organización como las cooperativas también representa una cualidad distintiva que habla de su buen manejo social, estableciendo una red de relaciones y estrategias reforzadas por los valores de la solidaridad y el compromiso a largo plazo. (Salcedo, De la O, y Guzmán, 2012).

El otro elemento clave de la definición es que la familia realiza múltiples estrategias de supervivencia y generación de ingresos, pero con el objetivo del autoconsumo. Ello explica, tal como argumenta Chayanov (1985) que la economía campesina, no es típicamente capitalista, en tanto no se pueden determinar objetivamente los costos de producción por ausencia de un mercado de bienes y de un mercado de factores. De esta manera, el retorno que obtiene un campesino luego de finalizado el año económico no puede ser conceptualizado como formando parte de algo que los empresarios capitalistas llaman ganancia. Rosas (2009) establece que el trabajo campesino carece de valor monetario, y ello le sirve de base para buscar en otros mecanismos la dinámica de la economía campesina. Si el trabajo allí carece de valor de cambio, consecuentemente no puede haber plusvalía ni ganancia; por tanto, "el motor que mueve a la economía campesina dice Chayanov (citado por Bartra, 2015), no es el mismo que mueve al modo de producción capitalista". 
Sin embargo, resta discutir si esta forma de organización permite resolver el tema de la pobreza y la desnutrición de la población más vulnerable de las zonas rurales, desde el punto de vista de los estándares estadísticos, parece haber consenso de que los ingresos monetarios o no generados, son insuficientes, pero el tema es retomado luego (FAO, 2014).

En cuanto a la relación de la Agricultura familiar y la política, es claro que el concepto intenta empoderar nuevamente a aquel campesino despojado de sus bienes, sus sistemas de intercambios simétricos, su autonomía y sometido a una extracción de excedente o transferencia involuntaria de recursos hacia grupos sociales más poderosos dentro de una sociedad de clases, que igual no le permitió un progreso en sus propios términos (Durston, 1982). En ese sentido, si bien hay un cierto consenso en este enfoque de la necesidad de políticas públicas fuertes por motivos económicos, se plantea que las mismas deben ser participativas (REAF, 2016). En otros autores, se profundiza la idea de que la relación con el Estado debe ser parte de la consolidación de un sujeto político decisivo. Y en este debate surge entonces la cuestión de género, que se analiza luego.

\subsection{Agricultura Familiar, Necesidades, Sustentabilidad, Seguridad y Soberanía Alimentaria, Economía Social y Solidaria, Armonía con el Medio, y Reciprocidad}

Los enfoques predominantes en la agricultura familiar la asocian a ésta con diversos valores que han sido planteados en esta tesis a manera de hipótesis: es decir, que esa satisfacción de las necesidades se logra mediante una relación armónica basada en la reciprocidad entre los miembros, respecto a las propias tradiciones, al ambiente biofísico y agronómicos que permite la 
seguridad y la soberanía alimentaria de las comunidades. Surge así primero un nuevo concepto de necesidad, luego de sostenibilidad.

a) Una noción diversa de necesidad.

Evidentemente la noción de necesidades cambia según los contextos y los enfoques.

Habrá una que surja de las tradiciones locales: el enfoque de la economía popular intenta mostrar que las familias del territorio gracias a la producción propia de alimentos han logrado vivir dignamente y satisfacer muchas necesidades sociales, materiales y espirituales, tanto individuales como colectivas. Estas necesidades son entendidas como construcciones sociales, desde cada contexto.

Hay un debate sobre el suministro correcto de servicios y bienes públicos ya que éstos tal vez no surgen originalmente del "local" pero son exigidos en determinado momento al gobierno (por ejemplo, la ambulancia, el hospital, nutrición, educación, salud, protección social, entre otros) y son necesarios para enfrentar un nivel definido socialmente de esas necesidades que debemos definir. Este puede ser el enfoque de Coraggio (2015) en el sentido de que, para él, el estado debe garantizar condiciones mínimas. Finalmente hay una definición de necesidades inherente al consumismo capitalista, fundamentalmente urbano pero que circula por los medios de comunicación continuamente y está presente en las estadísticas nacionales.

b) Sostenibilidad.

Es la versión más cercana a la economía popular que involucra un conjunto amplio de elementos físicos sociales y culturales y supone una articulación de los espacios en las diversas 
escalas y los tiempos inmediatos con el largo plazo (Torres, 1992; Pérez Correa, 1998, Vía Campesina, 2002). En otras palabras, que permiten que, bajo uso, se mantengan a través del tiempo las características fundamentales en cuanto a componentes e interacciones en forma indefinida; generando rendimientos razonables y estables a quien lo maneje y desde el punto de vista social, compatibles con los valores culturales y éticos del grupo involucrado (De Camino y Muller, 1993). El punto de vista es coherente con la idea de que la excesiva concentración de la tierra ha sido fuente constante de conflictos, muchos de ellos asociados a la expansión de la frontera agraria, que, a su vez, ha generado problemas ambientales, tanto por la desforestación a la cual, como por la ocupación productiva de zonas altas ambientalmente críticas, como los páramos (DNP, 2015, p. 10).

Mientras, se asume que la producción campesina en una gran parte de los casos involucra dentro de su lógica productiva y tecnológica los principios sostenidos por la moderna teoría ecológica, a saber: cultivo de varias especies; control de arvenses, control de insectos y enfermedades sin agroquímicos; fertilización orgánica; rotación de cultivos; integración agropecuaria-forestal; y uso de recursos y energía locales...Lo anterior confirmaría la tesis de que la producción campesina no solo aporta elementos para la seguridad alimentaria, sino que incorpora elementos de sostenibilidad al conjunto de los ecosistemas presentes en el país (Santacoloma-Varón, 2015, pág. 47). Sin embargo, algunas economías campesinas están más articuladas al mercado y tienen una mayor dependencia de insumos externos, por eso su configuración significa un desafío importante (Sánchez y Rosales, 2001). 
Así surge el planteo de la agroecología, entendida como un enfoque que valora estas dimensiones (Gliessman, 1990; Altieri, 1994; Acevedo Osorio, 2004), pero sobre todo como un movimiento que se opone a las prácticas convencionales, “por lo general basadas en el despilfarro del agua, el uso de los productos químicos y los monocultivos” (Ecología verde, 2018).

En esta tesis se parte de la base de que el enfoque de la agricultura familiar y el de la agroecología pueden ir juntos y dar lugar a una contribución clave para un modelo de desarrollo más general. Desde este punto de vista entonces, más allá de la supervivencia individual, la agricultura familiar representaría un aporte al Fortalecimiento de los esfuerzos hacia el desarrollo, por la relación entre la conservación de la agrobiodiversidad y el manejo sostenible de los recursos naturales junto a la seguridad alimentaria del país (Miranda, Suset, Cruz, y Machado, 2007). Se espera que, manejada sobre criterios de sostenibilidad ambiental, la riqueza ecológica del país es, además, una fuente potencial del aseguramiento de la alimentación y de otras actividades productivas, así como la preservación del entorno cultural y la equidad social (Martínez, 2005; DNP, 2015; Cardona, 2018). Esto significa que para el enfoque urge el fomento de estas prácticas para poner al monocultivo por parte del gobierno (Landero, et al. 2016).

Debe quedar claro que naturalmente los paradigmas convencionales plantean otra cosa, la teoría económica neoclásica busca responder a la cuestión de cómo proceder en la elección entre usos alternativos de un activo ambiental, considerando la validez o no de renunciar a la explotación económica en beneficio de la conservación de los espacios naturales y la forma en que deben combinarse los usos competitivos-pero que no son excluyentes- de un ecosistema 
(Restrepo, 2015). Para este enfoque, el incremento de los precios relativos causa una sustitución de aquellos recursos que se están volviendo escasos. Por otro lado, las transformaciones en el campo tecnológico ayudarán a que la sociedad mejore la confianza en la renovación de recursos naturales por otros similares en un efecto derrame.

En la teoría del desarrollo de posguerra, este aspecto no era muy diverso: fundamentalmente asignaba un rol central a los proyectos industriales, al instrumento de los polos de desarrollo y a la infraestructura, a partir de un paradigma mecanicista y racionalista desde una visión de dominio sobre la naturaleza, y dejaba a un lado el cuidado del medio ambiente (Miranda et al., 2007) esto sucedía incluso en la economía socialista.

En todos estos casos el crecimiento económico, la producción de bienes no sostenibles, la expansión progresiva de los costos medioambientales va juntos en un modelo que produce contaminación y derroche innecesarios. Si bien el evolucionismo plantea otros parámetros, sólo plantea junto al neo-institucionalismo una solución relacionada con los precios y los impuestos (Narodowski, 2012). Y cuando el desarrollo no se produce, aparecen las soluciones focalizadas vinculadas a lo local, pero sin un cambio de paradigma (Coraggio, 1994.)

c) Seguridad y soberanía alimentaria.

Según la definición de Vía Campesina de 1996, ONG/OSC, 2002; INCAP, 2014 y Mantilla (2009), soberanía alimentaria, es el derecho de los pueblos, las comunidades y los países de poder definir sus propias políticas agrarias y alimentarias con el objetivo de garantizar 
el acceso físico, social y económico a la alimentación nutricionalmente necesaria en función de sus preferencias y basándose en la pequeña y mediana producción, respetando sus propias culturas y la diversidad de los modos campesinos, pesqueros e indígenas. Según Esquinas (2006) la seguridad alimentaria mundial y el desarrollo agrícola sostenible van juntos al problema de la tierra ya mencionado se suma el del castigo estatal por el uso de semillas no certificadas en laboratorios,

Seguridad alimentaria es un estado en el cual "todas las personas tienen en todo momento acceso físico, social y económico a los alimentos suficientes, inocuos y nutritivos que satisfagan sus necesidades energéticas diarias y preferencias alimentarias para llevar una vida sana y activa”. (FAO,1996). Esta definición le otorga una mayor fuerza a la índole multidimensional de la seguridad alimentaria e incluye "la disponibilidad de alimentos, el acceso a los alimentos, la utilización biológica de los alimentos y la estabilidad [de los otros tres elementos a lo largo del tiempo]" (FAO, 2006).

La definición se ha ido perfeccionando, PMA (2003) dice que la seguridad alimentaria abarca 4 dimensiones: a) disponibilidad de alimentos, b) acceso a alimentos, c) consumo y utilización de los alimentos y d) estabilidad de los alimentos: mientras que Takagi, et al. (2006), exponen que en el caso de la seguridad alimentaria hay que tener en cuenta 4 aspectos: Cantidad de nutrientes, calidad de los nutrientes, regularidad en la ingesta de alimentos y dignidad en el tipo de alimentos que se consume (PMA, 2003). 
Este derecho no parece siempre garantizado, incluso parece no compatibilizarse totalmente con el rol de las comunidades en la alimentación de la población urbana. Según el Foro Rural Mundial (2014), el 70\% de los alimentos proceden de la agricultura familiar en el mundo, el $40 \%$ de las familias viven de la AF; las mujeres producen la mitad de los alimentos. Las explotaciones agrícolas familiares representan el $81,3 \%$ del total de fincas de América Latina y generan entre el 57 y el 77\% del empleo agrícola (FAO/BID, 2007). En Colombia, esta representa el $87 \%$ de los productores y aporta más del $50 \%$ de la producción agropecuaria. Por eso los organismos internacionales como FAO (2014) resaltan su capacidad para sacar de la pobreza y la desnutrición a la población más vulnerable de las zonas rurales, y de la población en su conjunto, ya sea urbana o rural. Sin embargo, son muchos los hogares rurales que no logran tener alimentos suficientes, generando un riesgo de desnutrición grande, debido a las condiciones de precariedad y de riesgos de toda índole, mitigados por sus propias capacidades, temas ya mencionados.

d) Economía Social y Solidaria.

La economía Social y Solidaria es - en un sentido más amplio - una propuesta política, social, cultural y económica que busca constituirse en una alternativa real al modelo tradicional vigente, es decir, al sistema capitalista. Busca construir una sociabilidad distinta a la imperante, corre el foco del afán de lucro como única motivación, para poner el centro en el ser humano y en la reproducción de la vida como objetivo esencial de la economía (PEARSON, 2014)

e) La armonía con la tradición y el ambiente. 
En cuanto a la armonía con las tradiciones y el ambiente, es útil el concepto de agroecosistemas, como alteración del ecosistema natural para la producción agropecuaria. (Altieri, 1995; Praguer, Restrepo y otros, 2002, Acevedo Osorio, 2004). Los dos pueden ser estudiado del mismo modo ya que ambos suponen elementos abióticos y bióticos que interactúan entre sí (Gliessman 2002; Acevedo, 2004). El planteo de las corrientes por las cuales nos hemos definido supone que la agricultura familiar contribuye a encarar el deterioro ecológico y social generado por los métodos intensivos tradicionales en la medida en que en la dimensión local están los sistemas de conocimiento (campesino, afro y/o indígena) portadores del potencial endógeno que permite cuidar la biodiversidad, contra la depredación de los modelos exógenos. Por eso, sostenibilidad ecológica y sociocultural van juntas (Sevilla y Woodgate, 1997 y 1998).

De todos modos, no se debe dejar de decir que hay una relación que puede considerarse negativa entre pobreza rural y deterioro ambiental, debida a un acceso insuficiente a los recursos necesarios para satisfacer las necesidades básicas. Bonhomme (2013) en su estudio sobre Mombin Crochu verifica una incapacidad de las personas para enfrentar esta situación de un modo sustentable. Easdae (2014) da cuenta de enfoques similares en relación con los efectos negativos de las producciones familiares de pequeña escala. Este tipo de enfoques no tiene en cuenta que el campesino ya ha sido despojado en muchos casos de su hábitat, además miden productividad en términos capitalistas (Quimbayo, 2009). Este punto será analizado para Montes de María, y nuestra hipótesis es diversa.

Por último, esta estrategia de relación con el ambiente puede complementarse, según lo que podríamos llamar el posestructuralismo (con conceptos como subalternidad en sus múltiples 
acepciones, insurrección de los saberes sometidos, etc) por nuevas formas de resistencia a las problemáticas históricas (desde la rebeldía abierta y los movimientos de protesta, hasta las formas de resistencia pasiva en la cotidianidad a los diferentes sistemas de dominación política), que fueron forjando determinados valores que aparecen incorporados a las memorias sociales (Sevilla y González, 2004; Sevilla, 2011; Escobar, Esteba, 2016).

f) Reciprocidad, solidaridad. Y en este enfoque esta subalternidad se asocia a la idea de reciprocidad, solidaridad o de relaciones horizontales entre los miembros.

El planteo surge como es sabido de Polanyi (1944), para él, otras formas de realización de la economía, además del mercado, son la reciprocidad y la redistribución. Desde otra perspectiva para Lomnitz (1975), la reciprocidad surge en situaciones de carencia de recursos materiales y es precisamente esa pobreza de recursos la que opera como motor que moviliza los recursos sociales y los convierte en recursos económicos.

Martínez (2016) afirma que estos valores son comunes en las familias agricultoras que producen no exclusivamente para mercados. Sotomayor (2017) dice que, al mismo tiempo, estos vínculos producen una conciencia común, una identidad. Para Torres (2013), la reciprocidad es una forma de organización, por el elemento de cohesión y capacidad de lucha; para dicha autora, en el contexto ya sea de estructuras vecinales o las familias. Por eso puede ser el modelo de relación, puede ser considerado un proyecto político en el que la sociedad se hace responsable de ella misma desde la solidaridad en la producción, la distribución y el consumo y que la práctica económica regenerando la vida social y política (Santana, 2008). 
Sin embargo, para Coraggio $(2010 ; 2015)$ la reciprocidad es difícil de lograr debido al individualismo, y por eso este autor plantea un mecanismo superestructural, con fuerte rol del Estado y con el apoyo de una variedad de organizaciones sociales que ofrecen una cantidad de servicios e intentan incidir en las políticas públicas de sus municipios.

Hay otros autores que piensan que ese vínculo de reciprocidad no es el determinante directamente del vínculo, por ejemplo a esta conclusión llega Narodowski (2014) y Anaya (2018).Y desde la ortodoxia directamente se cuestionan estos valores, Resico (2010), plantea que la propiedad privada es la base de la independencia del individuo, como valores centrales que favorecen la competencia y por eso a la sociedad en su conjunto. En el trabajo de campo se verá cómo funcionan estas relaciones en Montes de María.

\subsection{El enfoque de género en los análisis de la agricultura general}

Partimos de la base de que, a pesar de que la agricultura familiar ha logrado ser reconocida, aún se presentan debilidades en el reconocimiento del trabajo de las mujeres. A partir del análisis bidimensional propuesto por Fraser (2002), encontramos que la norma y las políticas han desconocido la problemática particular de las mujeres en sus hogares y en la economía doméstica, subsiste por eso la inequidad en la repartición sexual del trabajo al interior de las familias y las comunidades rurales. Es que, al trabajo cotidiano en las quintas, ellas deben sumar el absoluto cuidado de los miembros de la familia y la educación de los hijos. 
(MINSALUD, FAO, 2015). Incluso en la mayoría de las luchas por la tierra, eran quienes enfrentaban a la fuerza pública.

De acuerdo con León (2017) una razón es que la mujer es vista principalmente como ama de casa a pesar de su contribución en la agricultura, que se define como ocupación masculina. La falta de reconocimiento social del trabajo de la mujer en la agricultura puede servir como un mecanismo de exclusión de las mujeres frente a sus derechos de propiedad a la tierra. La división del trabajo se refleja en la composición de la herencia. Las hijas heredan animales, bienes domésticos, dinero en efectivo o la vivienda, mientras que la tierra se concentra en la línea de los varones. Por su parte, Velazco (2017) sostiene que la invisibilidad de las brechas y su escasa atención en materia de diseño de política pública agraria incluso comprometen seguridad alimentaria y el crecimiento económico.

Esta cuestión hoy está presente porque se asume el concepto de la perspectiva de género. Se reconoce que el género estructura relaciones asimétricas de poder entre los hombres y las mujeres al propiciar una distribución desigual de conocimientos, propiedad e ingresos, responsabilidades y derechos entre unas y otros, Estas relaciones de poder derivan de acuerdos gestados en instituciones sociales como el hogar, el mercado, el Estado y la comunidad, las cuales proporcionan a los hombres, más que a las mujeres, una mayor capacidad para movilizar reglas y recursos institucionales que promuevan y defiendan sus propios intereses. Así, en la mayoría de los contextos, los hombres gozan, en términos generales, de un mayor acceso a los alimentos, a los puestos políticos o a la tierra, una mayor movilidad física, menos responsabilidades en términos de auto cuidado y del cuidado de otras personas, una posición 
privilegiada en términos de control del trabajo -sobre todo del trabajo de las mujeres- y una sexualidad menos confinada (Murgibe, 2009).

Las desigualdades de acceso por género explican una vulnerabilidad particular de las mujeres en diferentes etapas: algunas no tienen acceso equitativo a los recursos naturales, no pueden decidir sobre ellos o ejercen solo un uso tradicional, generalmente limitado a la reproducción familiar. Esto aumenta su esfuerzo físico y su trabajo en el hogar o en la finca familiar de manera muy significativa (Ecadert, 2010; Martines y Leiva, 2017)

Por eso, como dice Matus (2007) uno de los desafíos más importantes es la incorporación de las cuestiones de género en el diseño, formulación, ejecución y evaluación de políticas, incluso dando la misma importancia a actividades económicas y no económicas.

León (2017) propone disminuir las desigualdades en la propiedad de la tierra entre hombres y mujeres, en procesos de titulación de tierras. E incrementaron las capacidades personales, empoderando a las mujeres y reconociendo conscientemente sus valores y fuerzas. La equidad de género es una necesidad definitiva para lograr un mundo mejor (Visbal, 2007) 


\section{Capítulo II.}

\section{Las Características de la Agricultura Familiar en el Contexto de la Economía Colombiana y Montemariana}

\subsection{Desarrollo Trunco Colombiano, Estructura Agraria y Políticas del Gobierno}

La economía colombiana tiene diversos problemas estructurales. Un desarrollo industrial trunco que generó a nivel urbano una terciarización temprana lo que da lugar a una estructura productiva muy desigual. Colombia había logrado cierto desarrollo industrial en la posguerra. La actividad crece primero muy rápidamente impulsada por el desarrollo del mercado interior y los estímulos que recibe, se estanca después y solo en algunos casos consigue incursionar de manera exitosa en el mercado mundial. Había crecido en base al mercado interno (Kalmanovitz, 2015)

Hay dos momentos de apertura comercial, en 1978 y luego en los años 90s, en ambos casos con un notorio proceso de apreciación real del peso y con un fuerte deterioro en la balanza comercial y la cuenta corriente de la balanza de pagos, y la desindustrialización (Zamudio, 2014). Este proceso se agudiza con la adopción de los Tratados de Libre Comercio firmados en el país y una política económica en general en contra de la industria. (Bernal, 2016).

De todos modos, el indicador de comercio total (exportaciones + importaciones) / PIB sólo aumentó por encima de los niveles que ya se habían alcanzado a finales de los ochenta con posterioridad a 1998 (Villar, 2005).Se seguía observando una escasa diversificación de las exportaciones y una disminución muy lenta de la pobreza, por debajo de las mejoras observadas, por ejemplo, en Chile (DNP, 2015). 
En consecuencia, desde 1974 y hasta el final del siglo XX la economía colombiana mostró una clara tendencia hacia su desindustrialización, medido como creación/cierre de plantas, generación de empleo, valor agregado sobre PIB. Se trata de los síntomas de la enfermedad holandesa, con una renta de exportación deteriorando la rentabilidad de exportaciones con valor agregado, constriñendo la producción de transables que es desplazada por importaciones abaratadas y financiadas por la renta (Revista Semana, 2019).

Y junto a la apertura, se produce el gran aumento de la producción y las exportaciones de petróleo, luego de los hallazgos de Caño Limón en 1984, y los de Cusiana y Cupiagua en 1992, pasando de los 150.000 barriles diarios en 1984 a casi 400.000 en 1990 y 584.000 en 1995. Luego vendría el aumento de los precios internacionales. Así la actividad agropecuaria pasó a representar el 2.3\% del PBI en el año 2014 (Entre enero y septiembre de 2014 la economía en general creció 5\% mientras el sector agropecuario en su conjunto lo hizo en 3,6\% (Nieto, 2015)), la minería el -0,2\% (el petróleo 5,2\% en 2014), la industria pasó al 12\% (Una caída de 2 puntos desde 2005) y los servicios sociales, comunales y personales al 5.5\%. Las exportaciones de petróleo y sus derivados entre 2010 y 2013 ascendieron al 51\% del total, en tanto que cerca del 37\% de los flujos de inversión extranjera directa (IED) al país se destinaron a esta actividad. De los ingresos del gobierno nacional, la actividad petrolera aportó en promedio el 15,6\% entre 2011 y 2014, en ese mismo período el ingreso por impuestos y dividendos de Ecopetrol representó el 2.2\% del PIB promedio, permitiendo la reducción del déficit fiscal del 3.3\% al 2.6\% (Navia, 2019) y las regalías petroleras aumentaron su participación en los ingresos de las entidades territoriales desde un nivel de 7,5\% en 2005 a 18,7\% en 2012 (Montes, 2016). El PBI como consecuencia de este proceso creció hasta 2014, cayendo ese año. 


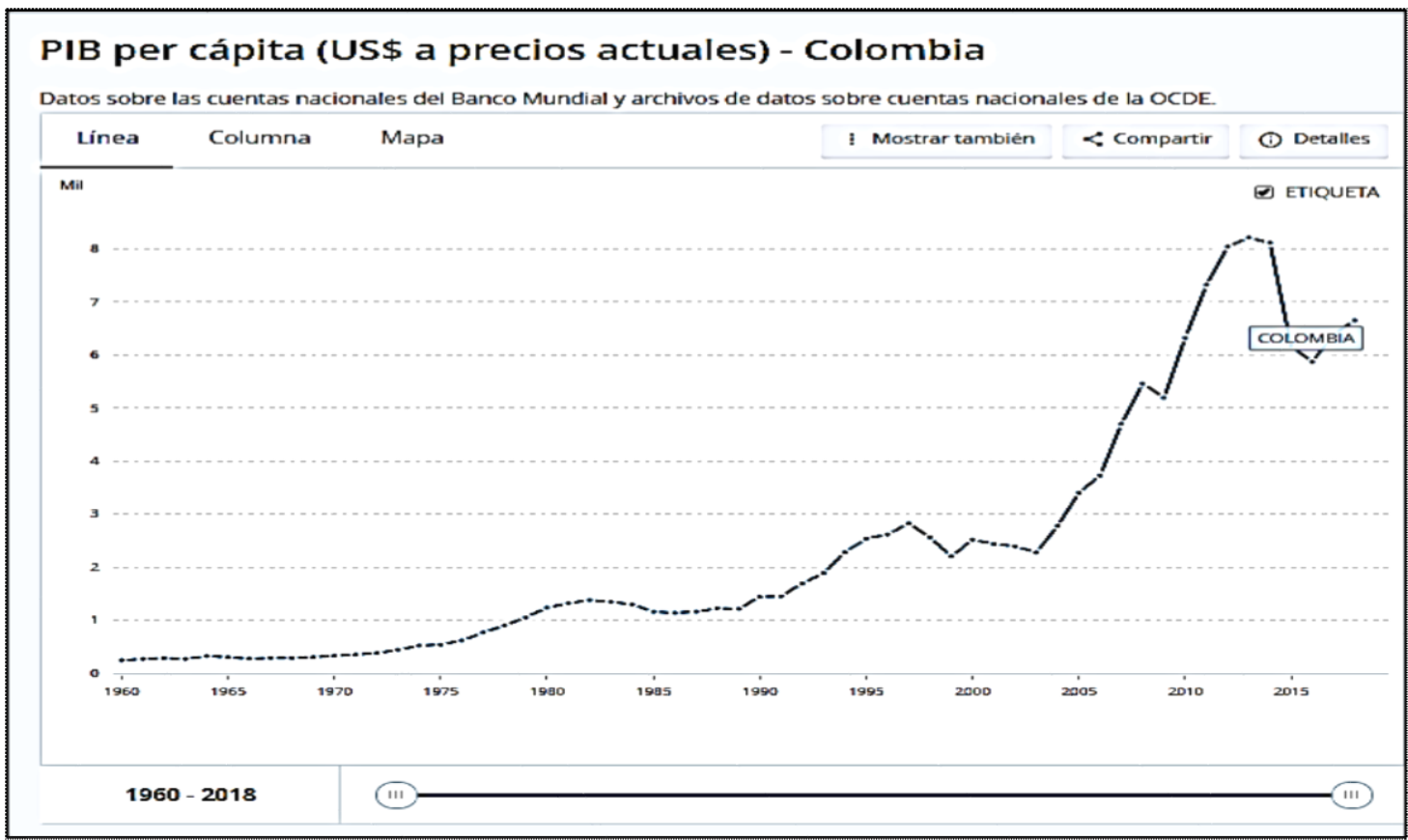

Figura No.1. PIB per cápita (US\$ a precios actuales) - Colombia.

Fuente: https://datos.bancomundial.org/indicador/NY.GDP.PCAP.CD?locations=CO

En la industria, según datos del Ministerio de Comercio, Industria y Turismo, los subsectores que registraron las mayores caídas en la producción industrial, entre 2010 y abril de 2016, fueron: hilatura, tejedura y acabados de textiles, ingenios, refinerías de azúcar y trapiches, metales preciosos, partes y piezas para vehículos automotores, productos elaborados de caucho y maquinaria no eléctrica. Además de la caída en la participación relativa ya mencionada cae en términos relativos el empleo manufacturero en las 13 ciudades principales del país y áreas metropolitanas, de $19.4 \%$ a $16.9 \%$, mientras que en las exportaciones la participación de la industria pasó de $60.9 \%$ a 40.4\%. Estas cifras evidencian un desacople entre el crecimiento de la economía nacional y el desempeño industrial, cuyo dinamismo ha sido menor que el de la economía en su conjunto (Bernal, 2016). Otero (2017) muestra que sólo ha habido una recuperación en 2016.

En cuanto a la actividad agropecuaria, ésta pasó de 6,9\% del PBI en el 2007 a 3,5\% en 2008 y 1,7\% en el 2009. En el primer trimestre del 2019, representa el 1,2 \% del PBI. Esta caída 
en la participación en el PIB se observa con particular rapidez durante los subperíodos de relativamente buen desempeño económico general, 1990-1997 y 2003-2014, en este último período, la expansión del sector fue apenas la mitad del que experimentó el PBI y muy inferior a los ritmos de crecimiento que prevalecieron antes de 1980. (Misión para la Transformación del Campo, 2015; DNP, 2015).

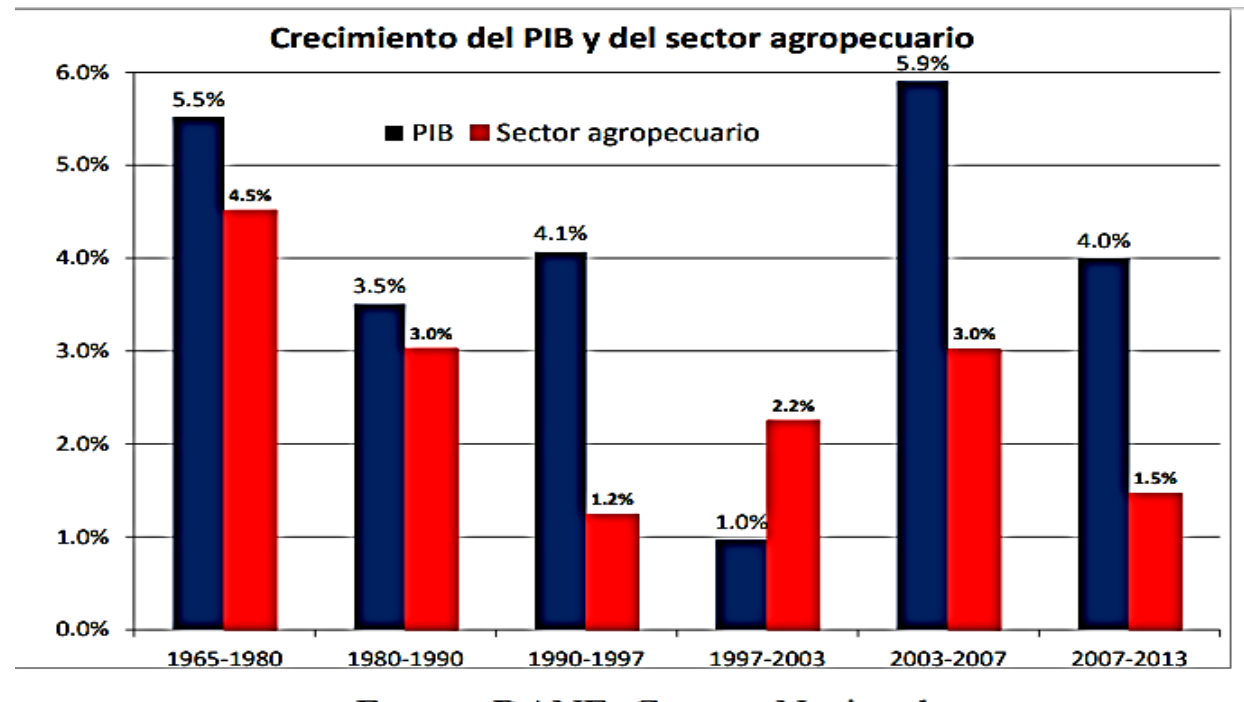

Fuente: DANE, Cuentas Nacionales

Figura No. 2. Crecimiento del PIB y del sector agropecuario.

Fuente: DANE, Cuentas nacionales, organizado por Misión para la Transformación del Campo

En la figura encontramos que ha habido una caída marcada en largo plazo y que el bajón del 90 al 97 se da especialmente por la apertura económica, en un país que no estaba preparado a nivel técnico y tecnológico, ni de infraestructura, maquinaria y demás, para enfrentar a un poder económico productivo como lo son los EE. UU. Se refleja una baja en los precios relativos de la producción agropecuaria nacional, cuando se mide mediante los índices de precios del PIB. En este largo plazo ha habido una reducción cercana a la mitad del PIB. 
Después del 2013 puede afirmarse que el sector agropecuario ha mostrado un gran dinamismo en los últimos años dónde la producción ha sido un factor determinante en la economía nacional. El sector agropecuario para 2016 contribuyo a la economía con el 9\% de la producción total, una suma considerable que podría justificar el esfuerzo de llevar al sector a un modelo bioeconómico (Villanueva-Mejía, 2018). Y En 2017 el sector agropecuario representó el 6,3\% del producto interno bruto (PIB) nacional. (Junta Directiva al Congreso de la república., 2018)

Dos de los principales reflejos de esta situación son, por una parte, el lento crecimiento y la escasa diversificación de las exportaciones agropecuarias en el último cuarto de siglo explica el deterioro agudo del balance comercial del sector desde 2008 debido al estancamiento de las ventas al exterior y el aumento de las importaciones, especialmente de cereales (DNP, 2015).

La balanza comercial del sector agropecuario a corte de 2016 es negativa con exportaciones de US 2’060.356,25 Dólares, (6.998 miles de millones de pesos), e importaciones con valor de US 2’125.423,23 dólares, (7.219 miles de millones de pesos), indicando un déficit de US 65.066,98 dólares (221 mil millones de pesos).

Como se ve en el gráfico, el déficit en 2018 es mayor. Debido a esto y al desbalance industria, el comercio exterior colombiano muestra una tendencia a ampliar el déficit. La situación anterior, es probable que obedezca a la firma del tratado de libre comercio con EE. UU., donde disminuyen restricciones a la entrada de productos agrícolas al mercado colombiano. (Villanueva, 2018) 


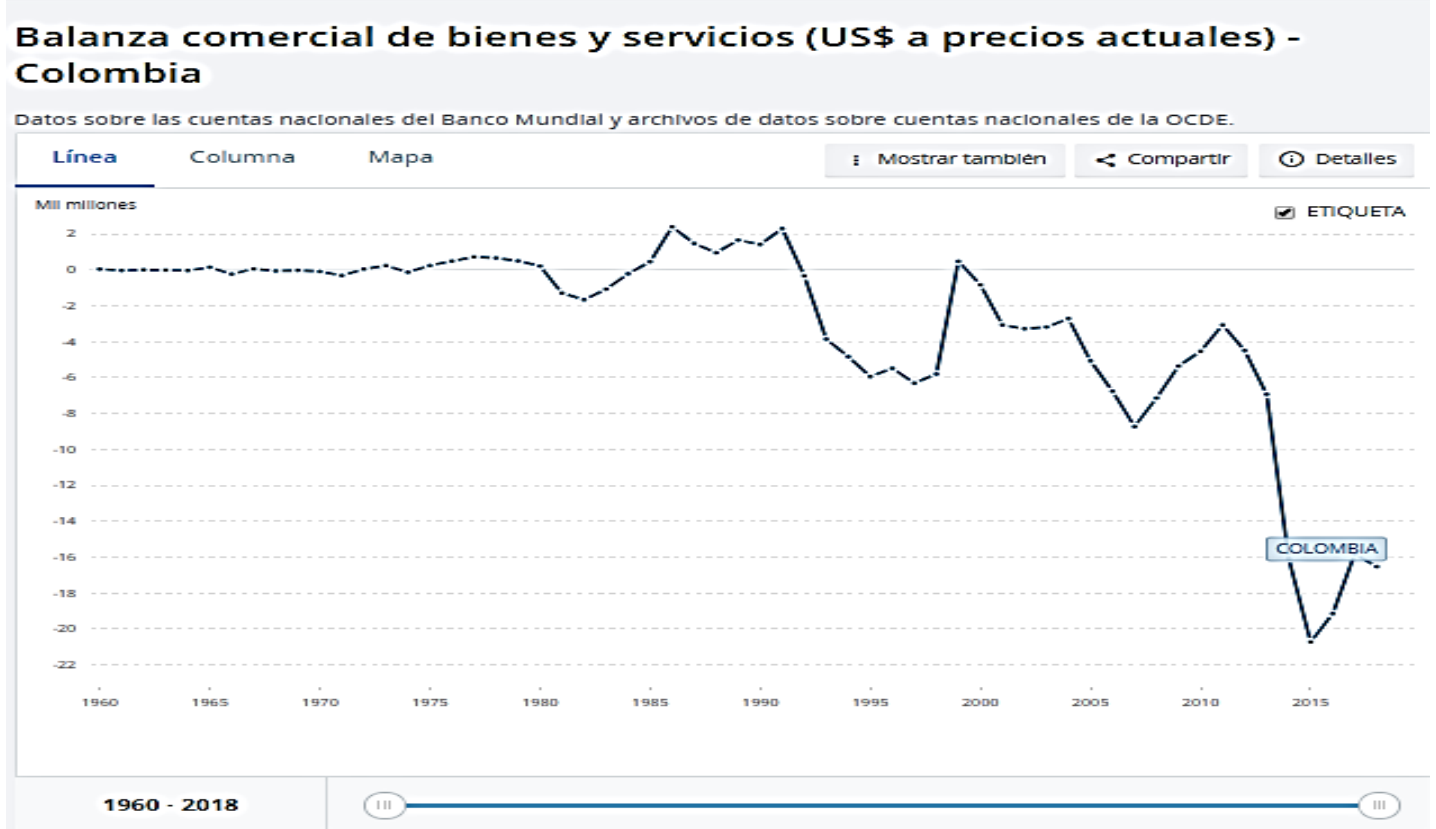

Figura No.3. Balanza comercial de bienes y servicios (US\$ a precios actuales) - Colombia. Fuente: https://datos.bancomundial.org/indicador/NE.RSB.GNFS.CD?locations $=\mathrm{CO}$

Para el año 2017, en los últimos 3 trimestres, según muestra el gráfico, el sector agropecuario ha sido el motor de crecimiento del país con un ritmo de expansión muy superior al de toda la economía colombiana. Según el DANE, en el periodo julio-septiembre de 2017 la actividad agropecuaria creció 7,1 por ciento, mientras que el producto interno bruto (PIB) total lo hizo en 2 por ciento. Un comportamiento similar se presentó en el primer y segundo trimestre de este año. En 2016 la fotografía era diferente. El sector agropecuario presentó caídas del 0,1 y 1,7 por ciento en el segundo y tercer trimestre, respectivamente. La industria, la minería y la construcción siguen decreciendo. En el tercer trimestre, la primera cayó 0,6 por ciento y los dos últimos sectores bajaron 2,1 por ciento, cada uno (Semana, 2017). 


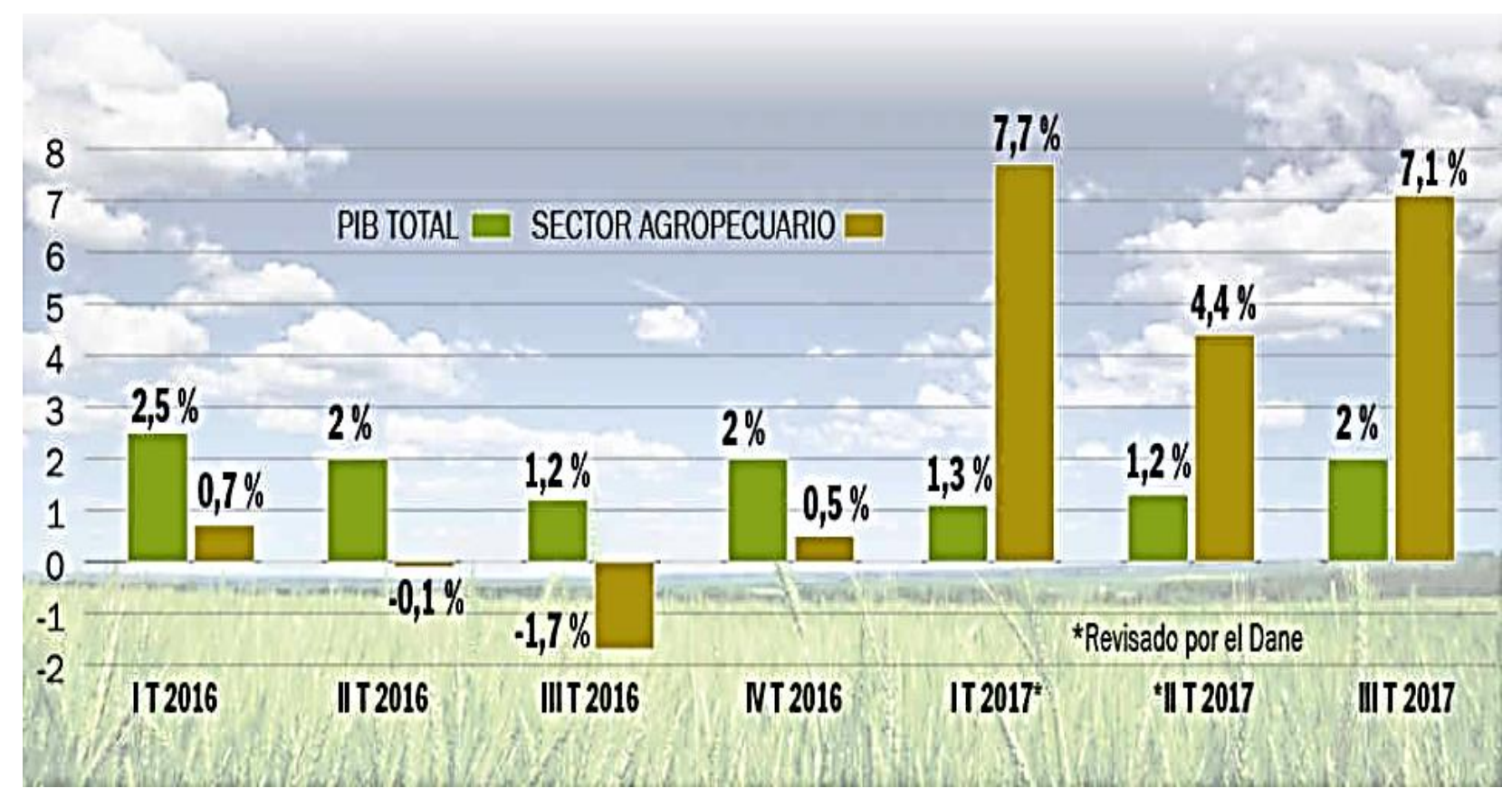

Figura No. 4. Evolución del crecimiento agropecuario frente al PIB total. Variación de porcentual anual. Fuente: artículo revista semana El agro: de cenicienta a líder

El PNUD (2011) propone una serie de factores estructurales que explican el pobre desempeño del sector. Junto a la violencia, menciona la concentración y subutilización de la tierra, la falta de capital humano y la escasa inversión en general y del Estado en obras de infraestructura para el desarrollo rural. Uno de los temas que resalta es la precaria cultura de riego: que de las (casi) 114 millones de Ha con potencial agropecuario del país, el 10,4\% es apto para riego y el 3,4\% para drenaje; de ellas se han desarrollado solo $900.000 \mathrm{Ha}$, es decir del 7\% del área con potencial. La mayoría de la adecuación de tierras en el país (61\%) ha sido desarrollada por el sector privado. Y se verifica también un limitado sistema de comercialización (DNP, 2015; Misión para la Transformación del Campo, 2015).

Y luego, en el período 2002-2009, la explotación de la minería, la producción de agrocombustibles y la actividad forestal, generó un nuevo proceso de concentración de la tierra y 
estimulo de inversión privada, amparada por políticas de gobierno, especialmente en departamentos afectados por el desplazamiento (Salinas, 2011).

Perry (2013) muestra que en el último período las políticas contribuyeron aún más a esa concentración estimulando la agricultura comercial y de gran propiedad, mientras que la agricultura de pequeña escala ha recibido pocos recursos y estos han sido principalmente dedicados a medidas compensatorias, no a resolver los problemas de fondo. En esta etapa aumenta la productividad de todos los factores, especialmente el factor trabajo y el uso de la tierra (Kalmanovitz, 2015). En este contexto se intensifica el uso de monocultivos, aumento del consumo de agrotóxicos, semillas terminator, con modelos empresariales para vender al mercado internacional, con altos niveles de deterioro de los recursos naturales y el medio ambiente. Se dejó de lado evidentemente el modelo de producción agropecuaria con una distribución equitativa del recurso tierra, amigable con el ambiente, limpia, diversa, que respeta la sabiduría local, las semillas criollas, y que permite la diferenciación territorial y la vinculación con lo cultural, lo ancestral, lo recreativo y lo social, como modo de lograr la eliminación de la pobreza y la inequidad en el sector rural.

En parte se justifica esta posición debido a la crisis alimentaria mundial y a los afanes de presentar soluciones rápidas a un problema que crece día a día, pero, la introducción de formas de producción agropecuarias amigables con el medioambiente son rechazadas por grupos monopólicos que controlan la producción de semillas y agroquímicos en el mundo. No obstante, todos defienden la posición que la forma actual de producir alimentos (tanto a pequeña, como a escala industrial), debido a sus altos costos ambientales y sociales debe ser urgentemente reformada. (Landero, et al., 2016) 
En este contexto, mientras que la agricultura comercial crece, la agricultura familiar la que produce cerca del 79\% de los alimentos; el 80\% de los agricultores son familiares y cerca del 30\% son mujeres. Una investigación desarrollada por Proyecto de Protección de Tierras y Patrimonio a la Población Desplazada (2010), muestra que cerca del 80 \% de los predios que abarcan menos del $6 \%$ del área total pertenecen al $78 \%$ de los propietarios y tienen menos del área que corresponde en cada zona a la Unidad Agrícola Familiar. Entre tanto, el 0,9 \% de los predios que pertenecen al 1,1\% de los propietarios abarcan cerca del $55 \%$ del área total (INDESCO, 2014).

Mientras la gran extensión es netamente exportadora, la agricultura familiar tiene un elevado porcentaje de autoconsumo e intercambio. Adicionalmente, la ACFC realiza la venta de sus productos principalmente a través de comercializadores (intermediarios) y en las plazas de mercado (Ministerio de Agricultura, 2010) (ver figura 5)

La figura muestra como la Agricultura campesina, familiar y comunitaria tiene altos niveles de ubicación de sus productos en los consumidores y mercados terminales, comparativamente frente a la No ACFC, con un 38,7\% de la producción para autoconsumo, frente a un $32,6 \%$ de la no campesina y familiar; un $17,3 \%$ de venta en cooperativa, frente a un $20,3 \%$ de la no ACFC, un 30,1\% de venta en plaza frente a un 38,1\% de la no ACFC, entre otros. 


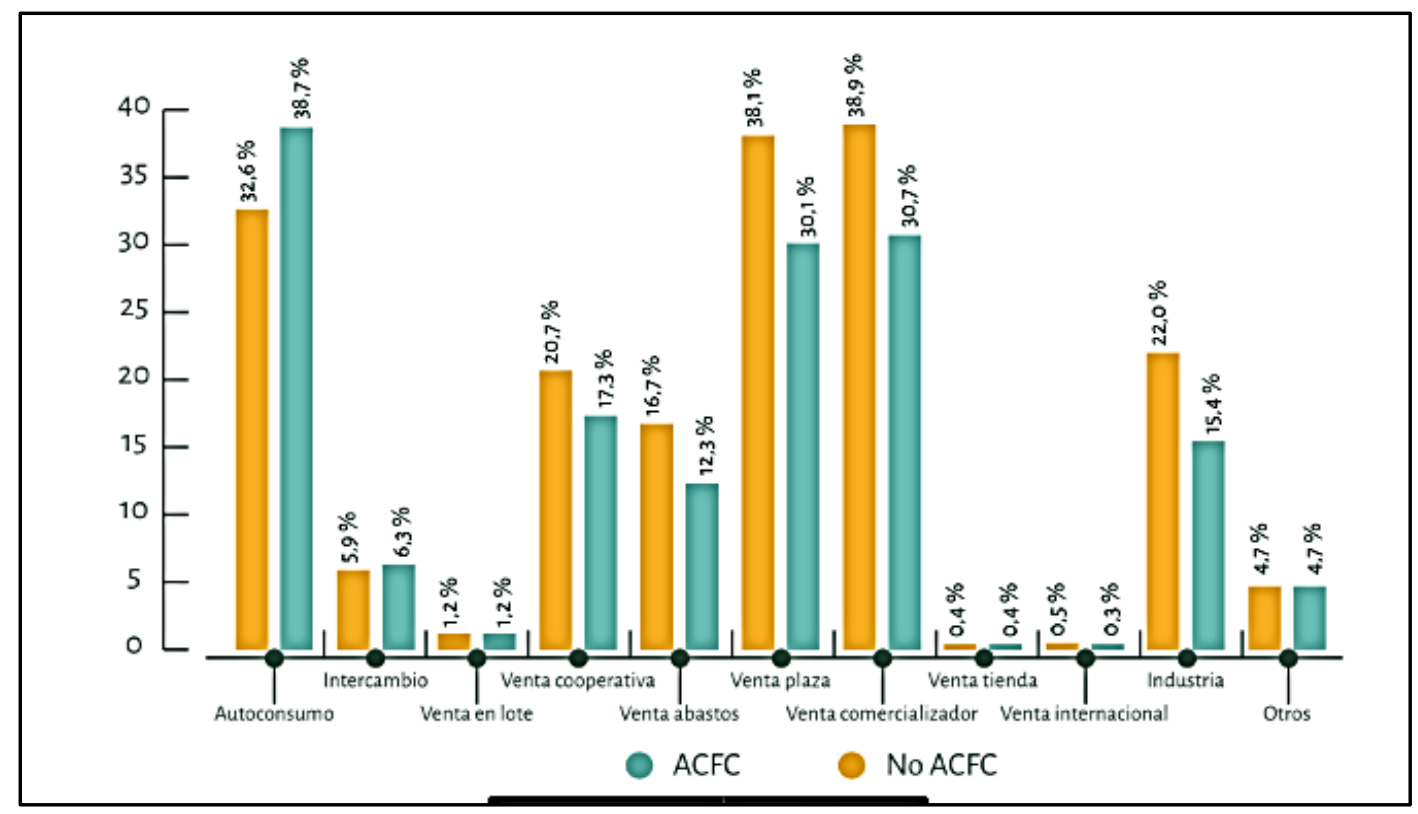

Figura No 5. Destino final de la producción. Fuente: Ministerio de Agricultura.

Y si se analizan los productos que más aumentaron sus rendimientos, se verá que la apertura ha generado cambios de orientación Los más competitivos fueron el maíz y las flores; también lo hicieron la soya y el sorgo, pero su participación en la producción es hoy en día marginal. El arroz, la papa, siguen siendo preponderantes, y tuvieron tímidas mejoras, mientras que el trigo, cacao, café, azúcar cruda, frutales y plátano de exportación vieron caer la productividad respecto a la década de 1990. La apertura económica y luego los bajos precios internacionales de productos tropicales, junto a los problemas de innovación ha llevado a un cambio en la estructura productiva del sector agropecuario colombiano, que consistió en el desplazamiento del café y cultivos de ciclo corto que competían con importaciones, a favor de algunos productos exportables (azúcar y palma africana), cultivos no transables y actividades pecuarias(DNP, 2015).Por otro lado, esa orientación al exterior genera pocas adaptaciones técnicas a la agricultura tropical (Balcazar et al., 2003). Incluso con errores conceptuales, y como 
el del algodón en los años ochenta, contraproducentes. También se verá que las diferencias entre los dos modelos se siguen ampliando.

Entonces, debido a esa concentración de la tierra, conviven dos sistemas, el de inversión (agricultura comercial) y el de trabajo intensivo (que hemos llamado agricultura familiar), y esos limitantes que marca PNUD serán diversos en cada caso. Quienes apuestan al primer modelo, plantean la necesidad de resolver los "cuellos de botella" que impiden el desarrollo de una agricultura capitalista (aumento del retorno esperado del proyecto, facilidades para la inversión extranjera, etc).

Por ejemplo, el Consejo Privado de Competitividad hace una serie de propuestas de política que hacen relación a la necesidad de ampliar las coberturas educativas en el área rural, eliminar la prohibición de que ninguna persona natural o jurídica pueda adquirir más de una Unidad Agrícola Familiar, ampliar el proyecto de alianzas productivas que adelanta el Ministerio de Agricultura con el Banco Mundial, continuar con el establecimiento de acuerdos de libre comercio con diferentes países que incluyan la agricultura y focalizar los subsidios en aquellos programas que tengan los mayores impactos positivos en materia de productividad (Perfetti, 2008).

Los que defienden a la agricultura familiar pondrán el acento en la necesidad de titularizar la tierra, el aumento del rol del Estado en la mejora de la infraestructura, resolver la falta de acceso a financiamiento. Aquí el ejemplo puede ser FAO (2008) que dice que el desarrollo de un territorio depende en gran medida de su capacidad para generar actividad económica en base a su capital natural, capital social, capital humano y conocimiento Cuando se cumplen estas condiciones el rol del estado deviene fundamental en cuanto el desarrollo 
endógeno implica un fuerte apoyo por parte de las políticas públicas incluyendo bienes públicos como educación salud e infraestructura y adoptando los incentivos económicos necesarios.

En lo que hace a la estructura social, por lo planteado, en el ámbito rural convive la empresa agropecuaria capitalista, con una agricultura empresarial moderna y el latifundio ganadero especulativo y la producción familiar minifundista sin tierra propia (DNP, 2015). El cuadro es de un alto nivel de polarización y lucha permanente por la tierra (García, 1973; Forero, 2001, Suescún, 2013).

Y esto ha tenido un impacto en la distribución del ingreso y la pobreza urbana y rural. A partir de 1998 la pobreza aumentó 9 puntos, afectando a casi cinco millones de habitantes. En las zonas urbanas se presentó la misma tendencia, aunque con un porcentaje inferior del 45\% en promedio, mientras que en las zonas rurales la pobreza aumentó durante toda la década, principalmente en la segunda mitad, en la cual pasó de 74\% a 85\% (Núñez, 2002).

De acuerdo con las categorías de ruralidad definidas por la Misión (Figura 4), los niveles de pobreza son mayores en las zonas rurales del país, tanto si se miden por ingresos como por el indicador de pobreza multidimensional, que estima el acceso a bienes de interés social y otras dimensiones de calidad de vida. La pobreza es, además, siempre mayor en la población dispersa que entre la que habita en las cabeceras municipales en todas las categorías de municipios. Esto es cierto, incluso en los municipios más rurales y dispersos y es particularmente marcado en el indicador de pobreza multidimensional. En efecto, este indicador alcanza en las cabeceras de los municipios rurales y rurales dispersos niveles de 30\% y 32\% respectivamente, esto es, 23 y 27 puntos porcentuales menos que en la población dispersa. La diferencia entre población nucleada y dispersa en términos de pobreza por ingresos es también importante, pero no es tan marcada. 
En los municipios rurales y rurales dispersos, la mitad de la población es pobre por ingresos, independientemente si viven en la cabecera o en zonas dispersas (DNP, 2015).
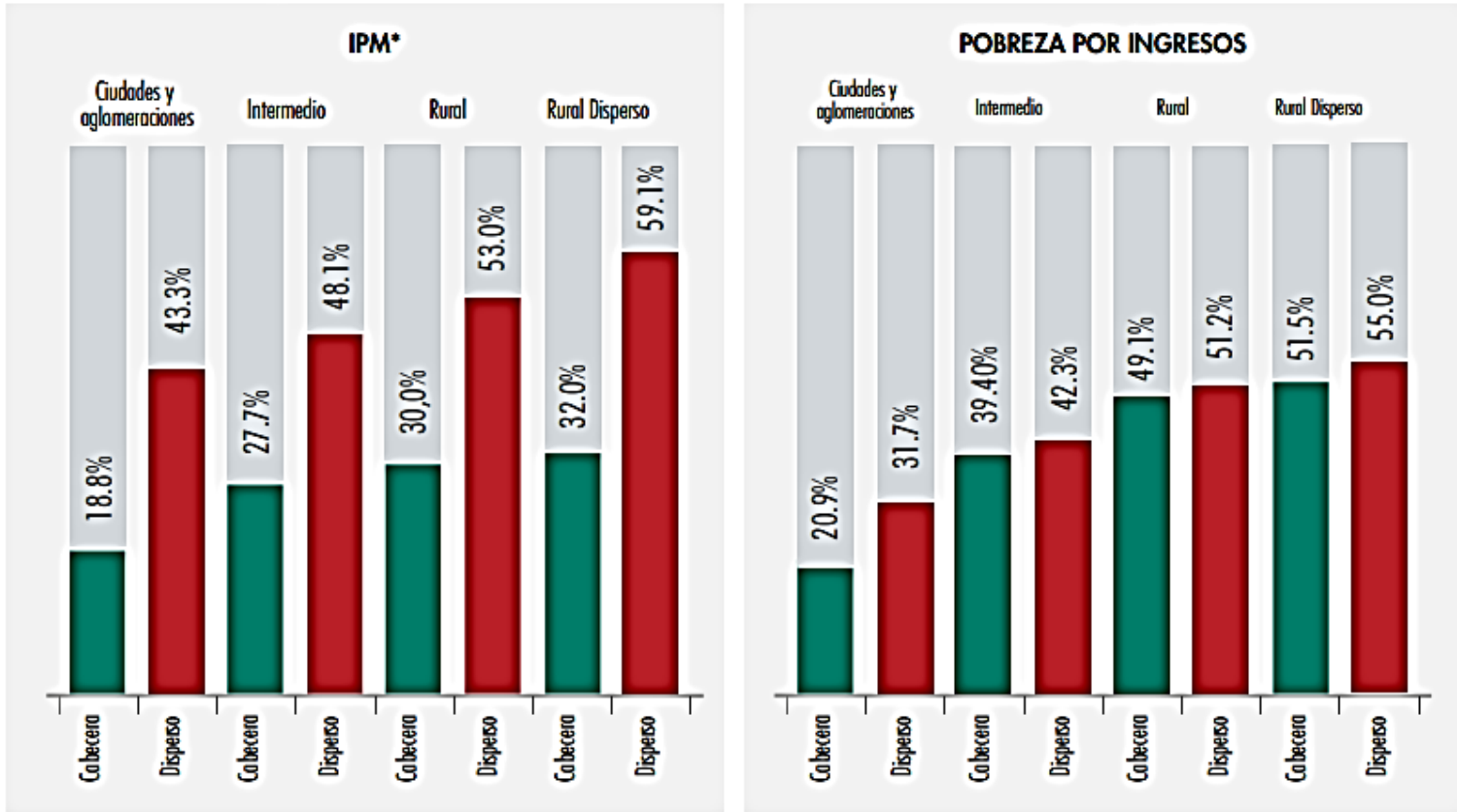

Figura No 6. Pobreza multidimensional y por ingresos según categorías de ruralidad de la Misión. Fuente: DANE. Misión para la transformación del campo, 2015.

\section{Valores absolutos}

\section{2-2018}

Personas en situación de pobreza monetaria Cifras en Miles

Cifras en Miles
\begin{tabular}{|l|rrrrrrr|}
\hline \multicolumn{1}{|c|}{ Dominio } & \multicolumn{1}{c}{$\mathbf{2 0 1 2}$} & $\mathbf{2 0 1 3}$ & $\mathbf{2 0 1 4}$ & $\mathbf{2 0 1 5}$ & $\mathbf{2 0 1 6}$ & $\mathbf{2 0 1 7}$ & $\mathbf{2 0 1 8}$ \\
\hline Nacional & $\mathbf{1 4 , 8 1 4}$ & $\mathbf{1 3 , 9 9 4}$ & $\mathbf{1 3 , 2 1 0}$ & $\mathbf{1 3 , 0 3 9}$ & $\mathbf{1 3 , 2 6 8}$ & $\mathbf{1 2 , 8 8 3}$ & $\mathbf{1 3 , 0 7 3}$ \\
Cabeceras & 9,836 & 9,426 & 8,765 & 8,695 & 9,090 & 8,966 & 9,124 \\
Centros poblados y rural & 4,978 & 4,568 & 4,445 & 4,343 & 4,178 & 3,917 & 3,949 \\
disperso & 3,881 & 3,633 & 3,339 & 3,267 & 3,429 & 3,432 & 3,570 \\
13 ciudades y A.M. & 5,954 & 5,793 & 5,426 & 5,428 & 5,662 & 5,535 & 5,553 \\
\hline Otras cabeceras & & & & & & & \\
\hline
\end{tabular}

Personas en situación de pobreza monetaria extrema Cifras en Miles

\begin{tabular}{|l|rrrrrrr|}
\hline \multicolumn{1}{|c|}{ Dominio } & \multicolumn{1}{c}{$\mathbf{2 0 1 2}$} & \multicolumn{1}{c}{$\mathbf{2 0 1 3}$} & \multicolumn{1}{c}{$\mathbf{2 0 1 4}$} & $\mathbf{2 0 1 5}$ & $\mathbf{2 0 1 6}$ & $\mathbf{2 0 1 7}$ & $\mathbf{2 0 1 8}$ \\
\hline Nacional & $\mathbf{4 , 7 0 4}$ & $\mathbf{4 , 1 4 9}$ & $\mathbf{3 , 7 4 2}$ & $\mathbf{3 , 7 1 8}$ & $\mathbf{4 , 0 0 3}$ & $\mathbf{3 , 5 3 4}$ & $\mathbf{3 , 5 0 8}$ \\
Cabeceras & 2,284 & 2,106 & 1,809 & 1,777 & 2,043 & 1,860 & 1,826 \\
Centros poblados y & 2,420 & 2,043 & 1,933 & 1,941 & 1,960 & 1,675 & 1,683 \\
rural disperso & 679 & 624 & 559 & 579 & 630 & 590 \\
13 ciudades y A.M. & 1,605 & 1,482 & 1,250 & 1,198 & 1,413 & Actival 1,270 dows \\
Otras cabeceras & & & & & & 1,196 \\
\hline
\end{tabular}

Tabla No 1.Personas en situación de pobreza monetaria y monetaria extrema. Fuente: DANE. Gran Encuesta Integrada de Hogares GEIH 2012-2018. 
En cuanto a personas en situación de pobreza, la anterior tabla muestra un recorrido desde el 2012 hasta el 2018, tiempo coincidente con dos periodos presidenciales

En Colombia, en el periodo del 2012 al 2018, la cantidad de personas pobres monetarias (personas residentes en viviendas con gastos per cápita escasos para obtener una canasta básica de alimentos y no alimentos) disminuyeron en un 11,75\%, es decir, 1'741.000 personas, mientras que en las cabeceras fue del $7,2 \%$, en los centros poblados y rural disperso del $20,7 \%$, y en otras cabeceras del $6,7 \%$.

Y para las personas que viven en viviendas con ingresos o consumos per cápita menores al valor de una canasta mínima de alimentos, sea en pobreza monetaria extrema, la disminución de este indicador en este periodo fue la siguiente: a nivel nacional fue del $25,4 \%$, o sea 1'196.000 personas, mientras que en las cabeceras fue del $20,05 \%$, en los centros poblados y rural disperso del $30,45 \%$, y en otras cabeceras del $25,5 \%$.

Cifras que debería ser mayores, en la medida que el gobierno nacional debería atender de mejor manera a esta población, con oportunidades para generar empleo e ingresos, acceso a educación, formación y todo lo concerniente a garantizar calidad y condiciones de vida. Y también hay diferencias regionales. 


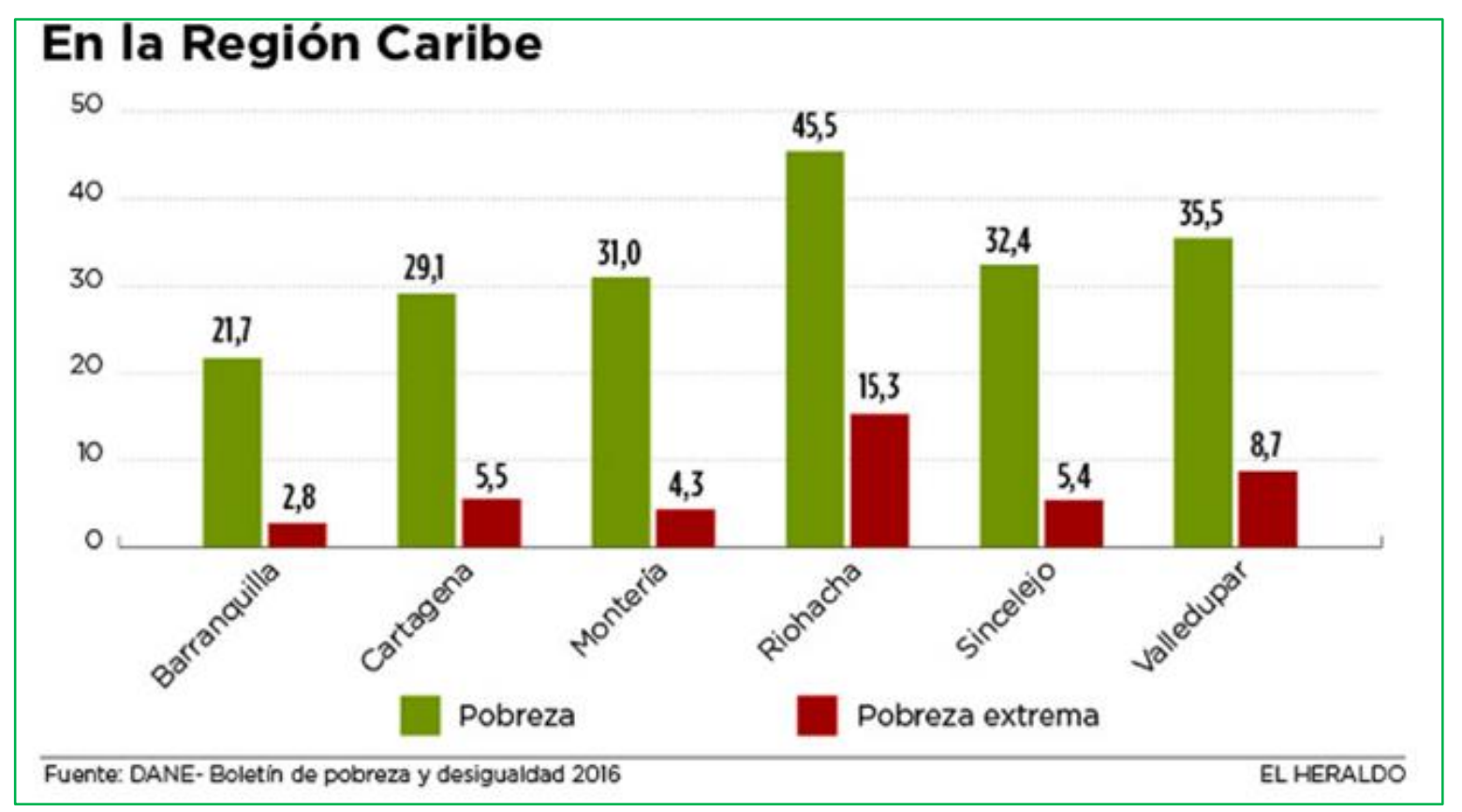

Figura No 7. Niveles de pobreza en el Caribe colombiano.

Fuente DANE, boletín de pobreza y desigualdad

Para el caso de Sincelejo, cabecera municipal de los municipios que hacen parte de este estudio que un 32,4\% de la población está en pobreza, es decir, aproximadamente 91'659,6, habitantes y 15.276,6 habitantes. Cuestión que se presenta entre otras causas por la falta de fuentes de ingreso y de empleo, a nivel de industrias, de empresas, de servicios, entre otras.

El resultado es el nivel de desigualdad en Colombia, el índice de Gini según la CEPAL, para el 2016 fue 0,517, pero en el sector rural este índice oscila alrededor del 0,892. Es evidente, por los resultados sociales, que no ha habido una gestión equitativa del campo y una promoción y salvaguarda de los derechos étnicos y campesinos sobre la tierra y sus usos, las problemáticas de precarización de la vida se profundizan, generando una brecha cada vez más amplia (Grupo Semillas, 2017). 
Frente a estas desigualdades y situaciones de desmejora de la población rural campesina que se dedica a la agricultura familiar, Machado (2009) sugiere que Colombia necesita una estructura agraria que rompa el binomio latifundio-minifundio dentro de un modelo de desarrollo agroindustrial.

Esta situación agraria descrita es consecuencia de todo el proceso económico y social colombiano, pero en lo específico, de una normativa que produjo el fortalecimiento y definitiva consolidación del impulso al desarrollo agrícola sobre la base de la gran propiedad territorial, la Ley 135 de 1961 (Balcázar, 1985). Las únicas acciones efectivas de reforma agraria fueron realizadas por movimientos campesinos que se desarrollaron a partir de "invasiones" a latifundios. La Ley 160 de 1994 de establecimiento de las zonas de reserva campesina podía ser un aporte, pero las zonas han sido muy poco tenidas en cuenta, y están en la discusión pública actualmente.

El Plan Nacional de Desarrollo 2010- 2014, enuncia políticas enfocadas a la restitución de tierras y la reparación de víctimas, por su parte el acuerdo final entre el gobierno colombiano y las FARC, contiene el acuerdo "Reforma Rural Integral", pero las medidas concretas fueron escasas.

En el contexto expuesto ha habido diversas políticas más que nada de asistencia a la agricultura familiar. Las mismas se inspiran en la Ley 731 de 2002 que impulsa la integración a cadenas agro-productivas, el turismo rural y ecológico, las artesanías, etc. En cuanto a las normas para favorecer a las mujeres rurales, la Ley 731 de 2002 tenía ese objetivo, sobre todo mediante 
la eliminación de obstáculos para el acceso a fondos, planes, programas, proyectos y entidades que favorecen la actividad rural, pero el impacto parece limitado.

En 2014 se crea el Programa de Agricultura Familiar y se establece una mesa técnica de trabajo que discutiera los alcances de las resoluciones, generando los ajustes necesarios que permitieran su implementación acorde a las necesidades de la Agricultura Familiar en el país.

En diciembre del 2017 fue promulgada resolución una la cual se establecen los Lineamientos estratégicos de política pública para la Agricultura Campesina, Familiar y Comunitaria (ACFC) y se dictan otras disposiciones, entre ellas, la derogación del Programa de Agricultura Familiar PAF. Se pretende una mayor y más integral acción del Estado y el fortalecimiento de las capacidades sociales, económicas y políticas de las familias, comunidades y organizaciones de agricultura campesina, familiar y comunitaria, sobre la base de un desarrollo rural con enfoque territorial que mejore la sostenibilidad de la producción agropecuaria y que genere bienestar y buen vivir a la población rural, de nuevo sin una implementación concreta.

En lo que hace al apoyo estatal a la seguridad alimentaria, debemos mencionar que el Gobierno Nacional a la fecha, ha formulado varios planes nacionales y una política pública relacionadas (Estupiñán, 2012). El primero es en 1967 cuando se plantea la necesidad del estado de atender el problema de la desnutrición (DNP, 1967). Como respuesta a esta necesidad se suministraron suplementos alimenticios que fueron donados por entidades internacionales, con la participación del país mediante organizaciones ejecutoras (Ministerio de Salud Pública, 1970), a raíz del impacto, las coberturas se aumentaron y se reestructuraron en el Plan Nacional de Alimentos (DNP, 1989). 
Según el relevamiento de Arenas (2003), en 1975, se creó el Plan Nacional de Nutrición (PAN) junto con el Programa de Desarrollo Rural Integrado (DRI), que planificaría y desarrollaría la producción de alimentos por medio del fortalecimiento a la economía campesina para aumentar la oferta y disponibilidad de alimentos básicos. El plan tuvo corta duración. Recién en 1989 se elabora uno nuevo.

En 1996 aparece uno nuevo, el Plan Nacional de Alimentación y Nutrición (PNAN) que posee una línea de seguridad alimentaria, sin visión integral y con propuestas de productos alimenticios culturalmente lejanos a los hábitos del país y de las regiones (Cardona, 2011).

El documento CONPES Social 113 de marzo de 2008 realiza una evaluación negativa y como resultado el Gobierno propone un proceso de construcción colectiva de concertación entre entidades del nivel nacional, departamental y municipal, con organizaciones de la sociedad civil, organismos internacionales, universidades y gremios y define la nueva Política Nacional de Seguridad Alimentaria y Nutricional, con una defensa de los derechos, un abordaje intersectorial e interdisciplinario cercano a los postulados ya analizados en párrafos anteriores y de gestión del riesgo. Al mismo tiempo se escriben los planes de seguridad alimentaria y nutricional departamentales.

Un decreto del 2009 crea la institucionalidad que permite abordar la problemática de Seguridad Alimentaria y Nutricional (SAN) en forma integral y articulada, y crea la Comisión Intersectorial de SAN (CISAN). Adicionalmente, define para dicha comisión, las funciones de coordinar, articular, elaborar e implementar el Plan Nacional de seguridad Alimentaria y Nutricional -PLAN SAN, con poca aplicación práctica. 
Arenas (2003) dice que estos documentos se convierten en actos administrativos que luego no se implementan. Según el planteo de Subirats, Knoepfel, y Varone (2008) y Roth (2014) son modelos Top Down, con un esquema tradicional donde es el estado a través de sus funcionarios quienes aportan las iniciativas, y los grupos afectados por la política, aunque son tenidos en cuenta para el análisis inicial, desaparecen al momento de la formulación. La participación de las comunidades y otros grupos de interés es escasa. Además, las políticas públicas de SAN, no cuentan con una articulación con otras políticas planteadas.

Hay un cierto consenso en que la agricultura familiar campesina e indígena en Colombia resiste en medio de la ausencia de políticas públicas que deberían estar dedicadas a protegerla. Pérez (1998) reforzaba lo anterior cuando dice que, en Colombia, es el sector rural en el cual se evidencia con mayor claridad la enorme distancia entre las metas de desarrollo social y las posibilidades reales de alcanzarlas.

Machado (2003) va más allá cuando plantea que para nadie es extraño que los modelos de desarrollo adaptados por Colombia hayan causado un proceso de continua marginalidad y desatención de las economías campesinas, afectando sus ingresos, su capacidad de negociación, su receptividad a los servicios y presencia del Estado, y sus posibilidades de integración a la vida nacional en todos sus órdenes, es parte de un proceso histórico. Según Noriega (2017), estos modelos económicos, no sólo no ha resuelto los problemas estructurales, sino que ha acentuado las desigualdades, extendido la pobreza y acelerado el deterioro del ambiente. 


\subsection{La situación de la mujer campesina en Colombia}

Según proyecciones del DANE, se estima que de las 25.501.149 mujeres que hay en Colombia, 5.442.241 viven en las zonas rurales. Y, según datos de la Dirección de la Mujer Rural del Ministerio de Agricultura, el 53.1 \% son indígenas, $46.4 \%$ afrodescendientes. Un porcentaje alto de las mujeres rurales $(37.4 \%)$ se encuentra en condición de pobreza, frente a un porcentaje mucho menor (12\%) de las mujeres que en las ciudades vive en esa misma condición (Mercado, 2018).

La pobreza multidimensional en Colombia ha disminuido en el periodo 2010 - 2016, pasando de 30,4\% en 2010 a 17,8\% en 2016, en cifras, pasamos de 13, 7 millones de personas en 2010 a 8,6 millones en 2016, con de 5.1 millones de personas que salieron de la pobreza multidimensional en ese periodo.

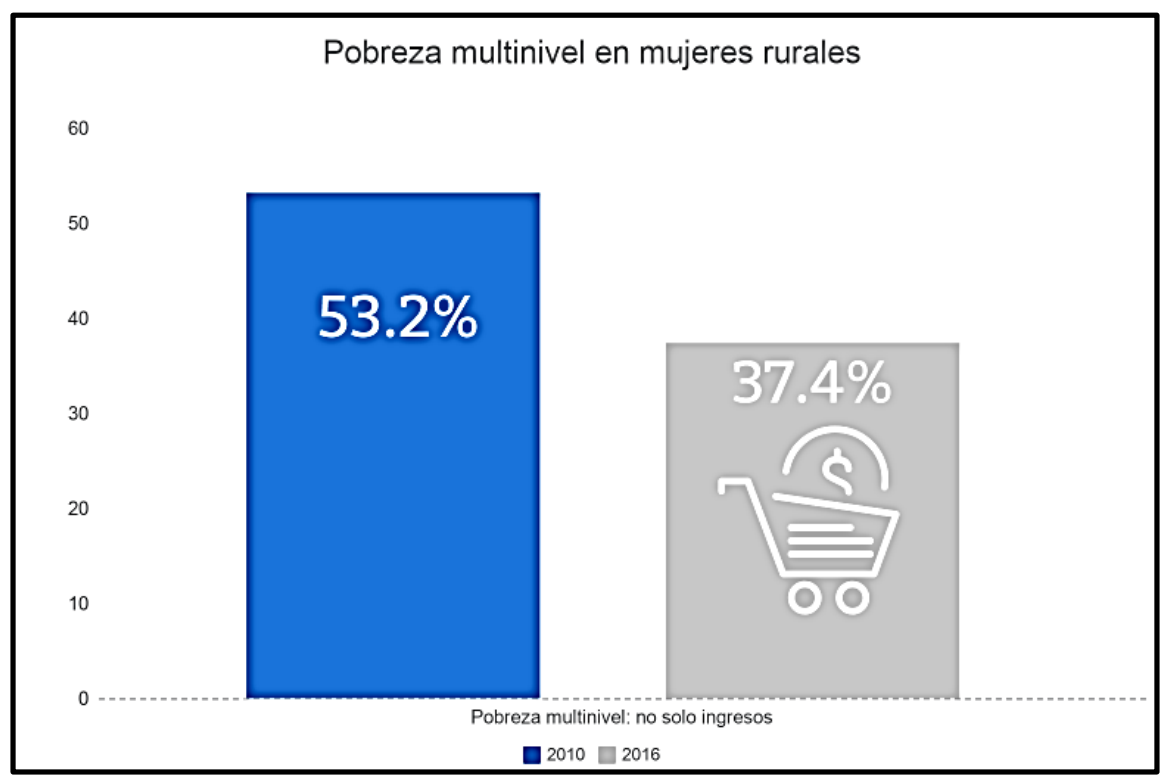

Figura No 8. Pobreza multinivel en mujeres rurales en Colombia.

Fuente: Cartilla de apoyo a la política de Desarrollo Rural Integral con Enfoque Territorial del Ministerio de Agricultura y Desarrollo Rural, con apoyo de la Unión Europea. 
La figura muestra como en un periodo de 6 años, las condiciones de pobreza multinivel para las mujeres bajaron en $15,8 \%$, muestra que en Colombia gran porcentaje de mujeres han mejorado sus condiciones de ingresos, disminuyendo carencias a nivel de los ámbitos de la salud, la educación y el nivel de vida.

Las mujeres presentan limitaciones y dificultades para desarrollar sus actividades agropecuarias, especialmente tienen menos tierra.

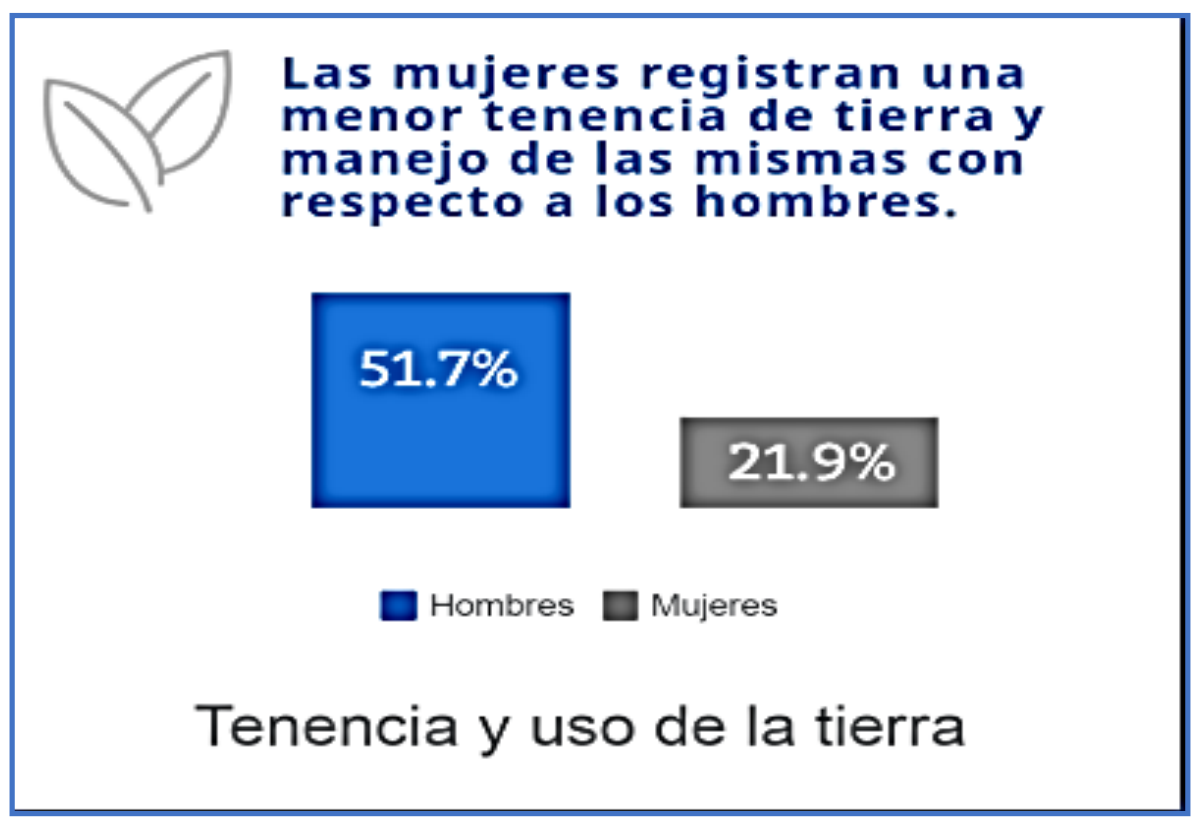

Figura No 9. Tenencia de la tierra por parte de mujeres.

Fuente: Observatorio de la democracia de la Universidad de Los Andes y Cartilla de apoyo a la política de Desarrollo Rural Integral con Enfoque Territorial del Ministerio de Agricultura y Desarrollo Rural, con apoyo de la Unión Europea

La mayoría de las mujeres no tienen acceso a las tierras como propietarias directas, ya que los procesos de adjudicación de tierras por parte del estado, después de las luchas 
campesinas e indígenas, fueron desiguales y daban propiedad a los hombres inicialmente, aunque más adelante las mujeres pudieron lograr ser incluidas en los títulos de propiedad

Vargas (2017) dice que debido a ellos tienen menos acceso al crédito por medio de bancos, cuentan con menos maquinaria y asistencia técnica para desarrollar las actividades rurales, a pesar de no ser menos estudiadas, toman menos decisiones de producción.

Cedaw (2019) dice que en Colombia, existe la persistencia de una discriminación que niega los aportes de las mujeres a la economía y solamente atiende a una visión androcéntrica y que este fenómeno persiste en el entorno agropecuario, donde la desigualdad y la inequidad se exacerban en lo relativo a las mujeres, constituyéndose así en uno de los sectores con mayores dificultades para las mujeres (CEDAW, 2019, pág. 11).

Y eso se ha profundizado durante el conflicto armado. La sentencia T-025 de la Corte Constitucional incide en que "el desplazamiento forzado en las mujeres constituye una situación de vulneración acentuada". El Alto Tribunal obliga en su dictamen a una "protección inmediata de estas por parte de las autoridades" y a medidas preferenciales de reparación, entre ellas el derecho a la tierra. Sin embargo, y según Oxfam, sólo el 0.8 por ciento de los casi tres millones de campesinas que reconoce la ONG en su estudio se han beneficiado en Colombia del Programa de Mujer Rural del Ministerio de Agricultura, implementado desde el 2011 para empoderar a las mujeres del campo (Alegre, s.f.). 
Las mujeres rurales tienen triple discriminación ser mujer, la que surge por el hecho de vivir en el campo y la que se deriva del efecto desproporcionado que el conflicto tiene sobre sus capacidades y sobre la posibilidad de realizar sus proyectos de vida. (PNUD, 2011). Díaz (2002) de todos modos plantea que las mujeres campesinas colombianas han emprendido una lucha, a pesar de los tantos contratiempos.

\subsection{La Vida en General y Agraria Particularmente, en Montes de María y Sucre}

Montes de María es una subregión conformada por 15 municipios de los departamentos de Bolívar y Sucre: Córdoba, El Carmen de Bolívar, El Guamo, María la Baja, San Jacinto, San Juan Nepomuceno, Zambrano, Chalán, Colosó, Los Palmitos, Morroa, Ovejas, San Ono fre, Sincelejo, Palmito y Toluviejo. Ocupa una superficie de $12.728,7 \mathrm{~km}^{2}$, de los cuales $46,5 \mathrm{~km}^{2}$ corresponden al área urbana y $12.682,1 \mathrm{~km}^{2}$ al área rural cuenta con tres tipos de paisajes: el montañoso, el plano y las zonas costeras.

La clasificación del bioma montemariano, según la zona de vida es bosque seco tropical (bs-T) de Holdridge. La subregión cuenta con ecosistemas de bosques secos tropicales y manglares, recursos hídricos (ciénagas, lagunas y aguas subterráneas), formaciones coralinas, playas marinas y una variedad de flora y fauna. Existen tres zonas de reservas naturales: La Reserva Forestal Protectora Serranía de Coraza y Montes de María (Colosó, Toluviejo y Chalán

- Sucre), El Santuario de Fauna y Flora Los Colorados en San Juan Nepomuceno y El Santuario 
de Flora y Fauna el Corchal entre San Onofre (Sucre) y Arjona (Bolívar), todas con potencial para el ecoturismo.

Importante resaltar que Montes de María es una región estratégica, no solo para los departamentos de Bolívar y Sucre, sino para todo el litoral Caribe y el país, por su localización geográfica, ubicada entre los centros económicos de Valledupar (al oriente) y el Mar Caribe (al Occidente), y entre el corredor urbano - regional de Cartagena - Barranquilla - Santa Marta (al norte) y la carretera transversal de la Depresión Momposina, que comunica a Sucre, Córdoba y Antioquia con el Magdalena y el Cesar (al sur).

En 2013, los Montes de María tenían una población de 601.892 habitantes, de la cual el $74,6 \%$ habitaba en la cabecera municipal. Sincelejo y El Carmen de Bolívar son los municipios más poblados y Chalán es el municipio con el menor número de habitantes $(0,7 \%$ del total de la subregión). El 65,6\% de la población habita en el departamento de Sucre y el 34,4\% en Bolívar.

Según el DANE, en los últimos 20 años la tasa de crecimiento poblacional de la subregión es de 19,6\%, inferior al crecimiento regional en 14,5 p.p., y al nacional en 10,6 p.p. En este período se presentó una tendencia decreciente de la población rural: pasó de representar el $34,9 \%$ de la población en el año 1993 al $25,4 \%$ en el año 2013 . Tal vez esto es debido a que ha vivido el terror del conflicto armado durante más de 30 años. Esta dinámica, y en consecuencia su situación de derechos humanos y Derecho Internacional Humanitario se ha presentado en gran medida debido a las condiciones socioeconómicas y geográficas del territorio. El enfrentamiento entre las autodefensas y guerrilla ha sido por obtener el dominio de las tierras y recursos naturales y la Fuerza Pública ha tenido un rol marginal. 
De acuerdo con los resultados del Índice de Ruralidad (IR) 2011, la subregión en su conjunto se clasifica como rural. Sin embargo, frente a la ruralidad nacional $(61,8)$ y regional $(52,5)$ la subregión presenta un menor índice. Los municipios de El Guamo y Córdoba (Bolívar) registran el mayor grado de ruralidad (51,5 y 50,9 respectivamente), mientras María La Baja y Sincelejo son los municipios menos rurales (40,2 y 22,6 respectivamente). El índice de Gini para la propiedad de la tierra era de 0,76 en 2011, lo cual refleja una alta concentración, aunque inferior a los promedios nacional $(0,90)$ y regional $(0,79)$. En comparación con el año 2000 , disminuyó la concentración de la propiedad en 1 p.b., bastante por debajo de la variación nacional y regional.

De acuerdo con el Ministerio de Agricultura y Desarrollo Rural, para el año 2012 en la subregión Montes de María el área utilizada en el sector agrícola correspondió a 82.679 ha, frente al año 2007 se registró una reducción del 7,6\%. El área total cosechada en los cultivos durante el 2012 fue de 69.826 ha, el 60,9\% correspondió a transitorios y 39,1\% a permanentes. Frente al año 2007 el área cosechada registró una reducción de 16\%, causada principalmente por la disminución del área en cultivos transitorios $(33,8 \%)$.

La zona de los Montes de María es de las más pobres de la Región Caribe. El Índice de Necesidades Básicas Insatisfechas, NBI, para los municipios de esta región es en promedio del $67 \%$, cifra superior al promedio nacional $(37,2 \%)$. Esta población, con excepción de Sincelejo, registra un ingreso anual promedio por habitante, inferior a los US800 dólares anuales y según la encuesta nacional de hogares del DANE, parte importante de esta población se encuentra en el 
límite de la indigencia rural sosteniéndose con menos de US2 dólares diarios por habitante rural (Álvarez y Dorado, 2006).

Carecen de agua potable, abundante y permanente para las labores productivas, su actividad se desarrolla con el ciclo de las aguas de invierno y cuando el tiempo es bueno sacan buenas cosechas y se mantienen sus animales, pero cuando el verano los golpea se quedan sin agua potable, disminuye su salud por el consumo de agua de mala calidad y los animales se pierden igual los cultivos, los Patios decaen notablemente, pero los mantienen utilizando todo tipo de estrategias para conservarlos.

Cada familia tiene una cantidad de tierra que va en promedio de una hectárea hasta 5 o 6 hectáreas, se utiliza una agricultura tradicional, según Aguilera (2013) la productividad no es la óptima. Al respeto Menco (2010), menciona que ha habido un mejoramiento sustancial de la producción, del ingreso y del empleo productivo en la subregión. El reposo de los combates entre grupos armados al margen de la ley y el ejército ha traído como un nuevo despertar de la economía monte mariana, lo que se manifiesta en unos volúmenes de producción importantes. No obstante, lo anterior, se requiere hacer mayores esfuerzos de inversión para lograr vincular al sector de la producción a un mayor número de personas, generando naturalmente más jornales y más empleo. Se necesita un mayor impulso a la actividad agrícola, repensándola y reorganizándola, de tal manera que la vocación de los suelos de cada municipio sea el principio rector para adelantar las inversiones agrícolas necesarias. 
La continuación de las huertas familiares como sistema productivo, pues a través de éste, las mujeres conservan muchas tradiciones, tratamientos medicinales, seguridad y soberanía alimentaria, que son elementos importantes en la cultura del territorio, de la cual se derivan muchas de sus costumbres.

En los municipios de Montes de María encontramos otras actividades económicas aparte de la agropecuaria, que también generan ingresos económicos para las familias del territorio, tales como la venta de servicios, productos transformados, mototaxismo, venta del jornal, trabajos domésticos, misceláneas, tiendas, además de productos industriales donde la transformación de los diferentes productos agrarios como leche, frutales, maíz y yuca están presentes (Corporación PBA, 2017).

La Mujer rural, como en toda Colombia es quien soporta en mayor grado las consecuencias del conflicto armado, del desplazamiento, de la violencia intrafamiliar y del aumento de la pobreza. Tienen menor acceso a la propiedad, a los créditos, a la asistencia técnica y sólo pueden hacerse participes de actividades de subsistencia y reproducción. Entre las manifestaciones de violencia contra la mujer, la violencia intrafamiliar y la violencia sexual son las más frecuentes y son consideradas como una barrera para su desarrollo humano, económico, político y social (Federación Latinoamericana de mujeres rurales, s.f.). Independientemente de esto, las mujeres campesinas, indígenas y afrodescendientes, del territorio de Montes de María son nobles, humildes, con arraigo hacia el campo, con ganas de vivir, dedicadas a criar especies menores, labores del hogar y crianza de los y las hijas, quienes heredan estas capacidades y conocimientos. 
Algunas de las mujeres que hacen parte de la investigación, están asociados en pequeñas organizaciones y asociaciones a nivel de cabildos, en corregimientos, veredas y a nivel municipal, en la búsqueda constante de innovar y mejorar la calidad de sus productos y las tecnologías con las que los elaboran para aumentar las producciones que les permitan abordar mejores mercados en consecuencia a una demanda que así lo exige.

Los programas que se han desarrollado en el territorio son:

De tipo privado:

a) Programa de Desarrollo y Paz de los Montes de María. que lideró y desarrolló procesos de planificación participativa de base a partir de iniciativas comunitarias para la identificación, formulación, y acompañamiento técnico de subproyectos; y el fortalecimiento de las organizaciones comunitarias; b)acuerdo de cooperación Tercer Laboratorio de Paz, entre el Gobierno Nacional y la Unión Europea: 32 proyectos para la generación de capacidades socioeconómicas, productivas y ambientales, fortalecimiento de iniciativas de la sociedad civil, participación social, incidencia en políticas locales, derechos humanos y acompañamiento a víctimas del conflicto armado (Henríquez, 2014); c) Diseño y desarrollo de un plan de posicionamiento en mercados nacionales de productos y/o servicios representativos de los Montes de María como componente inicial de una estrategia de marketing territorial, ejecutado por la Agencia de Desarrollo Económico Local Metropolitana de Bucaramanga (ADEL), d) USAID de los EE.UU., apoya Alianzas Público Privadas alrededor de productos agropecuarios y sus derivados; Programa de Tierras y Desarrollo Rural (PDTR), que busca mejorar la capacidad 
de los gobiernos regionales y nacionales para restituir las tierras a las víctimas del conflicto y mejorar la capacidad de las instituciones gubernamentales para formalizar los derechos de propiedad rural y asignar tierras públicas (Tetra tech, s.f. ).

\section{De tipo público:}

a) Departamento para la Prosperidad Social: DPS (2014) es el organismo del Gobierno Nacional que busca fijar políticas, planes generales, programas y proyectos para la asistencia, atención y reparación a víctimas de la violencia, la inclusión social, atención a grupos vulnerables y su re integración social y económica. b) Programas de Desarrollo con Enfoque Territorial -PDET (2017) instrumento de planificación y gestión para implementar de manera prioritaria los planes sectoriales y programas incluidos en la reforma rural integral, c) $\mathrm{La}$ estrategia Colombia Responde de los Montes de María fue un programa del Gobierno Nacional con el apoyo de la cooperación internacional, a través de la Agencia de Estados Unidos para el Desarrollo Internacional (USAID) para la implementación de la Política Nacional de Consolidación y Reconstrucción Territorial; con el propósito de articular esfuerzos estatales que contribuyeran a la seguridad y la paz (FUNCICAR, 2015) d) también han estado en el territorio programas del Ministerio de Agricultura tales como:

1. Alianzas Productivas, que busca incrementar la competitividad y el desarrollo empresarial de las comunidades rurales pobres, de manera sostenible, a través de alianzas orientadas por la demanda del sector privado comercializador (Ministerio de Agricultura, 2013).

2. Oportunidades Rurales, que contribuye a la lucha contra la pobreza rural, a través del incremento del empleo e ingresos de las familias más pobres, mejorando para ello la 
competitividad e integración a los mercados de las microempresas rurales, a través servicios financieros y servicios técnicos, conocimientos e información (Ministerio de Agricultura y Desarrollo Rural (2019).

3. Agencia de Desarrollo Rural -ADR (2019), es la entidad responsable de gestionar, promover y financiar el desarrollo agropecuario y rural para la transformación del campo y adelantar programas con impacto regional. Entre otras.

Según Henríquez (2014) algunas opiniones estas iniciativas han sido importantes para la consulta permanente entre los diferentes actores y para la construcción de un proyecto de región. Para otros han sido poco importantes. Sin embargo, afirman los miembros de la Sociedad Colombiana de Arquitectos (2016) que los cambios siguen siendo lentos para la dimensión del desastre que dejó la guerra en la región. Los esfuerzos y recursos invertidos no se ven en la magnitud esperable.

A pesar de los esfuerzos oficiales, estos no están dirigidos a una transformación de las causas estructurales de los conflictos. Por el contrario, aunque hay calma y progreso, que para las organizaciones sociales es una situación aparente y no es real, las brechas sociales y el estado de desarrollo se agravan con las dinámicas actuales. (Programa de las Naciones Unidas para el Desarrollo, 2010)

Como consecuencia de lo expuesto, Montes de María, el índice de Gini para la propiedad de la tierra era de 0,76 en 2011 , lo cual refleja una alta concentración, aunque inferior a los 
promedios nacional $(0,90)$ y regional $(0,79)$. En comparación con el año 2000, disminuyó la concentración de la propiedad en 1 p.b., bastante por debajo de la variación nacional y regional (Corporación PBA, 2015).

Por su parte, la población juvenil en Montes de María, no cuenta con oportunidades de empleo digno como consecuencias tienen dificultades para satisfacer sus necesidades básicas. El poco acceso a la educación superior ha generado gran problema en esta población ya que las y los jóvenes se encuentran en condiciones de vulnerabilidad, predispuestos al consumo de sustancias psicoactivas, alcoholismo, embarazos a temprana edad y lo más peligroso, a la vinculación a grupos armados al margen de la ley.

2.4. Algunas particularidades de los municipios bajo estudio

Como ya se ha dicho, el estudio se focaliza en los municipios de Sincelejo, San Onofre y San Antonio de Palmito, pertenecientes a Montes de María al norte de Colombia, frente a la Costa Caribe.

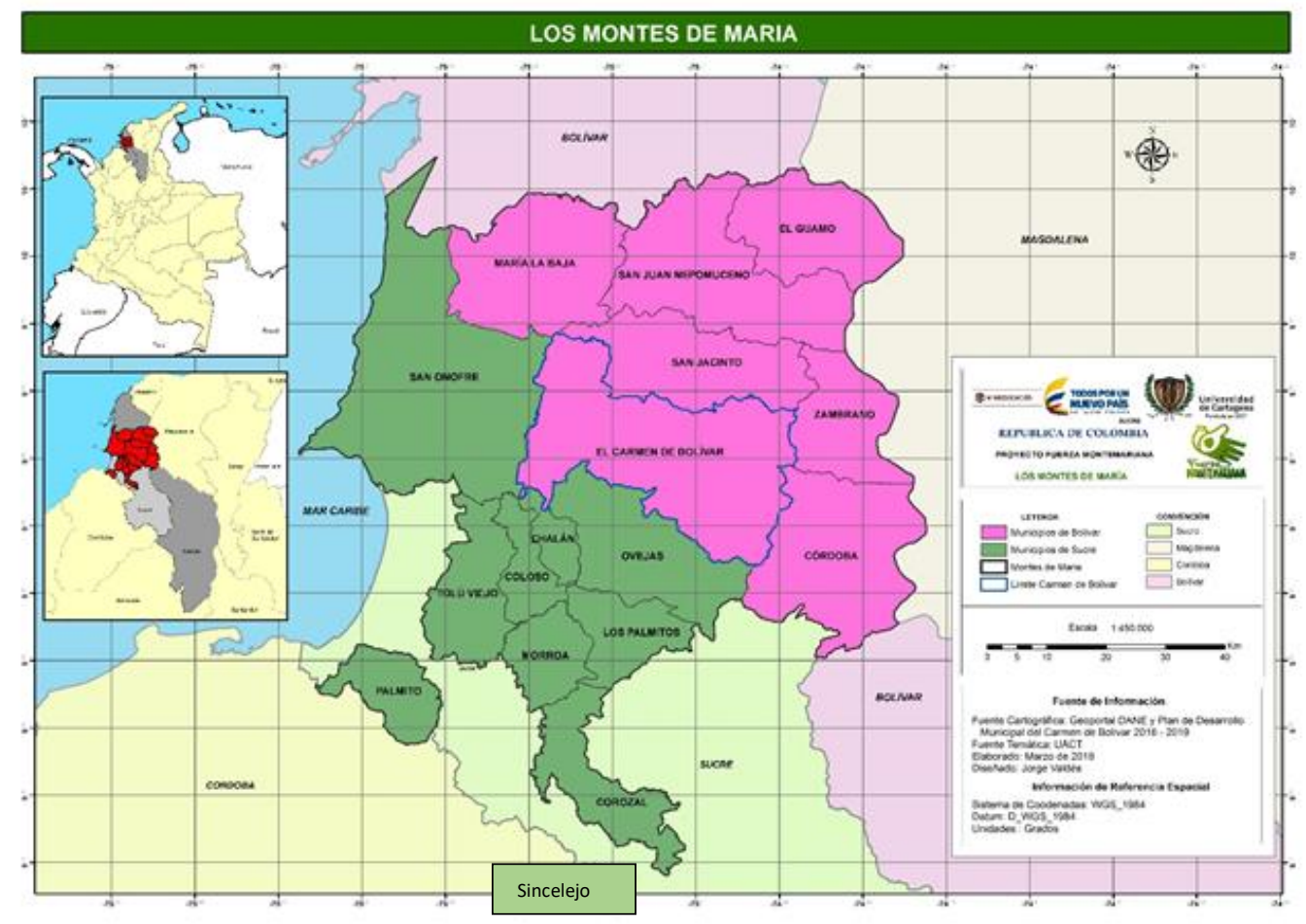


Figura 10. Ubicación geográfica de Sincelejo, San Onofre y San Antonio de Palmito Fuente: Facultad de Ciencias Sociales y Educación - Fuerza Montemariana - Unicartagena

La ciudad de Sincelejo es la capital del Departamento de Sucre, Centro subregional del sistema urbano del Caribe colombiano; tiene una extensión total de 28.504 hectáreas que representan el $2.67 \%$ del área total del departamento, de la cual el $92 \%$ corresponde a territorio rural. De acuerdo proyecciones de población DANE (2016) Sincelejo presenta un total de 279.031 habitantes. Entre las minorías sobresale la población indígena Zenú, unos 20 mil habitantes, lo que representa un 7.8\% de la población total. La población afrocolombiana es de 8.050 habitantes en la cabecera

Posee un área en la que la mayor parte de su territorio es plano, tiene un piso térmico cálido como el que corresponde a las extensas sabanas de las llanuras del Caribe. La red hidrográfica de Sincelejo está comprendida por las microcuencas de los arroyos Grande de Corozal, Canoas, La muerte, Mocha y San Antonio. Los arroyos (la Bomba, Cacique, Culumuto, el Bajo, Moquen, Salado, etc) son canales de escorrentía estaciónales que solo conducen aguas después de los aguaceros.

El clima es cálido seco, con una precipitación promedio de 500 a 1200 milímetros; la formación vegetal es el bosque seco tropical. La temperatura media anual está cercana a los $27^{\circ}$ C, con una mínima promedio anual de $19,7^{\circ} \mathrm{C}$ y una máxima de $35,3^{\circ} \mathrm{C}$. Se aprecia un mayor rango durante el verano donde hay marcados efectos ocasionados por bajas temperaturas en la madrugada y fuertes calores en las horas de la tarde. Con la llegada de las lluvias tiende a 
estabilizarse, con menos variaciones y una ligera disminución general, con el aumento de la humedad relativa (Alcaldía de Sincelejo, 2016).

Limita al sur con el Sincelejo de Sampués y con el Departamento de Córdoba; por el oeste con los Municipios de Palmito y Tolú; por el norte con los Municipios de Tolú y Toluviejo y por el este con los Municipios de Corozal y Morroa. La ciudad está conectada vialmente con las ciudades principales de dichos Municipios, ubicadas a una distancia máxima de 40 kilómetros. Tiene comunicación fluvial por Magangué (Bolívar), San Marcos y San Benito (Sucre) y marítima por Tolú y Coveñas. Y tiene acceso a tres aeropuertos, (Las Brujas ubicado en el Municipio de Corozal a $10 \mathrm{~km}$, el aeropuerto regional Golfo de Morrosquillo y el aeropuerto de Montería ubicado a $100 \mathrm{~km}$ ).

Según el Plan de Desarrollo Municipal 2016-2019, la economía urbana está determinada principalmente por actividades administrativas (que representan aproximadamente el 30\% de toda la actividad) como comerciales y terciarias. En la actualidad la ciudad cuenta con algunas factorías de productos alimenticios, confecciones, calzado y procesamiento de maderas especialmente. La zona rural se centra en la ganadería, especialmente ganado vacuno para carne y producción de leche de muy buenas condiciones, aunque se verifican bajos niveles de inversión y bajos rendimientos por hectárea. Además, al mal estado de las vías de comunicación que retrasan el envío de los productos a los centros de consumo, se suma la poca industrialización que le adicione valor agregado a los productos y los limitados canales de comercialización, entre otros, a lo anterior se suma la inseguridad. 
Sincelejo presenta una NBI de $42,02 \%$, con un $40,41 \%$ en la cabecera municipal y $61,18 \%$ en el área rural. El Departamento de Sucre presenta una NBI de 54,86\%, con el 46,60\% en la cabecera y del 69,48\% en el área rural (DANE, 2012). Según la Red Nacional de información - Unidad Para la Atención y Reparación Integral a las Víctimas, en Sincelejo hay 165.742(un 59\%) víctimas del conflicto armado, la población en situación de desplazamiento equivale al 51.63\%, o sea 144.062 personas (DANE, 2012).

El Municipio de San Onofre hace parte de la Costa Caribe del departamento de Sucre, subregión del Morrosquillo, con acceso directo a las playas en una extensión de 56 kilómetros, en la parte más septentrional del Departamento y distante de Sincelejo, 68 kilómetros. Cuenta con la mayor extensión territorial dentro de la subregión con un total de $1.102,42 \mathrm{Km} 2$, lo cual equivale al 10,36\% del departamento. Tiene una población de 51.991 habitantes. Conviven el aborigen, el criollo surgido del español y el negro africano esclavizado por los españoles (Municipio San Onofre, 2016).

El Municipio cuenta con diferentes tipos de relieve, con zonas escarpadas, pendientes medias y planicies, en una región de Bosque Muy Seco Tropical. Las lluvias anuales son inferiores a $900 \mathrm{~mm}$, y en otros casos pueden caer más de $1.200 \mathrm{~mm}$ al año. La temperatura media mensual es de $27,4^{\circ} \mathrm{C}$. La estación seca puede durar hasta cinco meses o más. La humedad relativa promedio es del 77\% (CARSUCRE, 2016). 
Desde su fundación, la agricultura y la ganadería fueron las principales actividades económicas desarrolladas en la región. En el siglo XIX, según la misma fuente, la zona era famosa por la producción de arroz. Más preocupante incluso que Sincelejo, es la baja inversión. Es inexistente el servicio de riego en esta zona, al igual que el servicio de centros de acopio y el servicio de cuartos fríos (Municipio San Onofre, 2016). Por otro lado, el reemplazo de cultivos tradicionales por maderables y palma africana en algunas zonas del Municipio como Palmira, Pajonalito, han disminuido la producción de cultivos como yuca, plátano, maíz y arroz. Con más profundidad que en otras zonas, el fenómeno de desplazamiento y estas nuevas actividades, afectaron la tenencia de la tierra por los pequeños campesinos.

Las NBI en San Onofre alcanzan un porcentaje del 65,1\%, (DANE, 2012) el tema de la seguridad ha sido importante. En San Onofre y sus corregimientos los paramilitares ejercieron como únicas autoridades, sin oposición estatal, y regularon la vida cotidiana de los habitantes a su antojo. Establecieron castigos públicos, imponían trabajos forzados, se apoderaron de las fiestas patronales y hacían valer por las armas privilegios económicos y sociales (Verdad Abierta, 2011). Durante la época de conflicto de grupos al margen de la ley en San Onofre entre (1985 - 2014) fueron expulsadas 41.760 Personas, de las cuales 25.448 personas fueron Declaradas y 5 masacres entre 1996 - 2012 (Red nacional de información, 2014).

El Municipio de San Antonio de Palmito es la tierra de indígenas Zenúes. Hace parte de la región fisiográfica denominada Llanura Costera Aluvial del Morrosquillo. Se encuentra ubicado al Noreste del Departamento de Sucre, a 20 km de Sincelejo. Tiene una extensión de 174 
$\mathrm{km} 2$, lo que corresponde al 1,6\% del total del área departamental. Limita al norte con el municipio de Sincelejo, al sur con el municipio de Tuchín y Momil en el departamento de Córdoba, al este con el municipio de Sincelejo (Sucre) y Tuchín (Córdoba) y al oeste con el municipio de Coveñas (Sucre) y el municipio de Tuchín en el departamento de Córdoba. Según DANE (2016) presenta una población de 13.953 habitantes lo que representa el 1,6\% de la población departamental. El 70\% de la población se reconoce como indígena y 86 personas son afro. Del total de la población el $39.1 \%$ vive en la zona urbana y el $60.9 \%$ vive en la zona rural.

Está en la zona montañosa de la formación de la Serranía de San Jacinto, con alturas promedio de 300-500 metros sobre el nivel del mar, posee una temperatura promedio de 27.5 grados centígrados siendo la máxima en el mes de Marzo $\left(28,1^{\circ} \mathrm{C}\right)$ y la mínima en el mes de Octubre $\left(26,7^{\circ} \mathrm{C}\right)$. Posee un régimen de precipitación bimodal ya que se presentan dos períodos húmedos en el que se registra una precipitación aproximada de $1585 \mathrm{~mm}$ anual. Se encuentra bañado por una serie de arroyos y cañadas de fuentes de agua superficiales temporales y aguas subterráneas (Alcaldía Palmito, 2016).

Las principales áreas están ocupadas por la ganadería extensiva con 13.685 hectáreas, contra 3.797 de la agricultura. En el primer caso, el ganado vacuno, en el segundo, maíz, yuca, ñame; por otro lado, la caña y el plátano. Existe un conflicto de uso del suelo ligero por la subutilización del sistema productivo idóneo (Plan de Desarrollo Municipal 2016-2019). Los problemas de inversión son comunes a los otros municipios. 
Según el plan de desarrollo municipal 2016-2019, en el municipio existe un potencial de recursos hídricos y subterráneos que permiten el abastecimiento de agua potable para la población, sistemas de riego y otros usos en la zona rural. Ahora bien, en materia de Distrito de riego, cuenta con uno privado, llamado Villa Patricia con 108 has, con riego por aspersión en 22 ha, en los cultivos de ají, mafufo (tipo de plátano), caña panelera y maíz.

El $83 \%$, de los pequeños propietarios con menos de 20 hectáreas tiene el $55 \%$ de las 32.514 hectáreas de tierra rural; en cambio el $17 \%$, \% de los que poseen predio hasta de 500 hectáreas, posee el $45 \%$ del total de la tierra. Los pueblos indígenas han luchado por la tenencia especialmente mediante los cabildos por la recuperación de sus tierras (Daniels \& Munera, 2011). Sin embargo, gran parte de los predios rurales aptos para la actividad agropecuaria, carecen de legalización y titulación (Municipio de Palmito, 2016).

Las arremetidas contra el pueblo Zenú y su territorio muestran ciclos característicos y recurrentes de violencia y despojo. Su historia ha estado ligada a las represiones de la hacienda feudal, la gran ganadería extensiva, que se fortalece, da paso a las apropiaciones de terratenientes con elevada incidencia y participación en los cuerpos políticos de la región y el país, a las desecaciones de las ciénagas para los cultivos agroindustriales y más recientemente, al paramilitarismo que bajo expresiones más violentas y frenteras, reivindica las mismas intencionalidades históricas: la sujeción económica, social y política y el avasallamiento cultural (RECAR, 2007). 
El conflicto armado dejó un impacto de terror en el municipio, pues es un corredor de la droga que llevan desde el sur de Córdoba hasta el mar. A dos kilómetros de la cabecera está la finca Simba, zona de operaciones de los primeros paramilitares del departamento de Sucre.

El deterioro de la gobernabilidad se confirma en el hecho de que para el periodo de gobierno 2000-2003 las presiones las FARC que exigían a los alcaldes y concejales abandonar sus cargos, obligaron al alcalde a despachar desde Sincelejo. (Daniels \& Munera, 2011). De igual manera, la organización indígena se debilitó por la intimidación que ejercieron los grupos paramilitares, después que se dieron las recuperaciones de tierras bloquearon la participación de la gente en los procesos organizativos e impidieron que los recursos de transferencias y de salud cumplieran sus objetivos reales en las comunidades. También se bloqueó el proceso de recuperación de tierras (RECAR, 2007).

La expansión del modelo de ganadería extensiva, la implementación de políticas de producción de biodiesel, la siembra de monocultivos, la introducción de transgénicos en áreas cercanas y la desesperanzadora migración de los jóvenes que obligadamente quedan raspando coca en Tierra Alta, Bajo Cauca y Sur de Bolívar, son las nuevas amenazas que se enfrentan en todos los casos (RECAR, 2007). Fenómenos como la parapolítica y la connivencia militarparamilitar hacen que la población desconfíe de las instituciones (Bocchi, 2011). 


\section{Capítulo III.}

\section{La perspectiva de las mujeres}

Este capítulo se aboca a dar respuesta al tercer objetivo específico de la investigación que se planteaba identificar las particularidades, conocimientos y dificultades de la Agricultura Familiar, según la perspectiva de las propias actoras del territorio de Montes de María

Como se señaló en la Introducción, para responder a ese objetivo se realizaron entrevistas semiestructuradas a las mujeres de los tres grupos: indígenas, afrodescendientes y campesinas en sus espacios de trabajo y ambiente natural, donde también se hicieron las observaciones (Kerlinger, 1979). Se realizaron 72 entrevistas entre los meses de enero a abril del 2019, a las propietarias de unidades familiares siempre en los municipios de San Onofre (Afro), San Antonio de Palmito y Sincelejo (indígenas y campesinas), del departamento de Sucre, todos pertenecientes a la subregión de Montes de María.

Las entrevistas se utilizaron para conocer el punto de vista de las mujeres (cómo expresan sus propias experiencias en el tema de la agricultura familiar) y para sistematizar información que permitiera caracterizar la actividad. De igual forma, a partir de las entrevistas se pudieron reconstruir historias pasadas, en torno a los sistemas productivos, el manejo agroecológico, el aspecto criollo, estudiar representaciones sociales, analizar qué discurso manejan las organizaciones y asociaciones de la investigación, y sus formas de apropiación. 
Con las observaciones se logró no solo observar la vida cotidiana de las mujeres en sus sistemas productivos de agricultura familiar, sino poder participar en sus actividades, facilitando una mejor comprensión del tema en estudio.

\subsection{La Cuestión de la Tierra y el Capital en la Economía Social}

Las mujeres vinculadas a la investigación, aunque son trabajadoras, poseen vocación y potencialidades productivas y capacidad para el manejo autónomo de sus unidades agropecuarias, tienen pocos activos para la producción, sus capacidades y estructura productiva no son suficientes para garantizar condiciones óptimas de explotación.

De las 72 mujeres entrevistadas, el 24,39\% son menores de 30 años; el 19,51\% están entre 31 y 40 años; el 26,83\% está entre 41 y 50 años, el 17,07\% está entre 51 y 60 años y el 12,20 tiene más de 61 años.

El 55\% cuenta con un área entre 100 y $999 \mathrm{~m}^{2}$ y lo distribuyen entre siembra (maíz, yuca, plátano, arroz, ñame, plantas medicinales), cría de animales (gallinas, cerdos, patos, pavos, coca, pollos) y su vivienda, el 28\% cuenta con un área entre los 1.000 y $9.999 \mathrm{~m}^{2}$ esta área la dividen en siembra de maíz, yuca, ñame, cría de animales y la ubicación de su vivienda, y el 17\% con un área con más de $10.000 \mathrm{~m}^{2}$ el cual lo dividen para sembrar yuca, ñame, maíz, arboles maderables, plantas medicinales (Jengibre, orégano, albahaca, toronjil, batatilla o cúrcuma, sábila, hierba buena, entre otras), criar animales, galpones, porquerizas y su vivienda. Esta situación muestra la poca capacidad de producción por área que tienen estas mujeres, lo que no 
permite mayores volúmenes de producción, especialmente de cultivos para el autoconsumo y para comercializar.

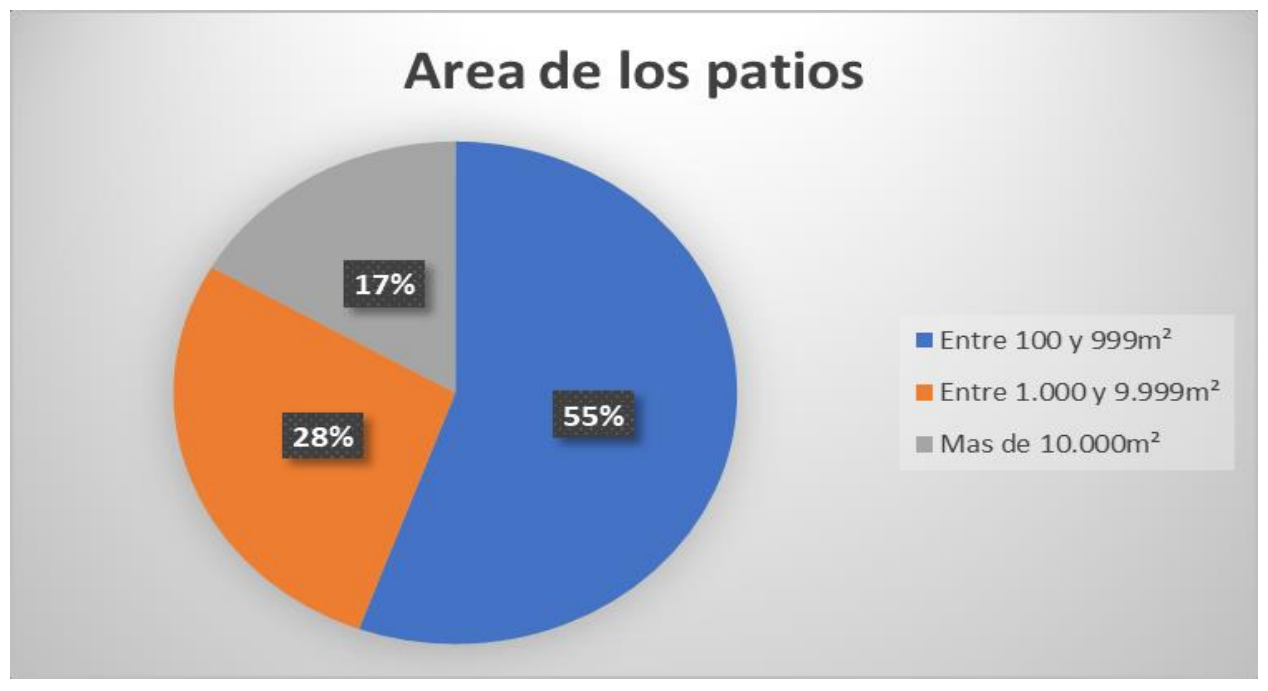

Figura No11. Área de los patios.

Fuente: Elaboración Propia.

El 49\% de las mujeres entrevistadas tiene el área donde trabaja a través de una herencia familiar y sea por parte de ella o de su compañero, el 25\% manifestó que lo compro a través de ahorros o préstamos recibidos, el 11\% manifiesta que es un área que arrienda para trabajar y el 15\% están en el área porque cuidan la finca o porque lograron recuperar esa tierra (restitución de tierras).

El 33,33\% de las mujeres dedicadas a la producción de cultivos, el $48,15 \%$ cultiva el asocio yuca - maíz, 22,22\% yuca-maíz-ñame, 7,41\% plátano, 7,41\% arroz,7,41 el asocio berenjena, habichuela, ají, 3,7\% ñame y 3,7 ahuyama; el 31,94 \% tiene el patio productivo y además gallinas, cerdos, patos, pavos; el 13,89\% elabora productos en artesanías y las comercializa (trenza para sombreros, bolsos, cosmetiqueras, monederos, carpeta porta 
documentos), el 11,11\% vende ropa, alimentos envasados, empanadas, pasteles, papas, jugos, patacón, hielo, bolis; y 4,17\% se dedica a la transformación de alimentos y bebida tradicional, el otro $4,17 \%$ a Servicios de telefonía celular), fotocopias, modista, venta repuestos motos y un $1,39 \%$ al alquiler de burro, venta de arena.

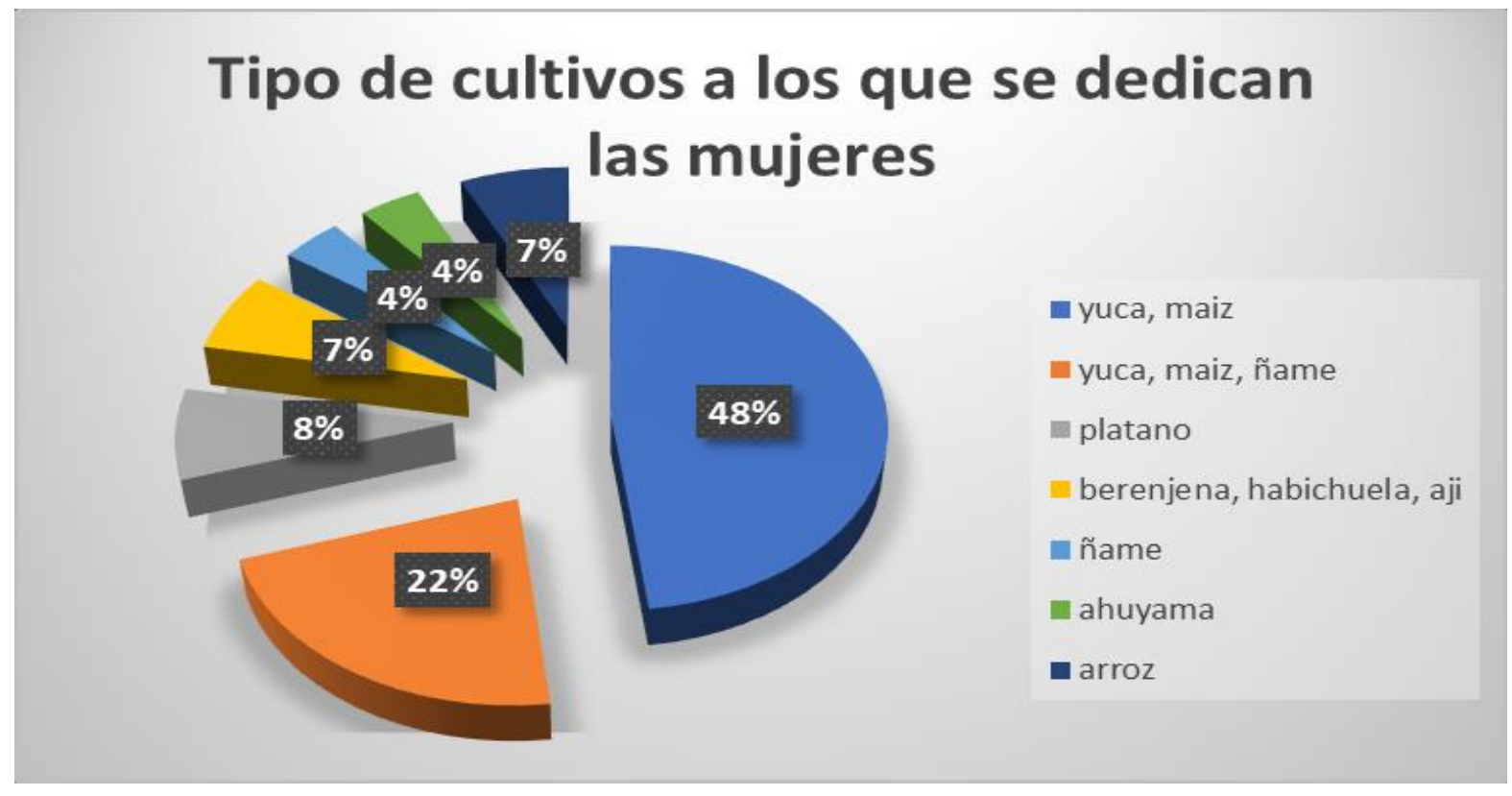

Figura No 12. Tipo de Cultivos A Los Que Se Dedican Las Mujeres (en porcentajes).

Fuente: Elaboración Propia.

Como señala en su testimonio una mujer indígena de la Asociación AMAP de San Antonio en Sincelejo “Cuando decidí coger el capital semilla compré unas gallinas, un gallo e insumos para artesanías en totumo, gracias al señor Jesucristo he obtenido US 31,6 (\$100.000 mil pesos) de ganancias me compre un cerdito que cuesta US 63.3 (\$200.000 mil pesos) y las artesanías en totumo las he seguido haciendo por encargo. Con el crédito decidí comprar una cerda de cría, insumos para modistería, porque yo también arreglo ropa” (Mónica Teherán Herrera). Esto pone de manifiesto que se trata de un segmento de subsistencia que trabaja con un patrimonio mínimo 
Todas las mujeres de la investigación cuentan con herramientas para desarrollar parte de sus labores de producción agrícola y pecuaria, pero algunas cuentan con un tipo de herramientas diferentes a las demás, de tal manera que el 49\% tienen pala, machete, barretón y martillo (siendo estas herramientas prioritarias para el trabajo de sus casas, la vivienda y los lugares en donde mantienen a sus animales), el 30\% con hacha, bomba, carreta, pico, manguera, alambre y tanque (estas herramientas se tienen para priorizar el arreglo de la tierra en su mayoría la usan las mujeres que siembran) y el $21 \%$ con rula, barra, tijeras, botas, rastrillo, paladraga. Frente al tipo de herramientas con que cuentan no existe mucha diferencia, pues todas se utilizan para las labores de producción.

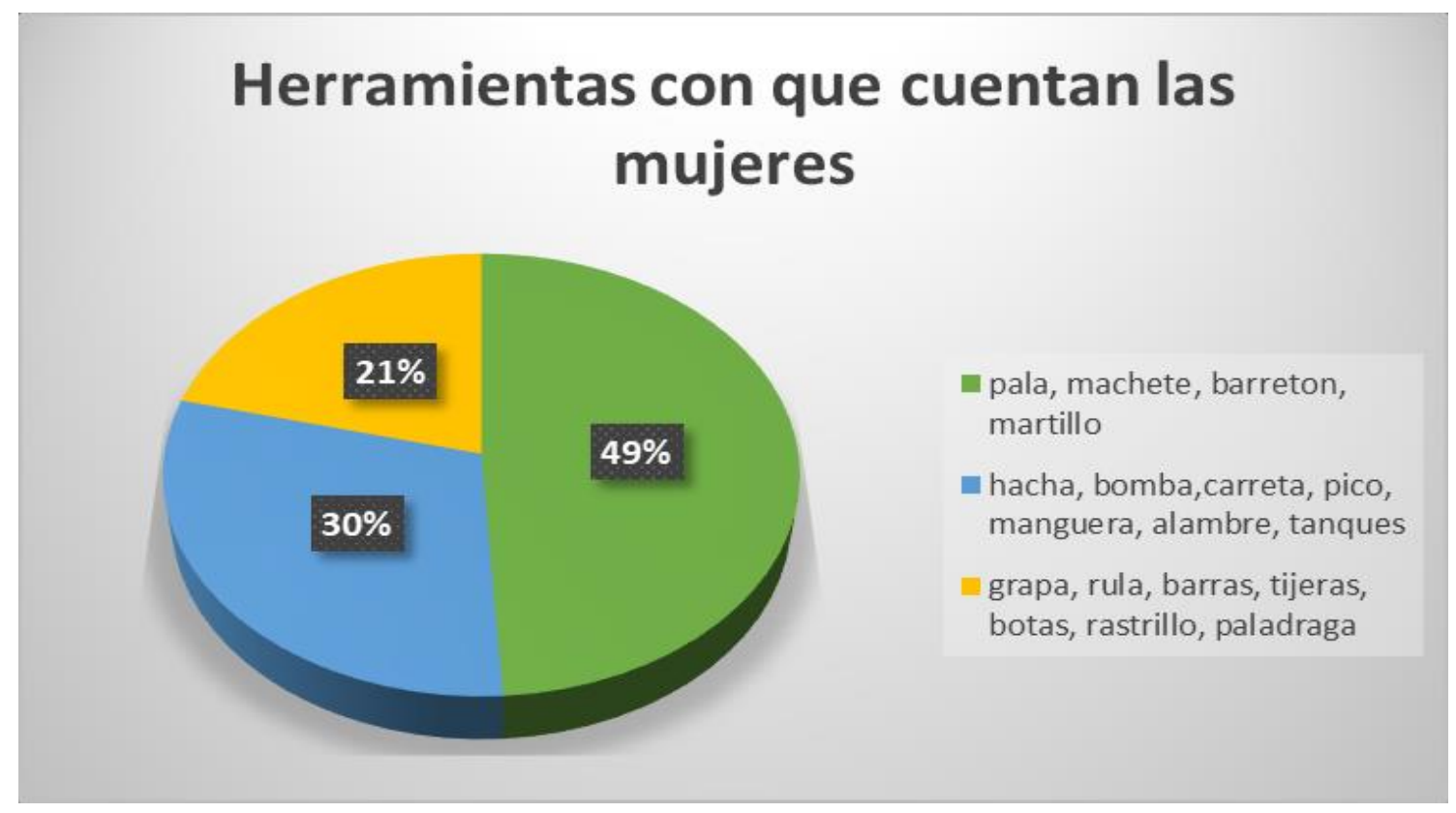

Figura No13. Herramientas con que cuentan las mujeres. Fuente: Elaboración Propia

E1 60\% de las mujeres encuestadas obtuvieron sus herramientas realizando compras producto del trabajo diario de ellas y de sus familias, el 35\% a través de donaciones de proyectos que llegan al municipio ya sea gestionados por el capitán, la asociación u otra entidad que se 
encuentre en el pueblo y el 5\% como no tienen acceso a compras por sus bajos ingresos y no pertenecen a ninguna asociación prestan las herramientas a sus vecinos.

De las 72 mujeres entrevistadas el 56\% nos comentó que le faltaría aumentar la cantidad de herramientas con las que ya cuentan porque solo tienen una de cada una y el 44\% le gustaría tener mallas, motobomba, azadón, palin, lima, guadañadora, cavador y paladraga.

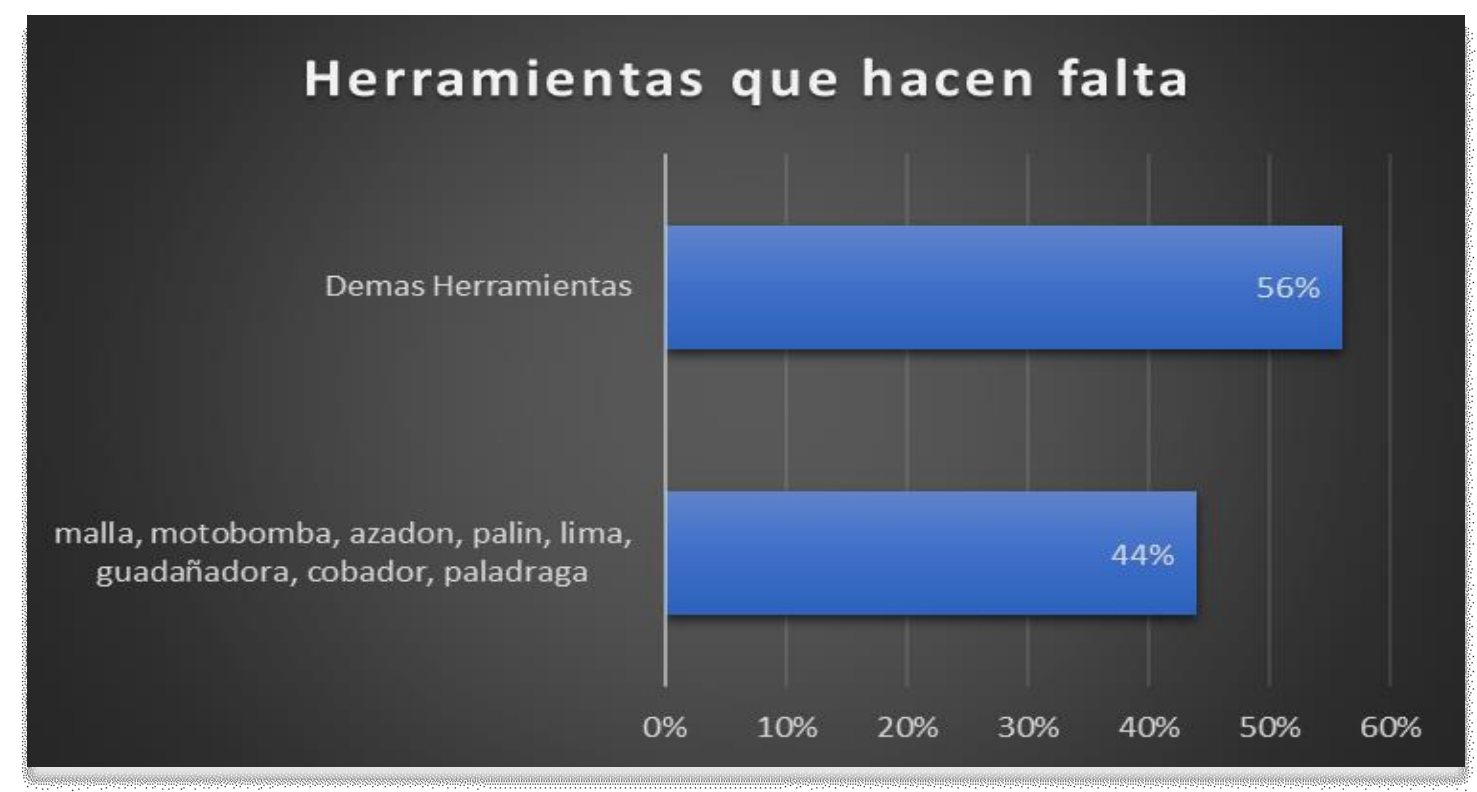

Figura No 14. Herramientas que hacen falta Fuente: Elaboración Propia.

Aunque las mujeres tienen capacidad y experiencia para la producción de alimentos en sus patios y parcelas, las áreas de producción, las herramientas, insumos y capital de trabajo, no son suficientes para tener producciones que permitan vender gran parte de sus excedentes, y poder competir por volumen en los mercados municipales 
De acuerdo con el objetivo específico, hemos podido identificar ciertas particularidades, además de los conocimientos y dificultades que presentan las mujeres al desarrollar su Agricultura Familiar.

\subsection{Acerca de la Actividad Familiar y Comunitaria, el Carácter Colectivo y las Tradiciones}

Uno de los temas a indagar en la tesis era esta idea recurrente de que históricamente las comunidades indígenas, afro y campesinas del departamento de Sucre, han podido avanzar en la producción de alimento para su sostenibilidad desde procesos comunitarios, basado en ciertos valores de reciprocidad vinculados a las tradiciones.

De las entrevistas surge que cada mujer produce, siembra o trenza; el 33\% de ellas se dedican al trabajo vinculando además de su familia a vecinos, amigos o hermanos, primos que tienen otra unidad familiar, con cultivos comunitarios, cría de animales en sus patios, siembra de hortalizas o tubérculos esto lo hacen con el fin de beneficiarse todos y el $67 \%$ trabaja en el marco de su unidad familiar primaria (madre, padre e hijos). Éstos lo hacen con patio productivo, lo hacen en el mayor de los casos porque no tienen apoyo de sus vecinos, amigos u otros familiares o porque les gusta trabajar de esa forma. Ese hogar primario cuenta con 8 o más miembros en el 9,3\%; con 5, el 20,9\%; con 4, el 55,8\%; el 4,7\% de los hogares se reporta con 3 personas. De todos modos, hay un $20 \%$ de las entrevistadas que hacen trabajos que requieren un compromiso estacional, cuando hay temporadas de cultivos, el 15\% es semestral, sembrando los cultivos y recogiendo las cosechas de yuca, ñame, maíz, entre otros. Para un 65\% es constante. Debe tenerse en cuenta que muchas veces los hombres salen a trabajar al campo ajeno. 


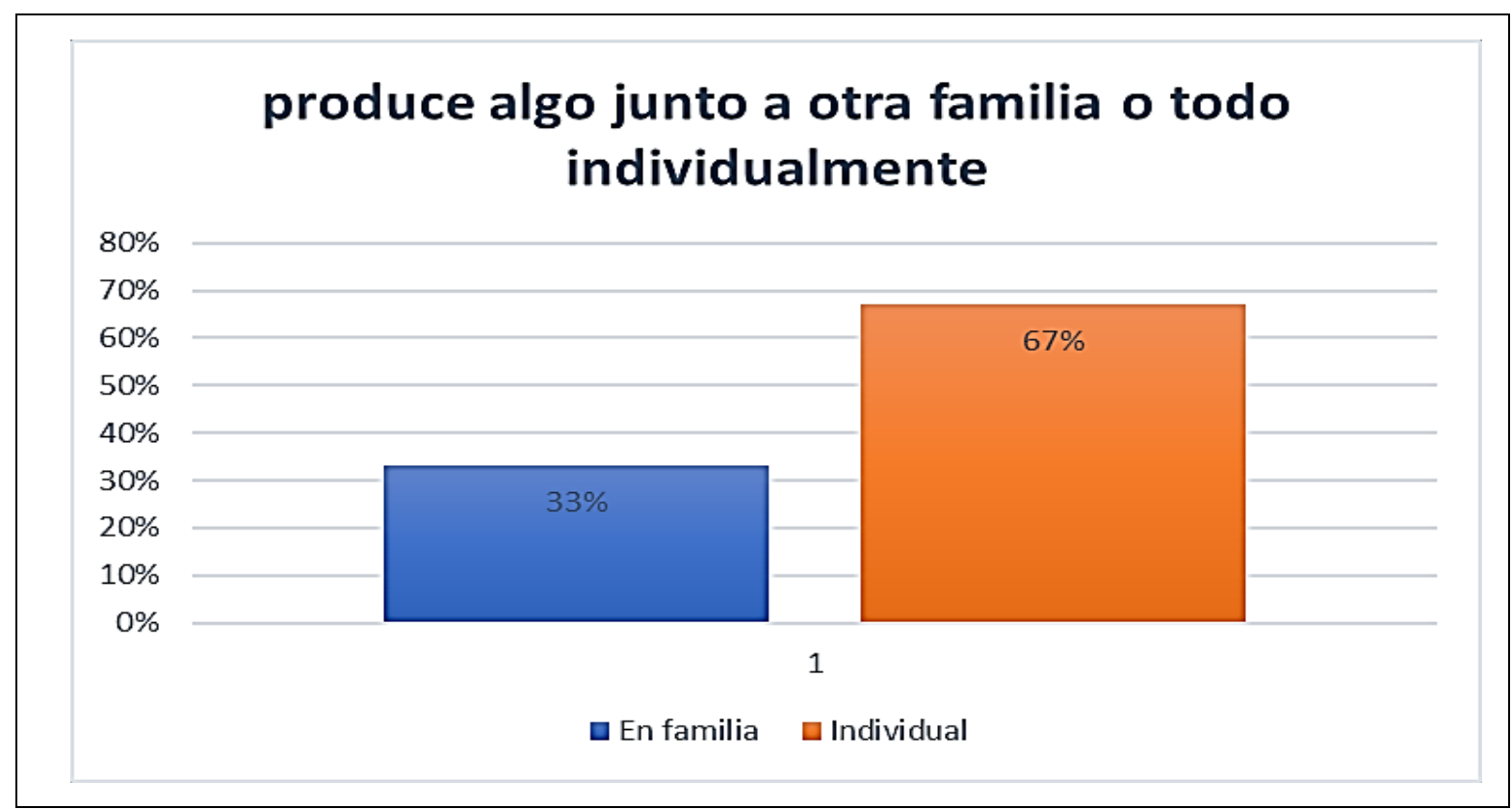

Figura No 15. ¿Produce junto a otra familia o solo con su núcleo familiar?

Fuente: Elaboración Propia.

Cuando se indagó acerca del origen de la actividad familiar, si era una imposición de los mayores o parte de una cultura, el 75\% contestó que todos tienen voluntad y están dispuestos a colaborar, pero el $25 \%$ no ayuda y no está dispuesto a hacerlo, en mayor medida los jóvenes. Incluso muchas madres los impulsan a ello para que no repitan la historia y se superen estudiando y haciendo cosas que generen más ingresos.

En cuanto a lo tradicional y lo nuevo, el $58 \%$ de las mujeres entrevistadas sostienen que en sus comunidades aún se conservan muchos valores como el respeto, la tolerancia, el amor, la responsabilidad y la convivencia para con sus familiares, vecinos y amigos y en cuanto a lo cultural conservan tradiciones con plantas medicinales para curarse, conservan juegos tradicionales, hacen reuniones mensuales y entre la comunidad hacen ollas comunitarias, en las comunidades indígenas se mantiene la tradición de hacer artesanías con base en fibra de caña flecha, desde el trenzado, donde se vincula por lo general toda la familia, hasta la elaboración de 
productos artesanales y el $42 \%$ cuenta que muchos valores y costumbres se han perdido debido a que los hijos no escuchan y no acatan ordenes por parte de sus padres se salen rápido de sus casas y en muchos de los casos toman caminos equivocados.

Un joven indígena del Cabildo de San Martín opina que: "Yo pienso que los jóvenes lo hacen por la falta de confianza que tienen con sus padres de familia, eso sería también por la falta de oportunidades, como hay muchos jóvenes que terminan el bachillerato y debido a la situación económica no tienen derecho a una universidad o hacer algo, y se encuentran con los muchachos y muchachas mal habidos y le dan malos consejos y cogen el camino de las drogas del licor más que todo”. (Ilich Pimienta Brito)

A nivel productivo, se mantiene la costumbre en algunas comunidades del modelo tumbaroza-quema, que consiste en tumbar el monte, quemar y recoger los residuos antes de preparar la tierra con arado o manualmente para sembrar las semillas, las cuales se conservan con ceniza para evitar ataque de plagas. Es común poder utilizar semillas criollas y densidades de siembra no comerciales, pues la mayor parte hace sus cultivos para el mantenimiento de la familia y comercializar los pocos excedentes que quedan.

En cuanto a la cría de animales se dejan los huevos y se echan (posturas de las aves) los animales para sacar cría de las mismas se van seleccionado los mejores pies de cría y se dejan en el patio. Se sigue alimentando con desperdicios de alimentos de la casa y residuos de cosecha.

"Manejo pollos de engorde, gallinas y artesanía, me ha servido porque con ellos he ayudado a mi familia, las gallinas de patio me dan huevos, que me sirven para la alimentación de 
mis hijas y ayudar en el sostenimiento de mi hogar, las ganancias que me dejan los pollos de engorde las utilizo para la alimentación de mi familia, las ganancias las invierto en gallinas de patio, en otras necesidades que tenga para mi familia, en medicina, alimentación y vestuario para mis hijas para mí, ya yo manejo mi negocio cosa que no hacía, manejo mis recursos, ya no espero que mi esposo traiga todo". (Magola Suárez, campesina del corregimiento de San Antonio en Sincelejo).

E1 80\% de las mujeres entrevistadas no llevan registro de las actividades que realizan porque en muchos casos no saben cómo hacerlo; el 20\% lleva registro en cuadernos o similares.

"La costumbre de comprar un cerdo, por ejemplo yo vengo acá donde mi compañera y le digo véndeme un cerdo para cría y yo le digo a ella: me vas a entregar la factura? y eso acá nunca se ha visto, me va a decir ella, fuera una vaca y su ternero, daría una, pero un Cerdo no y una gallina tampoco, bueno, entonces ya uno le echa el cuento que es para un plan semilla y debo tener eso y nos colabora y nos entrega un soporte o firma una cuenta de cobro, pero muchas personas no nos entregan eso porque acá todo es informal, por ejemplo yo he comprado así a personas que me dicen no eso yo no lo doy, entonces saben de mi proyecto y me colaboran". Ernestina Álvarez, mujer adulta mayor, indígena de San Antonio, Sincelejo

Como se ha visto, las formas tradicionales se mantienen especialmente en la producción. Cuando se indagó acerca de posibles innovaciones, el 67\% de las personas encuestadas comentan que no innovan y se quedaron con lo tradicional en el caso de la cría de los animales: sueltos en el patio, echándole comida al gusto, sembrando de la misma forma ellos mismos arreglando la 
tierra, sembrando sus semillas y recogiendo sus cultivos. E1 33\% que innovó lo hizo cambiando la forma de criar los animales haciendo galpones y encerrándolos en ellos, pastoreando a las gallinas, haciendo chupones (en el chiquero se crea un sistema de tuberías que va desde un pozo o tanques hasta el chiquero luego se instalan unas válvulas que al cerdo presionarla con el hocico expulsa el agua) y comederos para cerdos, en la alimentación de los animales están combinando los desperdicios de la comida y lo suplementan con el uso de alimento concentrado para animales.

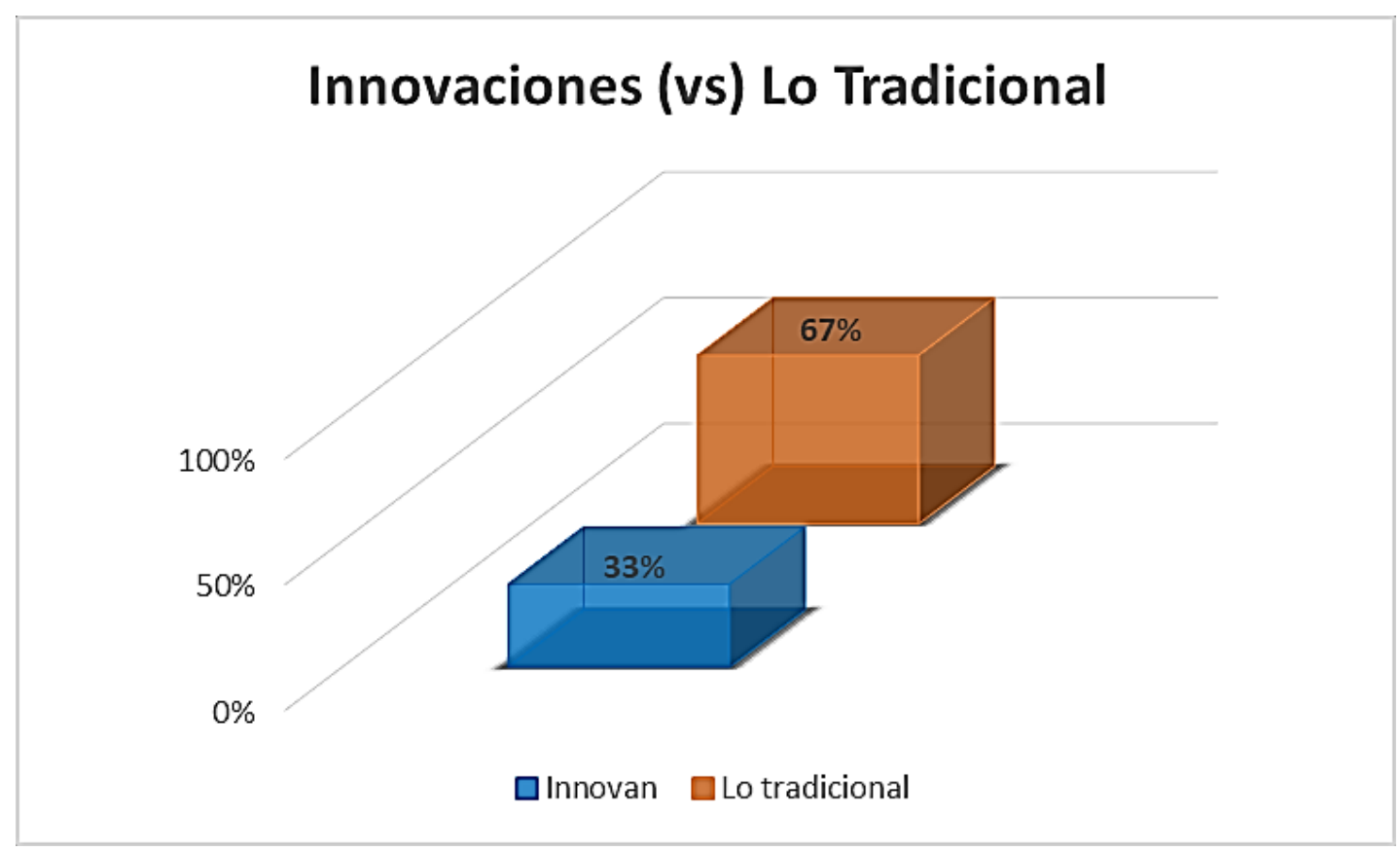

Figura No 16. Innovaciones Vs lo tradicional en los sistemas productivos.

Fuente: Elaboración Propia.

En el tema de la siembra de cultivos de pan coger, lo nuevo es hacer abonos orgánicos para echárselos a la tierra y de esta forma adecuarla para el momento de la siembra, disminuir el uso de agrotóxicos, utilizando controles biológicos para plagas y enfermedades, preparados por ellas mismas, a base de plantas medicinales como el tabaco, el ají picante y el ajo (llamados purines los que son fermentos de plantas e hidrolatos los que son cocimientos de plantas 
medicinales), la selección de semillas criollas, haciendo Fito mejoramiento, garantizando las mejores semillas para futuras siembras, especialmente con el maíz.

También lo nuevo es pilar o quitarle la cascara al arroz (se recoge el cultivo de arroz, el arroz se pone a secar, después de seco se echa en un saco se le da con un palo para desgranarlo, luego de eso se pone al sol, cuando el arroz está caliente de sol se echa en el pilón o mortero).

Para el caso de las artesanías en caña flecha, el 51\% de las mujeres se han quedado en el modelo tradicional de trenzado y se dedican exclusivamente a trenzar la caña flecha, un $32 \%$ ha hecho innovaciones, pero se ha quedado estancada y el 15\% innova permanentemente, especialmente en nuevos diseños de productos y de diseños.

Los nuevos diseños se dan especialmente en la elaboración de bolsos, mochilas, estuches para computador, cosmetiqueras, donde además de combinar colores, trenzados de fibras de caña flecha, se combina con cuero o con tejeduría en hilo de algodón, lo que les ha permitido poder participar en ferias locales, regionales y nacionales, con una gama variada de productos y coloridos.

Frente a este aspecto, una mujer indígena de los Cantares - San Martín, dedicada a la cría de especies menores y las artesanías en caña flecha, afirmó lo siguiente: "También aprendí a coser y a manejar la caña flecha, confeccionando productos para la venta en algunas ocasiones he tenido la oportunidad de ir ferias y mostrar y comercializar el producto, esto es muy gratificante 
debido a que das a conocer lo que elaboras de forma manual y te das cuenta de cómo algunos compradores valoran el tiempo y la mano de obra que se les dedica a estos" (Claudia Basilio),

Cuando se indagó acerca del sentido de comunidad y su posible institucionalización, la totalidad de las mujeres entrevistadas comentan que se relacionan con sus familias, amigos y vecinos, esto lo hacen de manera cotidiana, a diario y en algunos casos en el tiempo de vacaciones, fiestas patronales o en diciembre. Este tipo de relaciones en la comunidad es muy importante a la hora de trabajar la tierra pues en algunas familias se da el apoyo con jornales al momento de hacer las labores de preparación de tierras hasta la cosecha con la modalidad de mano vuelta (una persona apoya a la otra y esta le devuelve el jornal cuando la otra la necesita). Están muy pendientes de que nadie se meta al cultivo de las otras familias y se cuidan entre ellas y por otro lado, estos vínculos parecen institucionalizados pero al mismo tiempo con algunas divisiones sectoriales o geográficas, no partidarias.

El 10\% de las mujeres pertenecen a la organización ASOMARTIN en el municipio de San Martin, el 17\% pertenecen a AMEISAN organización ubicada en el corregimiento de San Jacinto, el 14\% son de AMAP corregimiento de San Antonio, el 12\% son la Asociación de Mujeres Indígenas Artesanas de las Huertas, el 19\% pertenecen a la asociación de ASPROINPAL que aglutina mujeres de 12 cabildos indígenas en el municipio de San Antonio de Palmito y el 28\% pertenecen a la organización ASOAFRO ubicada en San Onofre. Las mismas funcionan con su junta directiva que dirige y lidera el desarrollo de los procesos. Ésta es elegida por Asamblea. Del trabajo de campo e información brindada en él surge que las instituciones tienen estas trayectorias: 


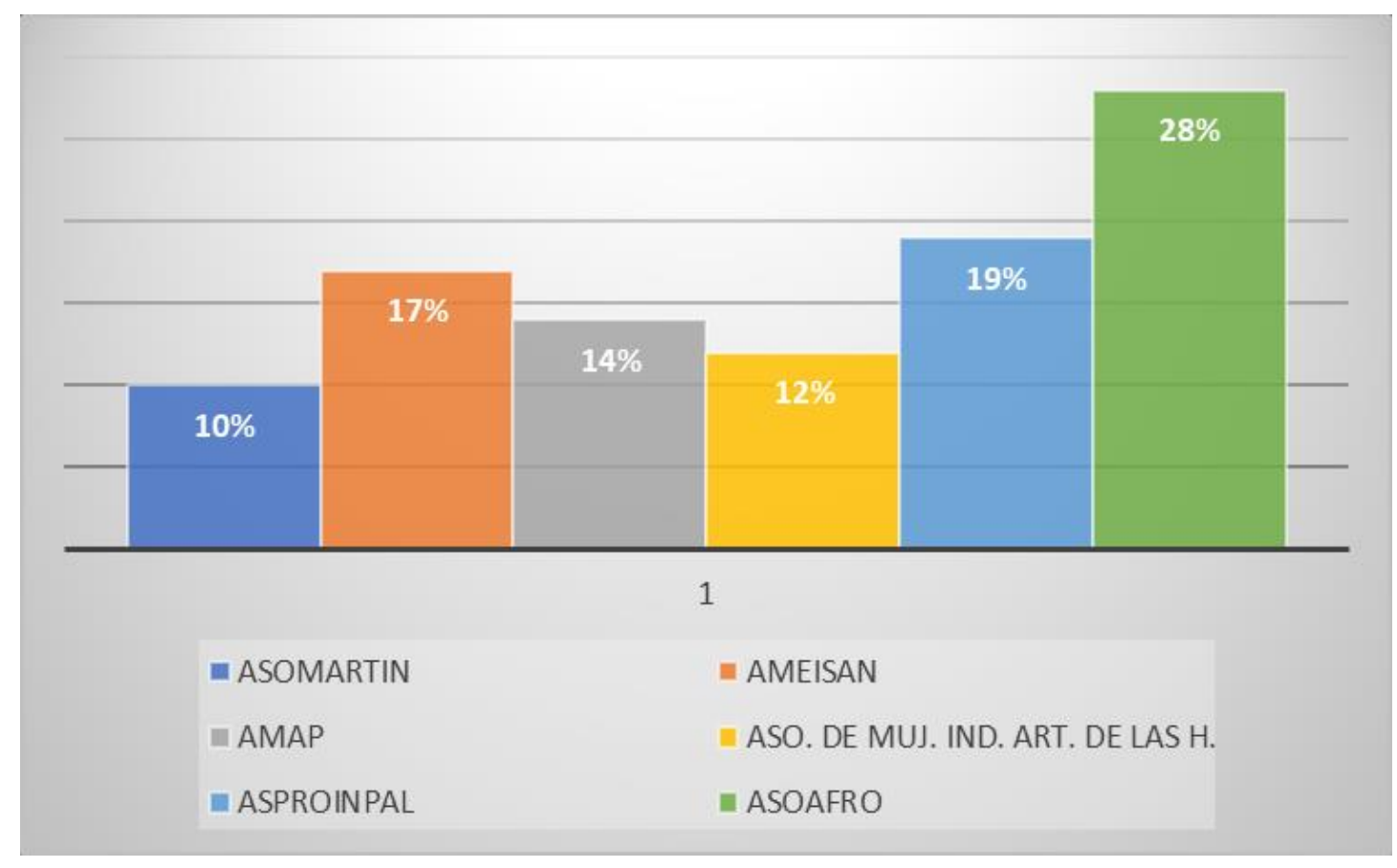

Figura No17. Organización a la que pertenecen las mujeres.

Fuente: Elaboración Propia.

“Tengo aproximadamente 5 años de estar en la asociación soy madre de 3 hijos, casada en unión libre; de mis proyectos le doy gracias a Dios por haberme incluido desde el principio, de llegar a ser una mujer impulsadora para el beneficio de mi hogar y mi familia. Gracias a estos proyectos de patio productivo y también la artesanía hoy en día soy una mujer emprendedora, luchadora, mujer activa que se atreve a defender mi hogar y solucionar problemas, a ser miembro de una comunidad, a la cual me vínculo con alegría, cariño, ayudando y apoyando a esas personas”. (Birlaidys Contreras, mujer indígena, habitante de la comunidad de las Huertas en Sincelejo - Sucre).

La siguiente tabla muestra los distintos grupos y sus características. 
Tabla No 2. Descripción de las organizaciones de mujeres

\begin{tabular}{|c|c|}
\hline GRUPO & aracterísticas \\
\hline $\begin{array}{l}\text { Asociación de mujeres } \\
\text { de San Martín en el } \\
\text { municipio de Sincelejo. }\end{array}$ & $\begin{array}{l}\text { Desde su creación hace } 20 \text { años, es un grupo con capacidad de } \\
\text { liderazgo, tiene mucha experiencia en el manejo sostenible de la } \\
\text { artesanía de la caña flecha. Tienen patios productivos y plantas } \\
\text { medicinales. }\end{array}$ \\
\hline $\begin{array}{l}\text { Grupo de mujeres de } \\
\text { San Jacinto en el } \\
\text { municipio de Sincelejo. }\end{array}$ & $\begin{array}{l}\text { Desarrollan sus actividades trenzando la caña flecha y criando } \\
\text { algunos animales para la subsistencia. Son mujeres muy arraigadas a } \\
\text { su cultura indígena, con capacidad de escucha y han avanzado en la } \\
\text { participación de la Junta Directiva del Cabildo Indígena. }\end{array}$ \\
\hline $\begin{array}{l}\text { Asociación de mujeres } \\
\text { artesanas de Alto Plano } \\
\text { AMAP en Sincelejo. }\end{array}$ & $\begin{array}{l}\text { Son mujeres sabias que aún mantienen parte de las tradiciones } \\
\text { asociadas a las plantas medicinales y siguen con la incubación y cría } \\
\text { de animales en pequeñas áreas, cuentan con un taller artesanal y una } \\
\text { sede. }\end{array}$ \\
\hline $\begin{array}{l}\text { Asociación de mujeres } \\
\text { indígenas y artesanas de } \\
\text { las Huertas en Sincelejo. }\end{array}$ & $\begin{array}{l}\text { Son mujeres con influencia de la tradición de la olla de barro que era } \\
\text { lo fuerte hasta hace poco en el corregimiento, además de los cultivos, } \\
\text { la ganadería y la cría de animales en el patio, cuentan con un taller } \\
\text { artesanal con caña flecha, sin sede. }\end{array}$ \\
\hline $\begin{array}{l}\text { Comunidades indígenas } \\
\text { de San Antonio de } \\
\text { Palmito }\end{array}$ & $\begin{array}{l}\text { Son comunidades que gestionan junto a su Cacica Territorial } \\
\text { Indígena sus reivindicaciones económicas políticas, sociales y } \\
\text { culturales. Tienen activo el Movimiento por una Política Pública para } \\
\text { la mujer. Trabajan la caña flecha y recuperación de semillas criollas } \\
\text { de maíz. }\end{array}$ \\
\hline $\begin{array}{l}\text { Comunidades afros de } \\
\text { San Onofre: ASOAFRO }\end{array}$ & $\begin{array}{l}\text { En San Onofre hay un Movimiento Activo de mujeres que impulsa } \\
\text { una Política Pública para las mujeres y reivindicaciones de las } \\
\text { mujeres afro. }\end{array}$ \\
\hline
\end{tabular}

Elaboración propia en base a las entrevistas realizadas

El $100 \%$ de las mujeres son socias y amigas de cada de una de las Asociaciones y se sienten parte. Dicen que la asociación las ha ayudado a salir adelante, a construir un patio 
productivo, a criar animales, desde la gestión, a conseguir recursos para fortalecer sus proyectos productivos. Las alianzas que las asociaciones generan, les permite garantizar capacitación, formación, asistencia técnica, acompañamiento en temas sociales, organizacionales. Ambientales, productivos, de manejo pos-cosecha, entre otros, además de recursos para apoyar los proyectos productivos, ya sea en especie o en efectivo. Incluido el acceso a crédito para sus unidades productivas.

Al respecto una mujer campesina de San Martín, dedicada a la agricultura y las artesanías en caña flecha, nos aclaró lo siguiente: "Mi vida ha cambiado al adquirir enseñanzas y aprendizajes agrícola y comercial, desarrollo mis actividades productivas, trabajo en mi propia empresa produzco y comercializo junto a mi familia, en la finca cultivamos, naranja, limón, plantas medicinales, y con el aprendizaje obtenido a través de la organización ofrecemos nuestros productos, puedo establecer un costo y realizar la comercialización y manejar mis propios recursos y a mi familia le ha permitido cierta autonomía económica, con lo que vendemos adquirimos nuevos productos e insumos necesarios para seguir produciendo y abastecer la canasta familiar" (Rosmari Brito).

Actualmente la totalidad de las mujeres entrevistadas participan en proyectos comunes. El proyecto con la Unión Temporal Construyendo Esperanza "UTCE", apoyo a cultivos de pan coger, producción y comercialización de artesanías, cría de pollos de engorde, etc. acompaña a 180 mujeres con capacitación, asistencia técnica, formación en temas productivos y construcción de paz y apoya con recursos de capital semilla y crédito; las mujeres acceden a 135 US para sus 
proyectos productivos no reembolsables, que entrega en dos partidas y otros créditos entre 31,6 US y 126,6 US.

"Vendo salchichas, salchichón, chorizo, hamburguesa y esto es venta caliente acá en mi pueblo, traigo las carnes frías desde Cartagena de allá me las mandan en buses, me quede sin recursos y el proyecto de la Unión Temporal Construyendo Esperanza, con capital semilla y crédito, me reintegro a mi negocio y estoy feliz, en cada pedido me gano US 28.5 ( $\$ 90.00$ mil pesos) llevo 4 pedidos y me ha quedo de ganancia US 113,9 (\$360.000 mil pesos) que me están sirviendo para todo es con lo único que cuento, me encanta trabajar y estoy muy contenta con el proyecto" (Dayaneth Bonilla Berrio, mujer afro, de Libertad en San Onofre y miembro de la Organización ASOMULEF).

Está también la Fundación Hijos de la Sierra Flor, Fundación Equipo Técnico, que conformaron la Unión Temporal Construyendo Esperanza, Corporación autónoma “Carsucre”, Colectivo de mujeres al derecho, etc. Las mujeres parecen estar muy contentas y animadas. Incluso el 35\% de las mujeres dicen que sacaron crédito sólo con el fondo de la asociación a la cual está vinculada, otro 40\% nunca sacó uno y sólo el 25\% lo hizo en bancos (Mundo Mujer, Bancamia, banco Agrario, Fincafe, Crezcamos, Ser Mujer).

Al respeto, una Campesina del Corregimiento de San Antonio en Sincelejo, comenta: "Como ya hemos aprendido a trabajar tratamos de hacer los proyectos juntas, cada quien dice sus necesidades, las escribe, se llena el formato de los costos que no los facilitan y ya es más fácil porque les estoy haciendo acompañamiento, entones yo me entero de que es lo que ellas quieren 
y en el comité de crédito comparto las expectativas que ellas tienen con su nuevo negocio o el que van a fortalecer...va la propuesta con lo que ellas necesitan, las cantidades y los precios entonces eso se habla delante del comité o más compañeras, eso lo hacemos siempre en las oficinas de Hijos de la Sierra Flor y halla cada quien tiene su espacio para hablar de cada proyecto, las expectativas que tiene la compañera y el monto de lo que se va a pedir" (Claudia Parra).

Sin embargo, si bien para el 56\% de las personas, los vecinos apoyan las actividades que realizan, un $34 \%$ dice que hay muchas polémicas y vecinos enojados y el 10\% se queja, muchos rememoran las épocas de mayor violencia. Pues, aunque ha habido acuerdos de paz, con pactos de tipo político, no se alcanzan a superar las diferencias que quedaron marcadas en los territorios y no se impulsan modelos de resolución pacífica de conflictos; en muchas personas quedo marcado el modelo de solucionar las diferencias y los problemas desde actos violentos y el concepto de reconciliación no se impulsa de manera verdadera. De igual manera se mantiene la crisis humanitaria, la gente de las comunidades se siente amenazada por diversos actores generadores de violencia tanto nuevos como antiguos.

Lo anterior permite sostener que los sistemas productivos familiares liderados por mujeres en Montes de María se basan en el carácter colectivo y ciertos valores de reciprocidad vinculados a las tradiciones, aunque con algunas pequeñas innovaciones. De todos modos, también se vio que algo de esto se va perdiendo. La presencia de organizaciones no gubernamentales “ONG” son importantes para preservar la unión, aunque las ayudas son siempre insuficientes. 


\subsection{Producciones Sustentables y Cuidado del Ambiente}

Acerca de la relación entre los sistemas productivos y el medioambiente, se destacan dos cuestiones.

Por un lado se sostiene que las especies, los niveles de producción y el uso de herramientas no atentan con las propiedades de la tierra. Esto es así tanto para los cultivos anuales como para los árboles frutales, las plantas medicinales, etc. y además se observa una buena diversidad vegetal y hay mucho uso de abono natural, aunque no sólo.

Por otro lado, existen otras acciones que destruyen el ambiente. Tradicionalmente, las mujeres han talado y quemado leña, han quemado siempre y echado a los arroyos basura, y en los últimos años habían adoptado fertilizantes y los agroquímicos para fumigar. Sin embargo, el $72 \%$ de las personas entrevistadas han respondido que están tratando de limitarse y el 28\% no lo hacen. Todos mencionan el problema de la falta de posibilidades, el caso más usual es que no tienen donde arrojar la basura y el camión de la basura no pasa; entonces optan por enterrarla.

Frente a lo anterior, una mujer indígena del corregimiento de San Antonio en Sincelejo nos comenta: "Hemos disminuido el consumo de bolsas plásticas y a los que vemos arrojando basuras en los arroyos, les llamamos la atención, pues esto tapona el cauce y genera inundaciones" (Elsa María Parra).

Así mismo otra mujer indígena da sus apreciaciones al respecto "Pues nosotras acá estamos limpiando la parte de los arroyos y la comunidad, haciendo la limpieza porque hay mucha contaminación con las bolsas y frascos de gaseosa, porque todavía tenemos el mal hábito de tirar, entonces estamos haciendo campañas de conciencia a la gente, de que si 
seguimos así estamos contaminando más el medio ambiente. Entonces a través de asociación estamos haciendo limpiezas en el corregimiento, barriendo los parques, recogiendo las botellas;

por lo menos el pozo que es una parte bastante contaminada. Ya nosotras tomamos el control de eso y estamos limpiándole los alrededores y diciéndole a la gente que hay que conservar”. (Maris Reales)

Las mujeres opinan que, si se cuida el medo ambiente y los recursos naturales, nos da salud, por que respiramos un ambiente sano, un ambiente nuevo.

Los niños están metidos en este proceso y lo pueden replicar, ya muchos conocen de plantas, reciclando las botellas en compañía de los adultos, aprenden a hacer artesanías con las botellas plásticas, en este proceso no solo trabajan las 20 personas que están en la asociación sino toda la comunidad se está metiendo en el proceso y es algo que nos ayuda a salir adelante en la comunidad.

El conocer y usar plantas ayuda a la salud de las familias y a mantener la naturaleza, ya que se trabaja naturalmente, sin agrotóxicos, lo que permite que no se generen enfermedades. Se ha dejado de cortar los árboles y con las hojas que se producen hacen abono, evitando la quema de basuras, compostandola o enterrándola. Todo se hace de manera didáctica para enseñar a nuestros hijos, explicándoles sobre la naturaleza que ya está muy deteriorada y que hay que conservarla porque ya hay mucha extinción de aves

En este aparte se concluye que: por la cantidad de área que usan las mujeres en sus sistemas productivos, el tipo de herramientas, el uso de insumos naturales en la mayor parte de 
su producción, estos sistemas son compatibles y no deterioran el ambiente, aunque muchas veces la falta de infraestructura y cierto descuido atentan contra este aspecto.

El modelo productivo que utilizan las mujeres del territorio trabaja sobre la base de cero labranza, reciclaje y producción de abonos orgánicos, control biológico de plagas y

enfermedades, asocio de cultivos, aprovechando al máximo la poca área con que cuentan, pero él no contar con servicios públicos adecuados, hace que muchos desechos sean arrojados y el control de residuos sólidos no sea el más adecuado, generando impacto negativo en el medio ambiente y los recursos naturales.

\subsection{Satisfacción de Necesidades y Excedentes}

El análisis de las necesidades satisfechas y no satisfechas surgirá del estudio de la producción, los gastos, las ventas y el autoconsumo, finalmente de las respuestas brindadas respecto a los deseos incumplidos, aunque este punto es controvertido. Para el desarrollo de las actividades productivas, agrícolas, pecuarias y artesanales, es necesario comprar insumos que no se tienen en el territorio, por lo que ellas durante el mes van en su mayoría a la cabecera municipal a conseguir lo que necesitan para poder elaborar sus productos o complementar el tema agropecuario.

Las dedicadas a los animales compran insumos compran alimento, las dedicadas a la agricultura, abonos y fertilizantes, sólo una parte compra semillas. Las artesanas compran la 
palma. La mayor parte va a distintos almacenes agrícolas, depósitos, abastos y/o almacenes agropecuarios de Sincelejo, San Antonio de Palmito y San Onofre, y lo pagan de contado.

Los animales de patio no se comercializan, por lo general se usan para consumo de la familia, en el caso de los huevos criollos, el $60 \%$ dijo que comercializa bastante más que lo que consume y el $40 \%$ destina más a su consumo, las gallinas juegan un papel de productoras de huevos, razón por la cual no las venden y cuando acaba su ciclo productivo, las consumen en el hogar. Un $30 \%$ de las familias consume al menos uno de sus cerdos del patio, alrededor del $28 \%$ de las familias dedicadas a la agricultura dice consumir más que lo que vende afuera. Las artesanas producen todo para vender.

De las 72 mujeres encuestadas el 52\% genera ingresos mensuales por ventas hacia afuera de entre $\$ 500.000$ y $\$ 999.999$ mil pesos, (157,78 US y 315,56 US) el $38 \%$ menor de $\$ 499.999$ (157,78 US) y el $10 \%$ más de $\$ 1^{\prime} 000.000$ de pesos (315,56 US). En el 35\% de las familias, hay que descontar la cuarta parte de esa cifra en gastos. A éstos se suman los recursos que generan otros familiares, ya sea vinculados a estos proyectos o vendiendo su mano de obra en los campos o en la cabecera municipal.

Al respecto una mujer indígena del corregimiento de las Huertas en Sincelejo, afirma que: los 3 créditos que he tenido en la asociación, el primero lo hice para compra de cerdos, gallinas ponedoras y artesanías, el segundo también en cerdos, gallinas ponedoras y artesanías y ahora éste último en cerdos, gallinas ponedoras, marotes (gallos) y pollas criollas; en cuanto a las ganancias en los 3 créditos que obtuve en estos 6 meses, fueron de casi unos US 126,26 
(\$400.000 mil pesos) y en ahorro por aparte porque se mueve el préstamo en compra y venta, tengo en ahorro US 157,8 (\$500.000 mil pesos) $)^{2}$ (Delcy Ruiz,)

En cuanto a los gastos, de las 72 mujeres encuestadas el 10\% genera gastos entre $\$ 100.000$ y $\$ 499.999$ mil pesos, (157,78 US) el 30\% entre $\$ 500.000$ y $\$ 999.999,(157,78$ y 315,56 US) el 35\% genera gastos entre $\$ 1^{\prime} 000.000$ y 1'499.999 mil pesos, (315,56 y 496,6 US) y más de 1'500.000, (más de 496,6 US), el 25\%.

Estos gastos incluyen: alimentación, salud, transporte, vestuario, recreación, aseo personal educación y servicios públicos, además de los insumos requeridos para cada actividad productiva. El $60 \%$ sería considerado pobres por las estadísticas oficiales, se encuentran dentro del 36,6\% de los centros poblados y rural disperso (DANE, 2018) ${ }^{3}$.

Al respecto, una productora agropecuaria y artesana indígena de San Martín en Sincelejo, sostiene que "puedo generar mis ingresos aquí en casa, estoy pendiente a mi familia; en algunos casos represento a la organización mostrando y ofreciendo los productos que elaboramos, esto nos ha permitido acrecentar nuestra mano de obra, genero ingresos en casa ofreciendo servicios de Internet y fotocopias, cuento con un estanque de piscicultura (vendo peces) y plantas medicinales, este espacio de trabajo me ha fortalecido y transformado, he mejorado mi calidad de vida y la de mi familia; ayudo a los gastos de la casa y los de mis hijos y me doy mis propios

\footnotetext{
${ }^{2} 1$ dólar = 3168 pesos colombianos.

${ }^{3}$ Obviamente este trabajo no ha discutido como corresponde los umbrales definidos por el organismo oficial, pero se pretendía dejar el dato como referencia
} 
gustos; como persona he crecido, esto me permite implementar otro tipo de negocios, a nivel de grupo me gusta motivar cada día más a mis compañeras a trabajar para que generen sus propios ingresos" (Mónica Basilio).

Esto hace que su economía crezca día a día.

Tabla No3. Comparativo en dólares

\begin{tabular}{|c|c|c|c|c|c|}
\hline $\begin{array}{l}\text { Nivel de } \\
\text { pobreza de } \\
\text { hogar } \\
\text { compuesto }\end{array}$ & $\begin{array}{l}\text { Ingreso total } \\
\text { por debajo de }\end{array}$ & $\begin{array}{l}\text { Familia en } \\
\text { cabeceras }\end{array}$ & $\begin{array}{l}\text { Familia en } \\
\text { centros poblados } \\
\text { y rural disperso }\end{array}$ & $\begin{array}{l}\text { En trece } \\
\text { ciudades } y \\
\text { áreas } \\
\text { metropolitanas }\end{array}$ & $\begin{array}{l}\text { En otras } \\
\text { cabeceras }\end{array}$ \\
\hline por & US & US & US & US & US \\
\hline personas & 325,9 & 358,5 & 214,2 & 359,3 & 357,5 \\
\hline
\end{tabular}

Fuente: Elaboración propia con base a datos del (DANE, 2018).

Al margen de la clasificación, esos gastos garantizan una ingesta razonable de a) proteínas: fríjol, huevos de gallina, carne de aves como gallinas, pavos, cocas y patos, carne de cerdo, b) vitaminas y minerales: hortalizas (Berenjena, habichuela, tomate, col, cebollín, ají, entre otros), mantienen frutales en el patio como guayaba, mango, guanábana, mamón, entre otros. c) Carbohidratos: yuca, maíz, ñame, arroz. Pero como muchos de ellos son estacionales, muchas veces les toca comprarlos en las tiendas del pueblo o en la cabecera municipal. Además, por la poca área que poseen no alcanzan a producir y a consumir permanentemente todos los tipos de alimentos.

Pero si se comparan los ingresos que generan las mujeres con los gastos mensuales, vemos que son mayores los gastos que los ingresos; es aquí donde aparecen otros ingresos solidarios adicionales que permiten a las familias garantizar el sustento diario y mensual, entre 
ellos tenemos: los aportes del esposo o compañero, los aportes de los y las hijas, subsidios que aporta el gobierno, como el programa de familias en acción, que aporta recursos económicos de acuerdo a los hijos e hijas o a los adultos mayores. La investigación muestra que comparativamente, las mujeres generan ingresos entre un 30\% y $60 \%$ de los gastos generales de la familia, siendo un aporte fundamental pero no suficiente.

Y sobre la posibilidad de ahorrar, la respuesta surge de la heterogeneidad descrita sobre los ingresos y los gastos. El 65\% de las mujeres encuestadas manifiesta que no hay excedente monetario y el 35\% que si existe, aunque mínimo, pero luego de sumados los ingresos del resto de los parientes. Todas las entrevistadas manifiestan sentirse satisfechas con sus proyectos productivos, el $65 \%$ no lo está con los ingresos y ahorros.

"Hago parte de la asociación AMAP, con mi capital semilla y créditos he fortalecido mi negocio porque lo tenía antes bastante poquito y ahora lo he variado de miles de cosas, antes tenía apenas la venta de ropa interior y ahora vendo también edredones, sábanas y sandalias con mi caña flecha trenzo y vendo los metros tengo patio productivo con gallinas, con la venta de los huevos se alimentan ellas y me alimentan a mí y a mi familia. Un huevo criollo lo vendo en US 0,16 (500 pesos) y la gallina pone huevos, algunas a diario otras, día por medio, otras cada dos días, dependiendo de la raza. Me he dado cuenta que tengo capacidad de ahorro y actualmente con los ahorros que tenía logre comprar una nevera que no tenía." (Ibeth Contreras Montiel, indígena del corregimiento de San Antonio en Sincelejo - Sucre). 
De acuerdo con lo anterior, podemos concluir, que los sistemas productivos manejados por mujeres son compatibles respecto a la noción de necesidad tradicional de las familias, no importa la productividad, pero logran el sustento, la sobrevivencia y permiten la soberanía alimentaria.

Al respecto, una mujer Indígena de San Jacinto, Sincelejo, sostiene: “tengo gallinas, cerdos, maíz para hacer bollos dulce y de caña flecha, también cultiva hortalizas y agrego más soluciones a mi hogar, me ha ido súper bien en estos procesos, con mi trabajo fortalezco mi soberanía, alimentación y el sustento del hogar” (Selmeria Basilio).

\subsection{Las Necesidades que Parecen Surgir de los Consumos Globalizados}

En relación a los consumos globalizados y las necesidades más típicas de la globalización, la pregunta es si las familias logran alcanzarlos por el escaso nivel de ingresos monetarios que logran.

En estas condiciones no parece posible lograr niveles de consumo como los difundidos en la globalización actual. Solicitadas de que hagan un ranking, las mujeres reiteran como primer anhelo mejorar la casa, cosa que se les hace muy difícil, luego comprar más y mejores herramientas e insumos y productos de la canasta familiar. En orden de prioridades le sigue el estudio de los hijos y luego los materiales para mejorar su casa y muebles, si se insiste mencionan la moto, o la bicicleta, dada la dificultad para moverse. Unas 5 mujeres de las encuestadas mencionaron la necesidad de tener computador pues sus hijos están en la 
universidad. Parecen responder a una idea de necesidad cercana a los niveles de subsistencia, la investigación no ha permitido saber si esto las frustra.

Por un lado es claro que una parte del resto de los ingresos, más allá del aporte del esposo, hijos, etc. provienen de los diversos subsidios, por ejemplo, el del programa llamado "Familias en acción" que ha sido el programa bandera de los últimos 3 presidentes nacionales, así mismo el Instituto colombiano de Bienestar familiar ICBF tiene programas de atención a madres gestantes, lactantes a la niñez hasta los 5 años, con programas de nutrición, y atención en salud, lo que permite que los niños y niñas menores de 5 años los cuide una madre comunitaria desde las 8 am hasta en las horas de la tarde.

El departamento para la Prosperidad Social DPS, a través del programa Familias en su Tierra (FES) busca contribuir a la estabilización socioeconómica de los hogares víctimas de desplazamiento forzado, retornados o reubicados, con apoyo en recursos para producción agropecuaria, activos, asistencia técnica y capacitación.

Por sí solas no mencionan la cuestión de la regulación de las tierras, tampoco exigen formación laboral o empresarial. Preguntadas, si dicen que la presencia del Estado Federal no es de un impacto enorme. Las mujeres se quejan, pero no hay al menos permanentemente actividades para exigir un aumento del apoyo.

Además, en los municipios escogidos para realizar la entrevista, gobierna un alcalde, el que debería ejecutar un programa de gobierno basado en un plan de desarrollo que demora 4 años. Consultadas las mujeres sobre su impacto, comentan que a pesar de haberse llevado a cabo 
mesas de trabajo en las comunidades para elaborar el plan de desarrollo municipal, mucho de lo que se dijo en ellas no se tuvo en cuenta y que son pocas las acciones y obras que desde la alcaldía se realizan en estas comunidades para generar desarrollo rural y mejorar las condiciones y calidad de vida de estas familias rurales, las vías están en mal estado, pocas oportunidades para las y los estudiantes, inseguridad, pocas obras de infraestructura para mejorar la producción agropecuaria, como sistemas de riego, entre otras.

En lo que hace a los servicios de agua y la energía eléctrica, así como otra obra civil. Las 72 mujeres entrevistadas dicen que el único servicio público con el que cuentan es con la luz y en su mayoría es pirata (ilegal), el agua es cogida del pozo o de tanques que tienen para cuando llueve. Otras obras no se ven. En cuando a las ayudas por parte del Departamento la mayoría desconoce el tema, otras dicen que no ayuda en nada y unas pocas manifiestan haber tenido ayuda por parte de este ente. Lo mismo opinaron del municipio.

También en las zonas indígenas de los municipios de Sincelejo y San Antonio de Palmito, gobierna un capitán junto a su cabildo, responsables entre otros temas de ejecutar proyectos. El $60 \%$ de las mujeres manifiestan no tener relación con el capitán y carecer de su ayuda, el 20\% manifiesta que algo de ayuda tuvieron y el $20 \%$ restante manifiesta que no lo conocen.

Los niños van a la escuela pública (aprovechando la gratuidad que hay en la primaria y en la secundaria) y la gran mayoría de estas les brindan a sus alumnos aparte de clases, útiles escolares y en algunos casos uniformes y zapatos. 
Algunas mujeres tienen hijos pequeños que aún no asisten al colegio, las que tienen hijos en edad escolar están agradecidas. De las 72 mujeres entrevistadas, solo 3 (4\%) tienen hijos en la Universidad. Una de Las huertas, que estudia derecho en Sincelejo en la Universidad de Sucre, que es pública, una de San Antonio Sincelejo, estudia Trabajo Social en la Universidad privada CECAR y una de San Onofre tiene un hijo en la Universidad de Cartagena, que es pública.

"Convivo con mi compañero, tuve dos hijos en el hogar, mi familia la conforman 4 personas tenemos un patio en el que trabajamos los 2, contamos con gallina, pavo, pato, carnero, cerdo y vacas; de ahí salió la producción para el estudio de mis hijos: la mujer cursos técnicos (criminalística, mercadeo y ventas, secretaria ejecutiva, sistemas) y el varón ingeniería y comunicaciones; con nuestra agricultura familiar pagamos la luz, el Internet, la comida, la ropa y todos los gastos necesarios" (Everlides Ruiz, mujer indígena, habitante de la comunidad de las Huertas en Sincelejo - Sucre)

Respecto a la salud, las mujeres opinan que se cuenta con puestos con poca dotación, faltan profesionales en general pero especialmente en los servicios de rayos X y odontología, laboratorio, etc. Casi no hay prevención y control. No hay una ambulancia que preste el servicio para la zona rural, no se cuenta con brigada de salud en las comunidades o cabildos, no hay programas en salud para mujeres indígenas. Hay poca entrega de medicamentos. La solución es ir a la cabecera municipal, con todo lo que representa. Muchas veces prefieren auto-recetarse o ir donde un médico tradicional de la comunidad. 


\section{Capítulo IV}

\section{Las Conclusiones}

Recordemos que el objeto de la tesis era estudiar la agricultura familiar y su relación con el territorio desde una lógica económica, productiva y en relación con el ambiente en un lugar particular, los municipios de Sincelejo, San Onofre y San Antonio de Palmito. A su vez se quería comprender la dimensión relacional de quienes llevan adelante las tareas, que son principalmente mujeres

En el primer capítulo se realizó una revisión bibliográfica sobre los aspectos teóricos que soportan esta investigación, lo que permitió tener elementos de juicio para desarrollar un ejercicio de análisis para diseñar los contenidos y organizar las categorías analíticas que fundamentan este trabajo.

Partimos de los antecedentes de la agricultura familiar y campesina, vimos por un lado las definiciones y alcances de la agricultura familiar, especialmente sus condiciones generales y sus posibilidades. En las posiciones más afines se planteó que la agricultura familiar liderada por mujeres produce gran parte de los alimentos que se consumen en el territorio, además juegan un papel importante en la producción sostenible de estos, incidiendo en la generación de ingresos y el empleo rural, desarrollando sus labores bajo una adecuada gestión ambiental del sector rural y su biodiversidad. De igual manera, el aspecto cultural es parte importante y significativa en la construcción de comunidades rurales productoras y base esencial para el desarrollo general de Montes de María y el país en general. Los enfoques más cercanos al liberalismo económico en 
cambio plantean que este tipo de agricultura no es rentable, es de subsistencia, es inviable, no cuenta con recursos suficientes o sea es descapitalizada y a veces periférica.

Por otro lado, encaramos la cuestión de las motivaciones de los actores y los elementos que hacen a los vínculos, fundamentalmente la presencia de reciprocidad. De nuevo aparecen las dos versiones, de los enfoques afines y del liberalismo. Para los primeros, la reciprocidad le permite a grupos rurales pobres, apoyados en sus propias tradiciones y basados en relaciones armónicas y horizontales, generar recursos económicos movilizando recursos sociales, situación que se presenta mayormente en familias campesinas, especialmente para producción de sostenimiento y los excedentes con fines de mercado, fortaleciendo además la conciencia común, las relaciones al interior de la comunidad, y la construcción y organización de grupos sociales y valorando el desarrollo rural endógeno.

Para otros autores ese vínculo de reciprocidad no es el determinante, pues para que funcione la economía, es necesario que exista la propiedad privada, como base de la independencia del individuo, sin darle mucho valor a la asociatividad. Además, plantean que la reciprocidad es difícil de lograr debido al individualismo.

Y finalmente el tema de la relación entre necesidades, seguridad alimentaria, armonía con el medio. Se ha visto que las posiciones giran alrededor de la respuesta que le dan los productores tradicionales (monocultivos) y comerciales a las necesidades básicas y las generadas por el consumismo, quienes para garantizar la satisfacción de las mismas y especialmente de la seguridad alimentaria, generan impactos negativos, incluso por encima de la 
armonía con el medio ambiente, y la que se dan en la agricultura familiar liderada por mujeres, quienes hacen uso correcto de los recursos naturales, apoyadas en saberes ancestrales, logrando vivir dignamente y satisfaciendo muchas necesidades sociales, materiales y espirituales, tanto individuales como colectivas.

A fin de entender el contexto en el que se trabajaba, se indagó sobre las características de la agricultura familiar en el contexto de la económica colombiana y montemariana, teniendo en cuenta el desarrollo trunco colombiano, estructura agraria y políticas del gobierno.

Profundizando sobre los diversos problemas estructurales de la economía colombiana, especialmente en el sector rural.

Aun en condiciones difíciles, hay estudios que muestran que la agricultura familiar en la Altillanura colombiana es viable y puede ser más redituable al menos para los propietarios de pequeñas parcelas que la agroindustria a gran escala (Universidad Javeriana, 2015). Esto se comprueba porque los ingresos de las familias campesinas superan entre dos y cuatro veces la alternativa de arrendamiento de tierras que les proponen las empresas (Forero, 2015). Este autor concluye con que hay gran capacidad de innovación, adaptativa y creativa. Al mismo tiempo, en verdad con un grado aceptable de tecnificación, se encontraron riesgos y problemas de seguridad alimentaria.

Así mismo se hace un análisis de la vida en general y agraria particularmente, en Montes de María y Sucre, con especial énfasis en las familias y mujeres rurales de este territorio. Encontramos que en Montes de María, que está ubicado en zona de Bosque Seco Tropical, que 
sufrió durante más de dos décadas la incidencia de grupos armados al margen de la ley y generó muchas muertes y desplazamiento, además de ser un territorio con altos niveles de pobreza, se presenta un deterioro de la parte ambiental por proyectos de extracción minera, modelo tumba, rosa, quema para la siembra de cultivos de pancoger, se han perdido fuentes de agua y se le apuesta al monocultivo, paralelamente a este tipo de actividades un grupo de familias encabezado por mujeres indígenas, campesinas y afrodescendientes desarrollan sus actividades de agricultura familiar, en armonía con el medio ambiente y los recursos naturales, bajo el modelo de las huertas familiares como sistema productivo, pues a través de éste, las mujeres conservan muchas tradiciones, tratamientos medicinales, seguridad y soberanía alimentaria, que son elementos importantes en la cultura del territorio, de la cual se derivan muchas de sus costumbres, generan ingresos y solventan las necesidades de sus familias

Se incluyen también los proyectos ejecutados por entidades públicas y privadas nacionales e internacionales que impulsan proyectos de desarrollo territorial y que apoyan con insumos, materias primas, maquinaria agrícola y recursos para la producción agropecuaria y la agroindustria en pequeña escala. A nivel local tenemos organizaciones no gubernamentales "ONGs" como la Fundación, Hijos de la Sierra Flor Fundación Equipo Técnico, Asociación de productores indígenas ASPROINPAL en Palmito, ASOAFRO en San Onofre, a nivel internacional tenemos a USAID y la Fundación Interamericana, ambas de los EE.UU, Swissaid de Zuisa; a nivel bancario tenemos: Mundo Mujer, Bancamía, Banco Agrario, Fincafe, Crezcamos, Ser Mujer.

De allí surgen algunas conclusiones que contribuyen al análisis: el subdesarrollo colombiano en general, las políticas fiscales que explican la ausencia del Estado y la existencia 
de instrumentos poco efectivos e insuficientes; en lo que hace a la agricultura familiar: falta de capital, los problemas de propiedad de la tierra y las dificultades normativas a lo largo de los años, los altos niveles de pobreza de las estadísticas oficiales.

Con ese contexto, se encaró el trabajo de campo, en el que se tenía que indagar los mismos temas pero para el caso concreto y además cuestiones relativas a la micro de las producciones y la subjetividad: la actividad familiar y comunitaria, el carácter colectivo y las tradiciones; las producciones sustentables y cuidado del ambiente; la satisfacción de necesidades y uso de excedentes; las necesidades que parecen surgir de los consumos globalizados y el acceso a la educación y salud por parte de las familias, especialmente de la niñez y juventud.

Tomando como base la Agricultura Familiar liderada por mujeres en Montes de María, en Sucre se ha visto que la construcción y mantenimiento de los sistemas productivos son netamente familiares, aunque hay un porcentaje de trabajo para terceros. Fuera de la familia hay un vínculo fuerte con el resto, solidificado en las instituciones, pero los más fuertes valores de reciprocidad se cumplen en familia. Estos elementos tienen un componente tradicional fuerte.

Se presentan bajos niveles de producción y comercialización de la agricultura familiar, debido a la presencia de sistemas de producción tradicional atrasados (insumos y materias primas inadecuadas y semillas no certificadas) y con tecnologías obsoletas (mal uso de los recursos suelos - agua - planta). No hay maquinaria agrícola e infraestructura para la producción, como tampoco centros de acopio y bodegas de almacenamiento de los productos agropecuarios. 
También encontramos una serie otra serie de problemáticas, frente a los siguientes tópicos:

a) Asistencia técnica y extensión rural. No ha sido integral ni multidimensional, poca pertinencia frente a las necesidades reales de las comunidades,

b) Acceso y tenencia de la tierra: la tierra está en pocas manos, no se aprovecha su vocación real y el uno de los principales problemas del conflicto armado ha sido el acceso a tierra y territorio,

c) Gestión del agua: la producción familiar y campesina no cuenta con sistemas de riego, o sistemas que aprovechen adecuadamente el agua para garantizar la producción agrícola y pecuaria

d) Financiamiento: los servicios financieros para la población rural son de difícil acceso, con muchas trabas (muchos trámites y requisito) y no llegan a todos los sectores,

e) Comercialización: el cuello de botella de la agricultura familiar, pues no hay centros de acopio o infraestructura adecuada, presencia de intermediarios, poca información sobre las cadenas productivas y el tema comercial, poca presencia institucional, se desconoce y poco aplican estándares y buenas prácticas de en la cadena de valor.

De todos modos, puedo verse que los sistemas productivos familiares son los más compatibles con el ambiente debido a que utilizan asocios, rotan cultivos, poco uso de agrotóxicos en el control de plagas, pero también se vio que hay un problema con los residuos y los mismos muchas veces se queman. 
Y lo que es central, así y todo las producciones parecen satisfacer la noción de necesidad tradicional de las familias, pues permiten disponibilidad de alimentos, en términos de diversidad y cantidad con variedades energéticas (yuca, maíz, ñame, plátano, arroz, ahuyama), otras de alto nivel proteínico como leguminosas (fríjol, habichuela), y de vitaminas y minerales, por la producción de verduras y frutas, ( berenjena, ají, y frutas en el patio de la casa como mango, guayaba, guanábana, mamón, etc. ); finalmente proteínas animales en huevos, carne de gallina, pavo, pato, y cerdos.

Como estas familias producen muchos de sus alimentos, con tecnologías propias y ancestrales, tienen la garantía de comer productos sanos, frescos y saludables, de igual manera se rodean de espacios ambientales donde se consiguen plantas medicinales con las que sanan muchas de sus dolencias y enfermedades primarias.

Una relación armónica (según valores locales) entre los componentes, biofísicos, agronómicos, tecnológicos y culturales permiten una satisfacción más plena de las necesidades (entendidas según el concepto local de las mismas), además, estas producciones son un medio para la seguridad y soberanía alimentaria de estas comunidades.

Pero también se vio que -debido a las restricciones mencionadas- los ingresos generados por los sistemas productivos familiares, es decir, lo consumido en la producción y en el sustento y lo vendido, no alcanza. Que muchas veces los hijos han podido estudiar, incluso hasta carreras universitarias, se han podido forjar activos, tales como máquinas de coser, lavadoras, televisores, incluso motocicletas, debido a la presencia de otro ingreso, ya sea por trabajos a terceros, por 
empleo estatal o por subsidios. Aunque las familias perciben ingresos monetarios, estos están por debajo del salario mínimo (solo un 10\% se acerca a este monto) y las necesidades de consumo familiar más típicas de la globalización, no satisfechas siguen siendo grandes en cantidad, diversidad y duración. De todos modos, cuando han sido preguntados, no parecen tener objetivos de consumo superfluos.

Todo en un contexto de un costo de vida elevado, y en el que el gobierno nacional no ofrece garantías para el mejoramiento de las condiciones de generación de ingresos de las familias campesinas de Montes de María. También requieren de los servicios de salud y educación estatales, sólo que la inversión pública es muy pobre y los servicios muy precarios.

En lo que hace a la relación con el Estado, una de las problemáticas más importante a nivel económico de las pequeñas familias productoras rurales de Montes de María, no la encontramos, consecuentemente, en los modelos de producción establecidos, ni en una posible falta de competitividad, sino en la cantidad de limitaciones que estas presentan para acceder a los factores que permitirían a la productora desarrollar sus potencialidades. Dicho de otra manera, podemos mencionar, que los bajos niveles de viabilidad de la producción familiar en Montes de María debemos encontrarla en el acceso y distribución de los factores de producción y no en la naturaleza misma de la producción de las familias del territorio.

En ese sentido se debería mencionar la falta de políticas para dar la propiedad de la tierra, ausencia de un verdadero banco de maquinaria, que depende de la Secretaría de Agricultura, Ganadería y Medio Ambiente, también la poca disponibilidad de agua para la implementación de 
sistemas de riego, que contribuyan a obtener los rendimientos por cultivos por unidad de área y que permita hacer de ellos cultivos sostenibles, y las deficientes fuente de energía requerida para el funcionamiento de motores y equipos; problemas en el mantenimiento y sostenibilidad de las vías terciarias que permita el transporte.

La ausencia del Estado se traduce además en que no se cuenta con asesoría y asistencia técnica integral con paquetes tecnológicos apropiados y adaptados a la zona, el acceso a créditos oportunos bancarios es limitado. No se los ayuda para mejorar la capacidad de mercadeo y comercialización, lo que disminuye los ingresos por ventas. Hay falta de capacitación y apoyo para mejorar la organización en procesos de producción, que les permita diagnosticar y controlar cualquier tipo de alteración, como plagas y enfermedades, que atente contra la producción. Falta de planes sectoriales y alianzas productivas de tal manera que se puedan adquirir los insumos a más precios y por ende disminuir los altos costo de producción de los cultivos y especies menores.

En medio de las dificultades generadas por el conflicto armado las mujeres indígenas y afro de Montes de María en Sucre, y por encima de la sistemática vulneración de sus derechos y animadas por la idea de construir un territorio lleno de paz, han promovido a partir de sus historias de vida, la agricultura familiar, que hoy es la base para generar ingresos y sustento para la seguridad y soberanía alimentaria. 


\section{Referencias Bibliográficas}

Acevedo, Á., y Martínez, J. (2016). La agricultura familiar en Colombia. Estudios de caso desde la multifuncionalidad y su aporte a la paz. Bogotá: Ediciones Universidad Cooperativa de Colombia. Recuperado de http://ediciones.ucc.edu.co/index.php/ucc/ catalog/download/33/35/204-1.

Agencia de Desarrollo Rural (ADR) (2019). Cooperación Internacional Marco Normativo e Institucional. Colombia. Recuperado de https://https://www.adr.gov.co/

Bartra, R. (2015). Kmarx.wordpress.

Bernal, M. (2016). La industria en Colombia ¿Cómo vamos?Revista de logística. Colombia. Recuperado de https://revistadelogistica.com/informes-especiales/la-industria-encolombia-como-vamos/

Cardona, J. (2011). Evaluación de políticas en el sistema de seguridad alimentaria de la ciudad de Medelín: un enfoque desde la accesibilidad económica. Medellín, Colombia: Universidad Nacional de Colombia Facultad de Minas, Escuela de Sistemas Medellín.

Catalán, J. (1993). Economía e industria: la ruptura de posguerra en perspectiva comparada. Universidad de Barcelona. Recuperado de https://core.ac.uk/download/pdf/39047935.pdf

CEDAW. (2019). Primer Informe Sombra específico de Mujeres Rurales y Campesinas en Colombia. Recuperado de file://C:/Users/USUARIO1/Downloads/2.4informesombramujeresruralescolombia.pdf

Comité Nacional de Impulso.(2014). Agricultura familiar y economía solidaria compendio de documento. Colombia. Recuperado de http://agriculturafamiliar.co/wpcontent/uploads/2015/07/Documento-General-Comit\%C3\%A9-de-Impulso-NacionalCIN-AF.pdf 
Congreso de Colombia (1961). Ley 135 de 1961. Diario Oficial No. 30.691 de 20 de diciembre de 1961. Colombia. Recuperado de https:/www.minjusticia.gov.co/portals/0/MJD/docs/ ley_0135_1961.htm

El Consejo Nacional de Política Económica y Social, CONPES (

Corporación PBA - CORPOICA (2011). Manual del facilitador rural métodos y herramientas para ayudar a grupos campesinos a conseguir sus metas. Colombia. Recuperado de http://www.corporacionpba.org/irp/herramientas/Etapa_III/eppr-fase-IIIconformacion_quipos/paso2 /Manual\%20del\%20facilitador_rural.pdf

Corporación PBA (2015). Lineamientos y estrategias de desarrollo rural territorial para la región Caribe colombiana. Grupo de Trabajo: Desarrollo con Cohesión Territorial. Documento $\mathrm{N}^{\mathrm{N}}$ 142. Recuperado de http://rimisp.org/wpcontent/files_mf/1437688081InformeLineamientos DesarrolloRuralconEnfoqueTerritorialparalaRegionCaribe_Final_editado.pdf

Daniels, A., y Maza, F. (2017). Los montes de maría: políticas públicas, educación y desarrollo Edición y compilación. Cartagena, Colombia: Editorial Universitaria. Recuperado de https://www.researchgate.net/profile/Francisco_Avila4/publication/323696668_LOS_MO NTES_DE_MARIA_POLITICAS_PUBLICAS_EDUCACION_Y_DESARROLLO/link s/5aa66bca0f7e9b463804c29f/LOS-MONTES-DE-MARIA-POLITICAS-PUBLICASEDUCACION-Y-DESARROLLO.pdf

Departamento Nacional de Planeación (DNP) (2015). El campo colombiano: un camino hacia el bienestar y la paz. Misión para la transformación del campo. Colombia. Recuperado de https://colaboracion.dnp.gov.co/CDT/Agriculturapecuarioforestal\%20y\%20pesca/El\%20 CAMPO\%20COLOMBIANO\%20UN\%20CAMINIO\%20HACIA\%20EL\%20BIENEST AR\%20Y\%20LA\%20PAZ\%20MTC.pdf 
Dourojeanni, A. (2000). Procedimientos de gestión para el desarrollo sustentable. CEPAL. División de Recursos Naturales e Infraestructura. Serie Manuales, (10). Santiago de Chile, Chile. Recuperado de http://scielo.sld.cu/scielo.php?script=sci_arttext\&pid= S086403942007000200001

Durston, J. (1982). Clase y cultura en las transformaciones del campesinado. CEPAL, 25.

ECADERT. (2010). Consejo Agropecuario Centroamericano. Recuperado de http://www.cac.int/sites/default/files/Estrategia_Centroamericana_de_Desarrollo_Rural_ Territorial_\%28ECADERT\%29.pdf

Ecología Verde. (junio de 2018). www.ecologiaverde.com. Recuperado de https://www.ecologiaverde.com/que-es-la-agroecologia-y-su-importancia-452.html

El Heraldo (2017). Así está la pobreza en Colombia. Recuperado de https://www.elheraldo.co/economia/asi-esta-la-pobreza-en-colombia-340595

El Nuevo Siglo (2019). PIB agropecuario creció 25\% en siete años. Colombia. Recuperado de https://elnuevosiglo.com.co/articulos/03-2018-pib-agropecuario-crecio-25-en-siete-anos

Esquinas, J. (2006). Seguridad alimentaria y políticas de lucha contra el hambre. Oficina de Cooperación Internacional de Desarrollo. Diputación de Córdoba Servicio de Publicaciones de la Universidad de Córdoba. Córdoba, Argentina. Recuperado de https://docplayer.es/13086470-Seguridad-alimentaria-y-politicas-de-lucha-contra-elhambre.html

FAO (2008). Enfoques de desarrollo territorial en proyectos de inversión estudios de caso 08/017 cp-lac. 24 de octubre de 2008. Programa de Cooperación FAO/Banco Mundial Servicio de América Latina y el Caribe División del Centro de Inversiones. Recuperado de http://www.fao.org/3/k3622s/k3622s00.pdf 
Forero, J. (2002). Red de desarrollo sostenible de Colombia. Recuperado de https://www.rds.org.co/aa/img_upload/.../cc7508bb694caee87ff688edb93cb824.pdf

FUNCICAR (2015). Sistematización de la experiencia de Colombia responde en la zona de consolidación territorial de los Montes de María. Cartagena de Indias, Colombia. Recuperado de http://www.funcicar.org/archivo/sites/default/files/archivos/informeok2editable-final.pdf

Henríquez, A. (2014). Actualización de las dinámicas estratégicas, sociales, económicas e institucionales de los montes de maría, mapa de gestión de alianzas y acciones que el PDP y el DPS deberían priorizar. Colombia.

INCAP. (2014). Instituto Colombiano de aprendizaje. Recuperado de http://www.incap.int/index.php/es/acerca-de-san/san-en-breve

Instituto de Economía Social y Cooperativismo (INDESCO) (2014). Paz, agricultura familiar y economía solidaria: un vínculo inseparable en Colombia. Recuperado de https://docplayer.es/19167810-Paz-agricultura-familiar-y-economia-solidaria-un-vinculoinseparable-en-colombia.html

Jaramillo, C. (2001). Evaluación de la seguridad alimentaria con una visión integral. Proyecto piloto: vereda Los Medios, municipio de Sonsón (Antioquia). Cuadernos de Desarrollo Rural (46). Recuperado de https://revistas.javeriana.edu.co/index.php/ desarrolloRural/article/view/2313/1625.

Jaramillo, C. (2002). Crisis y transformación de la agricultura colombiana: 1990-2000. Banco de la República, Bogotá, D.C. Recuperado de https://www.repository.fedesarrollo.org.co/bitstream/handle/11445/61/LIB_2013_Política s\%20para\%20el\%20desarrollo\%20de $\% 201 \mathrm{a} \% 20$ agricultura_Completo.pdf?sequence $=1 \&$ isAllo. Políticas para el desarrollo de la agricultura en Colombia 
Kalmanovitz, S. (2010). Nueva historia económica de Colombia. Recuperado de https://www.elmundo.com/noticia/La-nueva-historia-economica-de-Colombia2-/377040

Kerlinger, E. (1979). Enfoque conceptual de la investigación del comportamiento. México, D.F:Nueva Editorial Interamericana. Actualmente se publica por McGraw-Hill Interamericana. Recuperado de https://www.uv.mx/personal/cbustamante/files/2011/06/Metodologia-de-laInvestigaci $\% \mathrm{C} 3 \% 83 \% \mathrm{C} 2 \% \mathrm{~B} 3 \mathrm{n} \_$Sampieri.pdf

Kirchner, A. (2014). Encuentro regional de economía social y agricultura familiar, que se realizó en la provincia de Neuquén.Argentina. Recuperado de https://www.desarrollosocial.gob.ar/noticias/en-agricultura-familiar-hay-tres-palabrasclave-produccion-trabajo-y-solidaridad/.

Landero, B., et al. (2016). Agricultura sostenible para enfrentar los efectos del cambio climático en Nicaragua. Managua: Fundación Friedrich Ebert. Recuperado de http://library.fes.de/pdf-files/bueros/fesamcentral/12896.pdf

León, Magdalena. La desigualdad de género en la propiedad de la tierra en América Latina In: Du grain à moudre: Genre, développement rural et alimentation [en línea]. Genève: Graduate Institute Publications, 2011 (generado el 23 avril 2019). Disponible en Internet: . ISBN: 9782940503834. DOI: 10.4000/books.iheid.6756.

Leibovich, J y Estrada, L (2017) Diagnóstico y recomendaciones de política para mejorar la competitividad del sector agropecuario colombiano. Recuperado de https:/compite.com.co/wp-content/uploads/2017/05/208Agro.pdf

Machado, A. (2003). Ensayos sobre seguridad alimentaria. Bogotá: Universidad Nacional de Colombia. Red de Desarrollo Rural y Seguridad Alimentaria. RESA. 
Maletta, H. (2011).Tendencias y perspectivas de la Agricultura Familiar en América Latina. Documento de Trabajo $\mathrm{N}^{\circ}$ 1. Proyecto Conocimiento y Cambio en Pobreza Rural y Desarrollo. Rimisp, Santiago, Chile.

Mantilla, A. (2004). La alimentación que nos ofrecen. Alcatemas 4. Colombia: ilustrada. Recuperado de https://books.google.com.co/books/about/La_alimentaci\% C3\%B3n_que_nos_ofrecen.html?id=nTG8tQEACAAJ\&redir_esc $=y$

Menco, D. (Diciembre de 2011). Dinámica productiva agrícola en los Montes de María 2010. OIDLES, 5(11). Recuperado de http://www.eumed.net/rev/oidles/11/dmr.html

Ministerio de Agricultura (Minagricultura). (2010). Lineamientos estratégicos de politica pública. Agricultura campesina, familiar y comunitaria. Estrategia de Desarrollo Rural Integral con Enfoque Territorial en Colombia. Recuperado de https://www.minagricultura.gov.co/Documents/lineamientos-acfc.pdf

Minagricultura (2016). Estrategia de política pública para la gestión integral de riesgos agropecuarios en Colombia. Revisión integral. Colombia. Recuperado de https://www.minagricultura.gov.co/Documents/LIBRO\%20ESTRATEGIA\%20VERSIO N\%20FINAL.pdf

Ministerio de Agricultura y Desarrollo Rural (2019). Programa de la Dirección de Desarrollo Rural. Recuperado de https://plataformacelac.org/programa/486

Ministerio de Salud (2015). La mujer rural y la agricultura familiar en Colombia. Bogotá. Recuperado de https://www.minsalud.gov.co/sites/rid/Lists/BibliotecaDigital /RIDE/ VS/PP/SNA/Boletin-02-2015-Mujer-Rural\%20-agricultura-familiar-Colombia.pdf.

Narodowski, P. (2012). Los diversos abordajes de la relación entre ecología, economía y sociedad. Efectos del Urbanismo privado en humedales de la cuenca baja del río Luján. Buenos Aires: Imago Mundi. 
Pabón, G. (2018). Caracterización de la red logística de una asociación dedicada a la producción-distribución de café orgánico mediante análisis de competitividad, integración y coordinación de la cadena de suministro. Recuperado de http://vitela.javerianacali.edu.co/bitstream/handle/11522/10893/Articulo_cientifico.pdf?s equence $=2 \&$ isAllowed $=\mathrm{y}$

Pérez, E. (1998). Una visión del desarrollo rural en Colombia. Cuadernos de desarrollo rural. Revista Javeriana, 14. Recuperado de revistas.javeriana.edu.co/index.php/ desarrolloRural/article/view/2371/1673

Perfetti, J. et al, (2013). Políticas para el desarrollo la agricultura en Colombia. Recuperado de https://studylib.es/doc/5470281/agricultura-en-colombia

Programa de las Naciones Unidas para el Desarrollo (PNUD) (2010). Los Montes de María: Análisis de la conflictividad. Colombia. Recuperado de https://info.undp.org/docs/pdc/Documents/COL/00058220_Analisis\%20conflcitividad\%20Mont es\%20de\%20Maria\%20PDF.pdf

Programa de las Naciones Unidas para el Desarrollo (PNUD) (2011). Los Montes de María: Análisis de la conflictividad. Colombia. Recuperado de https://colaboracion.dnp.gov.co/CDT/Agriculturapecuarioforestal\%20y\%20pesca/Diagn \%C3\%B3stico\%20Econ\%C3\%B3mico\%20del\%20Campo\%20Colombiano.pdf.

Red Nacional de Agricultura Familiar (2016). La Agricultura familiar. Súmate a la campaña por la declaración del decenio de la agricultura familiar. Foro Rural Mundial (FRM). Recuperado de https://agriculturafamiliar.co/sumate-a-la-campana-por-la-declaracion-deldecenio-de-la-agricultura-familiar/

Restrepo, F. C. (2015). Economía del desarrollo sostenible: propuestas y limitaciones de la teoría neoclásica. Recuperado de https://revistas.udem.edu.co/index.php/economico/article/view/1367/1404 
Reunión Especializada en Agricultura Familiar (REAF) (2016). Una década de coproducción de políticas públicas entre el estado y la sociedad civil. Portugal. Recuperado de http://www.fao.org/3/a-i5749s.pdf

Rosas, M. (Enero de 2009). Una contribución a la economía ecológica: Actividades Nopropelatrias Generadoras de Ingresos. México.

Salcedo, S., y Guzmán, L. (2014). Agricultura familiar en América Latina y el Caribe: recomendaciones de políticas (en línea). Santiago, Chile, Oficina Regional de la FAO para América Latina y Caribe. Consultado el 20 de jun. 2015. Recuperado de http://www.fao. org/docrep/019/i3788s/i3788s.pdf.

Salinas (2011). Dinámicas en el mercado de la tierra en Colombia. Recuperado de ndepaz.org.co/wp-content/uploads/2012/03/608_COLOMBIA-TIERRAS-SALINASMAYO-11.pdf

Santacoloma, L. (2015). Importancia de la economía campesina en los contextos contemporáneos: una mirada al caso colombiano. Entramado, 11(2), julio-diciembre, 2015, pp. 38-50. Universidad Libre. Cali, Colombia.

Schneider, S., y Escher, F. (2016). El concepto de agricultura familiar en américa latina. San José, Costa Rica. Principios y conceptos que guían la cooperación técnica del IICA. Recuperado de http://repositorio.iica.int/bitstream/11324/2609/1/BVE17038696e.pdf.

Diaz, D. 2002. Situación de la mujer rural colombiana. Perspectiva de género. Cuadernos Tierra y Justicia. Recuperado de http://bdigital.unal.edu.co/40035/1/ Situacion\%20 de\%201a\% 20mujer\%20rural.pdf

Taymer, A. Suset, Aida Cruz, y Machado, H. (2007). El Desarrollo sostenible. Perspectivas y enfoques en una nueva época. 
Torres, J. (2013). Las relaciones de solidaridad y reciprocidad en la protohistoria final europea. SPAL 23: 49-63. Recuperado de http://institucional.us.es/revistas/spa1/23/art_3.pdf

Vargas, C. 2017. Diagnóstico de la situación de la mujer campesina en Colombia. Recuperado de https://repositorio.escuelaing.edu.co/bitstream/001/689/1/Vargas\%20Cotacio $\% 2 C \% 20 \mathrm{Cri}$ stina\%20de1\%20Pilar-2017.pdf

Varón, L. E. (diciembre de 2015). Importancia de la economía campesina en los contextos contemporáneos: una mirada al caso colombiano. Entramado, 11 No. 2.

Villanueva, Diego. (2018). Análisis de la situación y recomendaciones de política de bioeconómia. Anexo 1 análisis sector agrícola y pecuario. Universidad EAFIT

Medellín, Colombia. Recuperado de https:/www.dnp.gov.co/Crecimiento-Verde/ Documents /ejes-tematicos/Bioeconomia/Informe\%202/ANEXO\%201_ An\%C3\%A1lisis\%20sector\%20agr\%C3\%ADcola.pdf

Villar, L. (2005). El comercio exterior colombiano en el siglo XX. Borradores de Economía, Banco de la República, Bogotá. Recuperado de https://studylib.es/doc/1026375/villar--leonardoy-esguerra-pilar.-2005.-\%E2\%80\%9Cel-comercio-ext...

WorldRuralForum. (6 de marzo de 2014). La Agricultura Familiar alimenta al mundo, cuida el planeta. Recuperadode https://www.youtube.com/watch?v=jO4x-i4Xzs0. 